\title{
Utilisation of Excess Heat Towards a Circular Economy \\ - Implications of interorganisational collaborations and strategic planning
}

\author{
Sofia Päivärinne
}

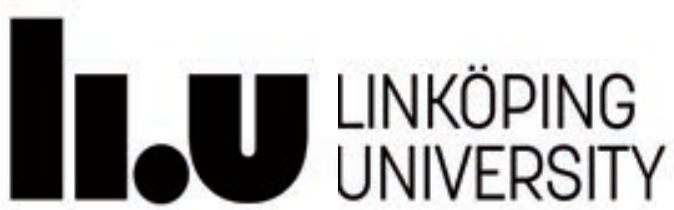

Environmental Technology and Management

Department of Management and Engineering Linköping University, SE, 58I 83 Linköping, Sweden www.liu.se

ISBN: 978-9I-7685-459-4

ISSN: 0345-7524 
(C) Sofia Päivärinne, 2017

Utilisation of Excess Heat Towards a Circular Economy

- Implications of interorganisational collaborations and strategic planning

Linköping Studies in Science and Technology

Dissertations, No. 1876

ISBN: 978-9I-7685-459-4

ISSN: 0345-7524

Printed by LiU-Tryck, Linköping 2017

Distributed by:

Linköping University

Department of Management and Engineering

SE, 58I 83 Linköping, Sweden 


\section{ABSTRACT}

In order to significantly lower the environmental impact from human activities, numerous efforts and approaches related to the transformation of human activities have developed during the last decades. Examples of such efforts are policies and strategies at different levels, some with a top-down approach focusing on extensive institutional changes, and some with a bottom-up approach focusing on industrial actors and industry-led activities.

One essential aspect of these efforts concerns the energy used producing the products and services provided within our society. This includes, for example, improved efficiency of processes in order to minimise the amount of energy used, or optimisation of efficiency by using energy with the lowest possible exergy value. It can also be about reuse of energy, which is the focus of this thesis. Heat, which is the main by-product of all energy systems, can be utilised for heating purposes to lower the primary energy demand for heating. Increased utilisation of excess heat, however, requires collaboration between normally unrelated actors, those with a supply of and those demanding excess heat.

In Sweden, which is a Northern European country with high demand for heat, the tradition of large energy-intensive manufacturing industries generating large amounts of excess heat, in combination with well-established district heating distribution systems, constitute good conditions for excess heat utilisation. Despite the fact that Sweden is among the world leaders in utilising excess heat, there is however, still a large unutilised potential.

From this background, the objective of this thesis is to identify challenges behind excess heat utilisation for heating purposes, and to propose practical suggestions to facilitate expanded excess heat utilisation. The overall objective is analysed with a focus on drivers and barriers behind interorganisational collaborations on excess heat utilisation, important components of interorganisational business models and how the technical conditions regarding supply and demand could be facilitated by strategic municipal spatial planning processes. The research is largely based on interviews conducted with societal actors with different perspectives on excess heat utilisation; energy companies, industries generating high-grade excess heat, facilities generating low-grade excess heat, facilities demanding low-grade excess heat, experts of utilisation of low-grade excess heat, branch organisations, municipal spatial planners, energy- and climate advisors, and developers. Document studies have been conducted in order to collect case specific knowledge. The research questions are explored based on literature studies on the principles of industrial symbiosis, business model perspective and strategic planning. Further, they are examined in a Swedish context.

It is concluded that the three perspectives complement each other by providing a system perspective on increased utilisation of excess heat as they seek to contribute both environmental and financial benefits at both a company and societal level. In order to facilitate further utilisation of excess heat it is important to focus on the organisational factors of humility, honesty, transparency, trust, fine-grained information transfer, joint problem solving, and shared visions of common goals, which are important conditions behind development of functional and long-term durable collaborations. Business models for collaboration could contribute to the creation of these organisationally important 
conditions. Such business models could also provide knowledge on how to create and capture joint values. For some collaborations involving actors lacking the technical knowledge related to the capturing and distribution of excess heat, a third-party providing services related to the technical knowledge required could be beneficial. Collaborations in which one of the actors consists of an energy company often entail the technical knowledge required. This implies that different collaborations involving different types of actors and under different prevailing financial, technical and organisational conditions require customised and flexible business solutions. Local authorities could, through their overall function, initiate interorganisational collaborations on excess heat within the framework of municipal spatial planning. The results do however show that the investigated planning processes could develop more extensive stakeholder participation to include further societal actors related to excess heat. More extensive stakeholder participation, have the potential to initiate new development of collaborations on excess heat between normally unrelated actors, both with and without involvements of third-party knowledge brokers. A broader participation is also expected to result in increased knowledge on how to plan to further facilitate the condition of excess heat utilisation. 


\section{SAMMANFATTNING}

För att minska miljöpåverkan från mänskliga aktiviteter relaterade till utarmningen av jordens resurser har ett flertal åtgärder och tillvägagångssätt utvecklats under de senaste årtiondena. Politiska strategier på olika samhällsnivåer är exempel på sådana åtgärder. Vissa toppstyrda strategier inriktade på omfattande institutionella förändringar och andra med mer decentraliserade tillvägagångssätt, fokuserade på industriella aktörer och branschledda aktiviteter.

En viktig del av dessa strategier handlar om åtgärder för att förändra energianvändning för produktion av produkter och tjänster. Dessa åtgärder berör bland andra; effektivisering av processer i syfte att minska mängden energi som används, det handlar också om optimerad energianvändning genom användning av energi med lästa möjliga exergivärde. Utöver detta kan det även handla om att återanvända energi, vilket är fokus för denna avhandling. Värme, den huvudsakliga biprodukten av alla energisystem, kan återanvändas i uppvärmningssyfte och samtidigt bidra till att minska primärenergianvändningen för uppvärmning. Ett ökat nyttjande av överskottsvärme kräver dock samverkan mellan aktörer som genererar ett värmeöverskott och aktörer som efterfrågar värme. Detta rör sig vanligtvis om aktörer från olika branscher som i normala falla inte är relaterade till varandra.

I Sverige, som är ett land med ett stort behov av värme är förutsättningar för nyttjande av överskottsvärme goda. Anledningen till detta är den omfattande energiintensiva tillverkningsindustrin, i kombination med väletablerade fjärrvärmedistributionssystem. Men trots att Sverige är världsledande vad gäller nyttjande av överskottsvärme finns fortfarande en stor outnyttjad potential.

Utifrån denna bakgrund syftar avhandlingen till att identifiera utmaningar bakom nyttjande av överskottsvärme i uppvärmningssyfte, samt till att föreslå åtgärder för ett ökat nyttjande av överskottsvärme. Syftet analyseras utifrån drivkrafter och hinder bakom utvecklingen av interorganisatorisk samverkan kring överskottsvärme, viktiga komponenter i interorganisatoriska affärsmodeller samt hur utbud och efterfrågan av överskottsvärme potentiellt kan underlättas genom strategiska kommunala fysiska planeringsprocesser. Forskningen är i huvudsak baserad på intervjuer med samhällsaktörer som alla relaterar till nyttjande av överskottsvärme på olika sätt; energibolag, industrier med höggradiga värmeöverskott, verksamheter som gen upphov till låggradig överskottsvärme, verksamheter i behov av låggradig värme, experter för nyttjande av låggradig värme, branschorganisationer, kommunala planerare, klimatoch energirådgivare och bostadsbolag. Som ett komplement har dokumentstudier genomförts i syfte att samla fall- och aktörsspecifik kunskap. Frågeställningarna har analyserats utifrån ett svenskt perspektiv, baserade på litteraturstudier av de tre vetenskapliga perspektiven industriell symbios, affärsmodellsperspektiv samt strategisk planering.

Slutsatserna visar att de tre vetenskapliga perspektiven kompletterar varandra genom att bidra till ett övergripande systemperspektiv för ökat nyttjande av överskottsvärme, både ur ett ekonomiskt perspektiv och ur ett miljöperspektiv, för en såväl enskild företagsnivå och bredare samhällsnivå. För att underlätta nyttjande av överskottsvärme är det viktigt att fokusera på de organisatoriska faktorerna; ödmjukhet, ärlighet, transparens, tillit, 
informationsutbyte, gemensam problemlösning samt gemensamma visioner och målsättningar. Dessa faktorer utgör viktiga förutsättningar för utveckling av funktionell och långsiktig samverkan. Affärsmodeller för samverkan kan bidra till att skapa dessa organisatoriskt viktiga förutsättningar. Dessa typer av affärsmodeller kan också bidra till en ökad kunskap om hur gemensamma värden skapas. Samverkan mellan olika typer av aktörer med olika finansiella-, tekniska- och organisatoriska förutsättningar kräver dock flexibla affärslösningar. För viss samverkan mellan aktörer som saknar tekniska kunskaper relaterade till distribution av värme, kan en tredje part i syfte att tillhandahålla tjänster relaterad till den tekniska kunskap som krävs, underlätta samverkan. För samverkan där en av aktörerna utgör ett energibolag finns ofta redan den tekniska kunskap som krävs. Kommuner har genom sin övergripande funktion möjlighet att initiera interorganisatorisk samverkan inom ramarna för den fysiska planeringen. Resultaten visar dock att de undersökta planeringsprocesserna skulle kunna utveckla mer omfattande deltagandeprocesser innefattandes fler samhällsaktörer relaterade till överskottsvärme. Mer omfattande deltagandeprocesser kan potentiellt initiera ny samverkan kring överskottsvärme mellan aktörer med utbud och behov av värme, både med och utan involvering av en tredje part. Ett bredare deltagande förväntas också leda till samlad ökad kunskap om hur områden bör planeras för att öka de fysiska förutsättningarna, med avseende på utbud och efterfrågan, för framtida nyttjande av överskottsvärme. 


\section{ACKNOWLEDGEMENTS}

This $\mathrm{PhD}$ thesis summarises and concludes my past years of research. The process has been challenging, at times frustrating but yet very interesting and enlightening. I have learned a lot about the field of study, and not least about myself and my own capabilities as a researcher.

First, I would like to thank my supervisors Olof Hjelm and Sara Gustafsson for contributing valuable knowledge and critical feedback in the development of my research, and of me as a researcher. The commitment you have shown, especially during the stressful last months, was invaluable. Thank you!

Jenny Ivner, who was my first assistant supervisor and who introduced me into this research field, also deserves special thanks. Thank you Jenny! I would also like to thank Mattas Lindahl for his commitment and straightforward approach, providing guidance and feedback around the clock in the development of two of my papers. Mattias, I really enjoyed working with you!

I am also thankful to all of my colleagues at Environmental Technology and Management at Linköping University for their support. Special thanks for your support, ideas, and valuable input during my last seminar. Wisdom, it's been a great asset and pleasure having you as a roommate!

Furthermore, gratitude goes out to Dick Magnusson for reading the first draft and providing valuable feedback. Another thank you goes to Mica Comstock for proofreading every sentence of the cover essay and most of my papers, making sure it was all comprehensible.

Additionally, I would like to thank Tekniska Verken in Linköping and Futureheat (former Fjärrsyn) for financing parts of my research, as well as all participating respondents who made this research possible.

Sofia Lingegård, my friend and former colleague, thank you for your moral support during this last summer and fall. Your concern meant a lot to me!

My BFF Alice, I miss having you around! You and Fredrik, the unbeatable party organisers. Thank you for the laughter, all the great times we spent together, pre and post kids, and for arranging the crayfish party (together with Mats of course, thank you Mats!) where I met Marko. Our friendship means a lot to me; see you in London soon!

Many thanks to my friends and family in Norrköping (Moa, Andreas, Erica, Jonas, Jonna, Marcus, Johan, dad, mom and Thomas) who always, regardless of how or at what time, welcomed me with open arms when the journey home to Stockholm sometimes felt too long to manage. Thank you for cheering me on and making me feel good about myself.

Mom and Thomas, thank you for taking such good care of me during my sleepovers, for all the nice evenings we spent together at your place, and for providing me super healthy food and confidence. Thank you also for keeping Bill busy by taking him to theatre performances, swimming, to pick blueberries, on walks and on bike excursions in your 
beautiful archipelago last summer - it provided me with valuable time for this thesis. Mom, your amazing support during my minor breakdowns and panic attacks during the later and most stressful phase of this process was just fantastic; you're the best!

Thank you also to my parents-in-law for taking such good care of Bill during both my and Marko's sometimes extreme workload.

My stepdaughter Nåmi, thank you for helping me to choose the best thesis cover - you really have a thing for taste! Thank you also for being the best big sister and extra mom Bill could ever wish for. Your ability to make Bill break out in laughter is like magic! How do you do that?!

My husband Marko, you are my love, rock and best friend. Thank you for your endless support, love and for believing in me when I did not. Thank you for taking me on travels around the world, music events and dinners - sometimes very well planned, and sometimes very spontaneous. Thank you also for providing me delicious Finnish liquorice and high-quality coffee with perfectly steamed milk. But most of all, thank you for being my husband and for making me a mom. Together we make the best team!

Last and most importantly, Bill, I have finished the book now. All I want now is to spend time with you! Playing, dancing, reading you stories, singing you songs and being there supporting you through all kinds of new adventures life will bring you. I'm proud of many things in life, yet nothing beats being your mom. I love you like only I can!

Stockholm, November - 2017 


\section{APPENDED PAPERS}

Paper 1: Päivärinne, S., Hjelm, O. and Gustafsson, S. (20I5). "Excess heat supply collaborations within the district heating sector: Drivers and barriers". Journal of Renewable and Sustainable Energy, Volume 7, Issue 3, 2015, Pages 033II7-I-I6.

Paper 2: $\quad$ Päivärinne, S. and Lindahl, M. (20I5). "Exploratory study of combining Integrated Product and Services Offerings with Industrial Symbiosis in order to improve Excess Heat utilization”. Procedia CIRP, Volume 30, 20I5, Pages I67-I72.

Paper 3: Päivärinne, S. and Lindahl, M. (20I6). "Combining Integrated Product and Services Offerings with Industrial Symbiosis - a study about opportunities and challenges". Journal of Cleaner Production, Volume 127, 20 July 20I6, Pages 240-248.

Paper 4: Päivärinne, S., Hjelm, O. and Gustafsson, S. (2017). "Strategic spatial planning - a missed opportunity to facilitate district heating systems based on excess heat". Manuscript, submitted to Journal of European Planning Studies.

Paper 5: Päivärinne, S. (20I7). "Local authorities as promoters of interorganisational collaborations of excess heat utilisation". Manuscript. 


\section{RELATED PUBLICATIONS 1}

Päivärinne, S. and Lindahl, M. (20I5). "A Product Service System approach to facilitate Sustainability Transitions regarding Excess Heat Recovery". Contribution to the 7th IPSS conference "Industry transformation for sustainability and business".

Persson, S. (20I4). "Product service systems within excess heat supply business collaborations". Presented at the 5th "Sustainability Transitions Research Network Conference", Utrecht, The Netherlands.

Persson, S., Hjelm, O. and Gustafsson, S. (2012). "Development of district heating. -A study of the development of excess heat based district heating in two Swedish communities". Presented at the Greening of Industry Network (GIN), Linköping, Sweden 2012.

Persson, S., Ivner, J. (20II). Uncovering Industrial Symbiosis in Sweden: - Exploring a possible approach. Presented at the World Renewable Energy Congress, Linköping, Sweden 20II.

Ivner, J., Persson, S. (2009). Fysisk planering och fjärrvärmeexpansion i praktiken: Förstudie om beslutsprocessen vid kommunal fysisk planering och fjärrvärmeexpansion i nyexploaterade områden. Presented at the Swedish District Heating Association's distribution day 2010.

IThe author changed name from Persson to Päivärinne in 20I4, which means that Päivärinne and Persson refer to the same author. 


\section{THESIS OUTLINE}

The cover essay of this thesis includes Chapters I-8. The appended Papers are found in the Appendix.

\begin{tabular}{|c|c|c|}
\hline Part & Chapter/Paper & Content/Paper \\
\hline \multirow[t]{8}{*}{ Cover thesis } & I. Introduction & $\begin{array}{l}\text { Introducing the research topic, scope and key } \\
\text { literature }\end{array}$ \\
\hline & $\begin{array}{l}\text { 2. Utilisation of excess heat } \\
\text { - an overview }\end{array}$ & $\begin{array}{l}\text { Historical background, necessary preconditions } \\
\text { and actors involved as well as spatial planning in } \\
\text { relation to utilisation of excess heat }\end{array}$ \\
\hline & 3. Theoretical background & Theoretical framework used in the research \\
\hline & 4. Methodology & Description of methodological choices \\
\hline & 5. Results and Discussion & Presentation and discussion of key results \\
\hline & $\begin{array}{l}\text { 6. Conclusions and } \\
\text { Implications }\end{array}$ & Main conclusions and contributions \\
\hline & 7. Further research & Further research is discussed \\
\hline & 8. References & \\
\hline \multirow[t]{5}{*}{ Appendix } & Paper I & $\begin{array}{l}\text { Excess heat supply collaborations within the } \\
\text { district heating sector: Drivers and barriers }\end{array}$ \\
\hline & Paper 2 & $\begin{array}{l}\text { Exploratory study of combining Integrated Product } \\
\text { and Services Offerings with Industrial Symbiosis in } \\
\text { order to improve Excess Heat utilization }\end{array}$ \\
\hline & Paper 3 & $\begin{array}{l}\text { Combining Integrated Product and Services } \\
\text { Offerings with Industrial Symbiosis - a study about } \\
\text { opportunities and challenges }\end{array}$ \\
\hline & Paper 4 & $\begin{array}{l}\text { Strategic spatial planning - a missed opportunity to } \\
\text { facilitate district heating systems based on excess } \\
\text { heat }\end{array}$ \\
\hline & Paper 5 & $\begin{array}{l}\text { Local authorities as promoters of } \\
\text { interorganisational collaborations of excess heat } \\
\text { utilisation }\end{array}$ \\
\hline
\end{tabular}

Chapter I, the introduction, gives a background to the research topic of this thesis, describes the context in which this research has been carried out, and presents the objective and research questions. Chapter 2 continues with brief background presentations of excess heat utilisation from a historical, international and Swedish perspective. This chapter also includes a background presentation of excess heat-based systems for district heating in relation to the Swedish municipal spatial planning process. In Chapter 3, the theoretical background, the different theories used to discuss the objective and the research questions of this thesis are presented. Next, Chapter 4 
describes the methodology - how the research for this thesis has developed, and why it has taken certain turns. It also includes descriptions of the methods for data collection and the analytical approach for compiling the cover essay. This is followed by a presentation of the appended papers and a discussion on the quality of the research. Chapter 5, the results and discussion chapter, then presents and discusses the compiled results from each paper based on the research questions of the thesis. Subsequently, the conclusions regarding the overall objective and research questions are presented in chapter 6. Finally, a discussion regarding further research is presented in Chapter 7. 


\section{TABLE OF CONTENT}

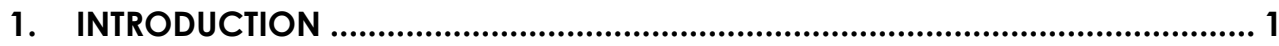

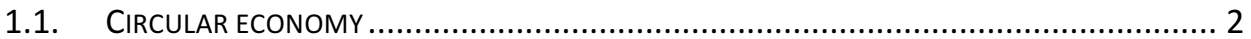

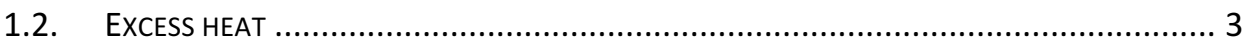

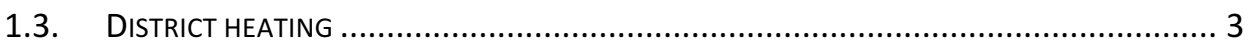

1.4. ColLABORATION AND AN INCREASED BUSINESS PERSPECTIVE ...................................... 5

1.5. PLANNING FOR NEW DEVELOPMENT OF EXCESS HEAT UTILISATION ............................ 6

1.6. OBJECTIVE AND RESEARCH QUESTIONS.......................................................... 7

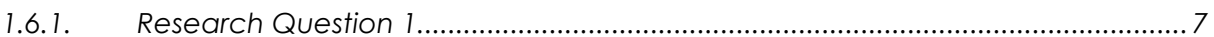

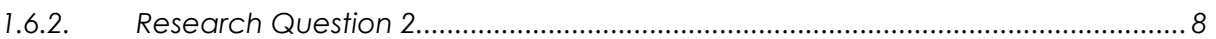

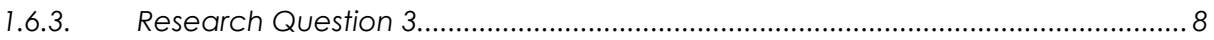

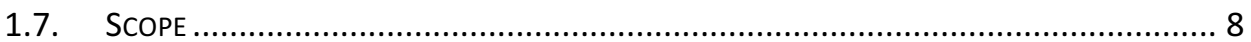

2. UTILISATION OF EXCESS HEAT - AN OVERVIEW .......................................... 11

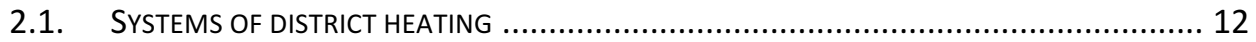

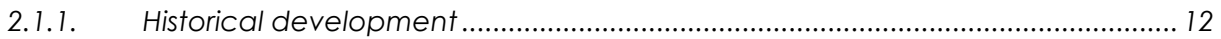

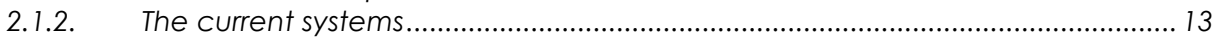

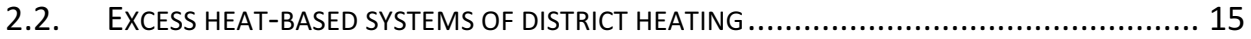

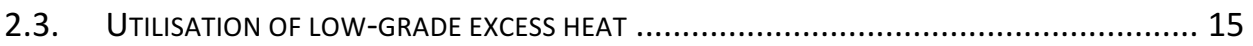

2.4. MUNICIPAL SPATIAL PLANNING IN SWEDEN ................................................. 16

2.4.1. Historical glance back at the Swedish planning system .................................... 17

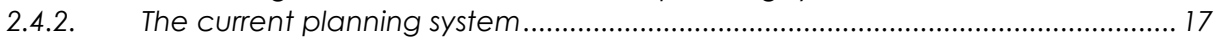

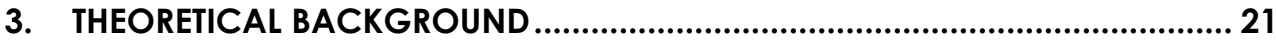

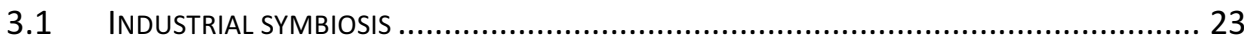

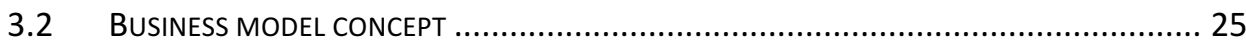

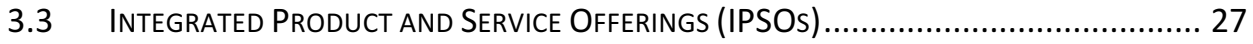

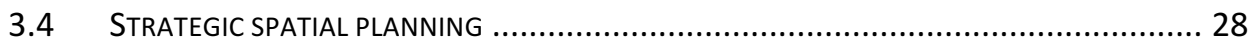

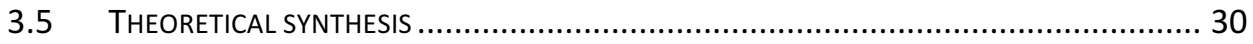

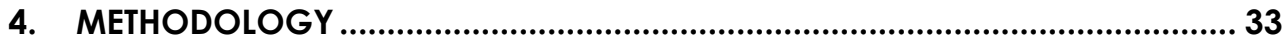

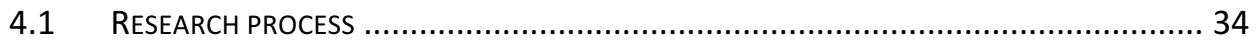

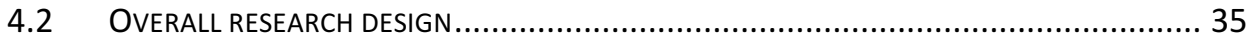

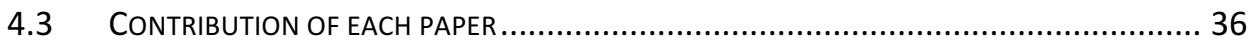

4.4 OVERVIEW AND MOTIVATION OF METHODS AND ANALYTICAL APPROACHES .................. 37

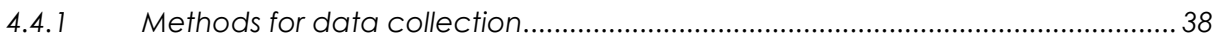

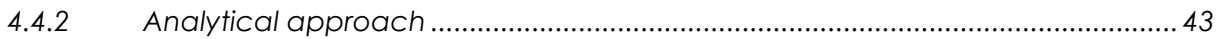

4.5 APPENDED PAPERS ......................................................................... 44

4.5.1 Paper 1 - Excess heat supply collaborations within the district heating sector:

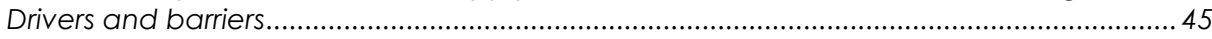

4.5.2 Paper 2 - Exploratory study of combining Integrated Product and Services

Offerings with Industrial Symbiosis in order to improve Excess Heat utilization..................... 45

4.5.3 Paper 3 - Combining Integrated Product and Services Offerings with Industrial

Symbiosis - a study about opportunities and challenges .................................................. 46

4.5.4 Paper 4 - Strategic spatial planning - a missed opportunity to facilitate district

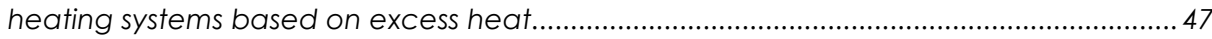

4.5.5 Paper 5 - Local authorities as promoters of interorganisational collaborations

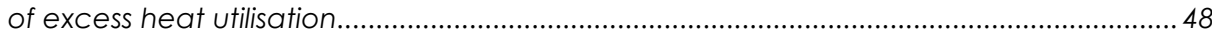

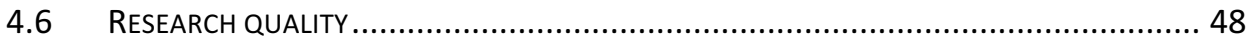


4.6.1 Transferability, dependability, credibility and confirmability..... 49

5. RESULTS AND DISCUSSION .................................................................... 53

5.1 DRIVERS AND BARRIERS BEHIND DEVELOPMENT OF INTERORGANISATIONAL

COLLABORATIONS ON EXCESS HEAT UTILISATION ....................................................... 54

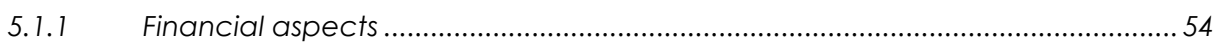

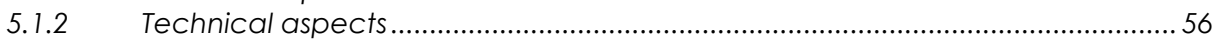

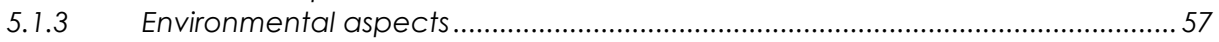

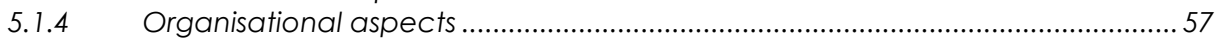

5.2 IMPORTANT KEY ELEMENTS OF INTERORGANISATIONAL BUSINESS MODELS................... 59

5.2.1 Implications of applying the IPSO approach in order to facilitate utilisation of

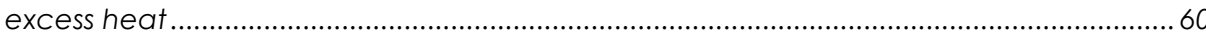

5.3 IMPLICATIONS OF APPLYING STRATEGIC SPATIAL PLANNING IN THE SWEDISH SPATIAL PLANNING PROCESS TO FACILITATE THE UTILISATION OF EXCESS HEAT ................................. 64

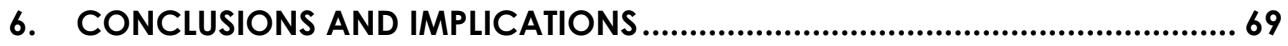

6.1 MAIN DRIVERS AND BARRIERS BEHIND THE DEVELOPMENT OF INTERORGANISATIONAL

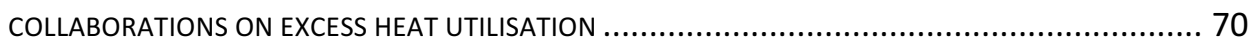

6.2 IMPORTANT KEY ELEMENTS OF INTERORGANISATIONAL BUSINESS MODELS .................. 70

6.3 IMPLICATIONS OF STRATEGIC PLANNING FOR INCREASED UTILISATION OF EXCESS HEAT .... 70

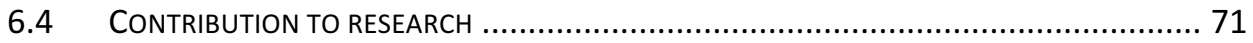

6.5 PRACTICAL SUGGESTIONS FOR INCREASED EXCESS HEAT UTILISATION ........................ 71

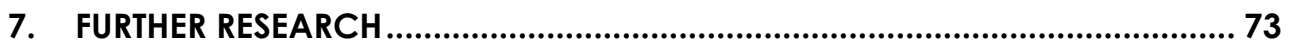

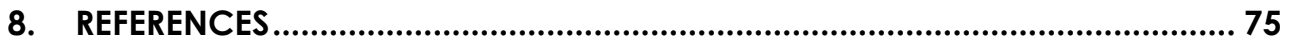

\section{APPENDIX - PAPERS}

PAPER 1: EXCESS HEAT SUPPLY COLLABORATIONS WITHIN THE DISTRICT HEATING SECTOR: DRIVERS AND BARRIERS.

PAPER 2: EXPLORATORY STUDY OF COMBINING INTEGRATED PRODUCT AND SERVICES OFFERINGS WITH INDUSTRIAL SYMBIOSIS IN ORDER TO IMPROVE EXCESS HEAT UTILIZATION

PAPER 3:COMBINING INTEGRATED PRODUCT AND SERVICES OFFERINGS WITH INDUSTRIAL SYMBIOSIS - A STUDY ABOUT OPPORTUNITIES AND CHALLENGES.

PAPER 4: STRATEGIC SPATIAL PLANNING - A MISSED OPPORTUNITY TO FACILITATE DISTRICT HEATING SYSTEMS BASED ON EXCESS HEAT.

PAPER 5: LOCAL AUTHORITIES AS PROMOTERS OF INTERORGANISATIONAL COLLABORATIONS OF EXCESS HEAT UTILISATION. 


\section{LIST OF FIGURES}

FIGURE 1: THE MAJOR STEPS IN THE PLANNING PROCESSES DESCRIBED BY THE PBA (SFS 2010:900).

\section{LIST OF TABLES}

TABLE 1: DESCRIPTION OF THE NINE BASIC BUILDING BLOCKS DESCRIBED BY OSTERWALDER AND PIGNEUR (2010).

TABLE 2: CONTRIBUTION OF EACH PAPER, 1-5 TO THE RESEARCH QUESTIONS 1-3.

TABLE 3. DESCRIPTION OF METHODS FOR DATA COLLECTION, ANALYTICAL APPROACH AND THEORIES USED FOR EACH APPENDED PAPER.

TABLE 4. NUMBER OF RESPONDENTS FROM EACH PAPER, REPRESENTING DIFFERENT PRIVATE/PUBLIC ORGANISATIONS

TABLE 5. FINANCIAL, TECHNICAL, ORGANISATIONAL AND ENVIRONMENTAL DRIVERS AND BARRIERS BEHIND DEVELOPMENT OF EXCESS HEAT COLLABORATIONS

TABLE 6. POSSIBLE OPPORTUNITIES AND CHALLENGES OF INVOLVING A THIRD-PARTY IPSO PROVIDER. 


\section{INTRODUCTION}

In this chapter, a background to the research topic is provided, followed by a description of the context in which the research has been carried out. Thereafter, the objective and research questions of this thesis are presented. 
Currently, the Earth's resources are consumed in a non-sustainable manner, and as a consequence, our society is facing a variety of environmental problems, which are predicted to increase even more in the future (Rockström et al., 2009). Since all environmental issues are linked to different social and financial dynamics, they in turn create very complex challenges (Steffen et al, 20I5; Blomqvist et al., 20I2). In order to significantly lower the increasing and undesirable environmental impact from human activities, there is a need to transform today's society toward a more sustainable one (Sachs, 2009).

As a reaction, numerous efforts and approaches related to the transformation of human activities have been initiated and developed during the last decades (Kates et al., 200I; Komiyama and Takeuchi, 2006). Examples of such efforts are policies and strategies at different levels. Some have a top-down approach, focusing on extensive institutional changes like, for example, national strategies or industrial policies (European commission, 20I4). Others have a bottom-up approach, with a focus on industrial actors and industry-led activities like industrial standards and environmental management systems (UNIDO, 20II). Green supply chain management is another example (Srivastava, 2007). One concept embracing many different dimensions of efforts and approaches to sustainability - both top-down and bottom-up - is the concept of the circular economy (Ellen MacArthur Foundation, 2015).

\subsection{Circular economy}

Circular economy is a relatively new concept influenced by several areas such as industrial ecology, industrial symbiosis, lifecycle management, waste management and business management, among others. It is a concept that, in parallel to green and sustainable supply chain management, has been developed in an effort to reduce the negative environmental consequences of production and consumption (Ellen MacArthur Foundation, 20I5).

The concept addresses the problems related to the traditional linear economic model based on "take, make and dispose" (Ellen MacArthur Foundation, 2015; Ness, 2008; European Commission, 2016). It acknowledges a more environmentally sound bio-based and renewable resource use. As the name reveals, the focus of a circular economy is "the realisation of closed-loop material and resource flows" (Geng and Doberstein, 2008), and to maintain the added value in products for as long as possible in order to minimise waste. The objective is to create more value from each unit's natural resources compared to the traditional linear models (Di Maio and Rem, 20I5), as it keeps the resources within the societal economy even after the products no longer serve their initial function. This is done in order for the resources to be used over and over again to generate more value (Pearce and Turner, 1990). In addition, innovative manufacturing methods enable the same functional value using less resources both primary and recycled (Di Maio et al., 2017). The resources are kept "within the economy whenever possible" through various practices of circulation such as sharing, leasing, reusing and recycling (European Commission, 20I6). A circular economy entails radical changes of societal systems and requires innovation, not only in terms of technology, but also in terms of organisation, society and politics.

One essential aspect within the circular economy concept concerns the energy used producing the products and services within the circular system boundary (Ellen MacArthur Foundation, 20I5). Resource-efficient energy use refers to decreasing the 
required energy while delivering the same industrial output (European Commission, 20I5). It can be about improving the efficiency of processes in order to minimise the amount of energy used, but it can also be about optimising efficiency by using the energy with the lowest possible value of exergy, which is a term derived from thermodynamics as a measure of the quality of the energy (Prodromidis and Coutelieris, 2017). Furthermore, it can be about re-using energy.

\subsection{Excess heat}

Heat, which is low value energy with low exergy, is the main by-product of all energy systems. The excess heat varies in temperature, depending on the process it arises from. Energy-intensive industrial activities are examples of activities generating high-grade excess heat, with temperatures of $70^{\circ} \mathrm{C}$ and above (Cronholm et al., 2009; Frederiksen and Werner, 20I4). There are also examples of less energy-intensive activities generating low-grade excess heat, with temperatures around $30^{\circ} \mathrm{C}$ and sometimes in smaller amounts. Such examples are smaller industrial activities, such as data centres, grocery stores or other facilities with cooling systems generating excess heat (Swedish University of Agricultural Sciences, 20I2).

Excess heat can be utilised for heating purposes to lower the primary energy demand for heating (Hirvonen et al., 20I4). Currently, the most common use of excess heat worldwide is from industrial processes generating high-grade excess heat utilised for internal and external heating purposes, for example in systems of district heating (Hirvonen et al., 20I4). Excess heat can also be utilised to generate electricity (Swedish Energy Agency, 20I6). This, however, is a relatively new technology which is under current development and not yet in significant use.

Although technological development has led to new and better technologies for utilising low-grade excess heat (Arnell et. al, 2012; Swedish Energy Agency, 2010), there is still a great unutilised potential (Elamzon and Nordberg, 20I4). An upcoming area for utilisation of low-grade excess heat is cultivation processes within the food industry (Swedish University of Agricultural Sciences, 2012) such as greenhouse cultivation, fishand shrimp farms and algae production. Yet, the currently most common utilisation requires high-grade excess heat (Cronholm et al., 2009).

\subsection{District heating}

As mentioned above, high-grade excess heat can be utilised for heating purposes in existing systems of district heating ${ }^{2}$ for heating households and public buildings. (Hirvonen et al., 20I4; Frederiksen and Werner, 20I4). The heat source used in the district heating system has a direct impact on the system's environmental impact. Since excess heat-based systems of district heating provide heat using energy that would otherwise be wasted, these systems are generally considered resource efficient (Frederiksen and Werner, 20I4; Werner, 2004). Besides excess heat, the heat sources of district heating can also be either fossil fuels, biofuels or household waste. In Central European countries, oil and natural gas are the traditional energy sources predominantly used for heat generation in the system (Frederiksen and Werner, 20I4). Systems of district heating consist of a central combustion facility producing hot water. The heated water is

\footnotetext{
${ }^{2}$ District heating is a collective and local system for the distribution of heat for heating purposes mainly supplied to cover the need for the heating of buildings and tap water, and for industrial processes (Frederiksen and Werner, 20I4).
} 
transported to each property provided with district heating through well-insulated pipes. Each connected property has a heat exchanger that heats the radiators and tap water.

In the northern parts of Europe with a high demand for heat, district heating is more developed and accounts for about 50 percent of the total heating market (Frederiksen and Werner, 20I4). In Sweden, which is one of the northern countries of Europe and also the focus of this thesis, the history of consistent climate and energy policies has set a good foundation for the emergence of district heating. The policies include taxing fossil fuel use while encouraging and subsidising less environmentally damaging heat supply solutions (Swedish District Heating Association, 2009). During the past decade, district heating's expansion in Sweden has decreased, however, as the most economically profitable areas for district heating already have district heating. Most areas still not having district heating normally consist of suburban single-family houses villas. These areas are typically less economically profitable for district heating because of their low heat density. This means that the revenue from the heat sold is low compared to the investment cost for establishing a local distribution grid (Forsaeus Nilsson et al., 2008).

In addition, several recent societal developments have resulted in changed conditions for the continued development of district heating. One example is privatisation, which has led to a shift from systems developed with a monopoly position of public ownership to systems partly or wholly under private control, bringing organisational and operational changes in the development of these systems. New environmental standards have led to increased pressure to transform land use of energy provisions into energyefficient systems (Magnusson, 2013). One example of this is new standards on energyefficient buildings and an upcoming EU directive on zero-energy buildings for new and significant remodelled houses (Directive 20IO/3I/EU) with lower heating demands. These new conditions often make traditional systems of district heating based on primary energy, such as fossil fuels or biofuels, less suitable. Systems of district heating based on low exergy excess heat are, however, positively influenced by the upcoming EU directive. This is because the energy used will be measured as primary energy: that is, the total amount of energy needed to provide energy to the end users, and excess heat is not considered as primary energy (Directive 20IO/3I/EU). In addition, since excess heat is less expensive than primary energy, it is possible to achieve profitability for systems of district heating despite reduced heating demand (Doménech and Davies, 20II). During 20I6, 4.3 TWh of excess heat was utilised in systems of district heating, which corresponds to 7 percent of the total amount of energy supplied to the Swedish district heating systems (Swedenergy, 2017). There are no recent estimates of the total amount of excess heat currently generated, neither high- nor low-grade. Older estimations on the potential of high-grade excess heat made by the Swedish District Heating Association do, however, show that the potential in 2009 was I.6 times greater than the current utilisation at the same time (Cronholm et al, 2009). This data concern potential utilisation of high-grade excess heat for district heating purposes, which is also the main focus of this thesis. Similar estimations made by the Swedish Energy Agency the year after show that approximately 50 percent of all high-grade excess heat generated from large energyintensive industries in Sweden is unutilised (Swedish Energy agency, 2010). Based on these earlier estimates, it can be concluded that there most probably still is a great potential not being utilised. The question is: Why? 


\subsection{Collaboration and an increased business perspective}

Increased utilisation of both low- and high-grade excess heat requires collaboration between actors with a supply of excess heat and actors demanding excess heat. Interorganisational collaborations as such, where different organisations and/or companies collaborate for specific business intentions, have previously been studied within the research field of industrial symbiosis. Industrial symbiosis is a research field of studies on interorganisational collaborations on resources between normally unrelated actors, similar to the collaborations of excess heat studied in this thesis. Industrial symbiosis research provides examples of collaborations across the traditional business boundaries, successfully exchanging resources to improve financial and environmental outcomes for the involved organisations and for society at large (Domenech and Davies, 2009; Chertow, 2007; 2000).

There are however well-known barriers against development of collaborations in line with industrial symbiosis networks; these barriers consist of financial- or risk-related issues (Walls and Paquin, 20I5). Other factors highlighted as bringing resistance towards industrial symbiosis networks are trust, and the fact that industrial symbiosis activities are normally outside the core aspects of the businesses involved (Walls and Paquin, 20I5). Previous research within the research field shows that resource collaborations do not always occur, even though the technical conditions exist (Chertow, 2007). Despite the fact that reasons for engaging in resource sharing often evolve from internal business strategies (Tsvetkova and Gustafsson, 2012), comparably little emphasis in research has been put on the organisational perspective of interorganisational collaborations (Walls and Paquin, 2015). Further, there is sparse literature on suitable business models for interorganisational collaborations (Tsvetkova \& Gustafsson 2012; Walls and Paquin, 2015).

Since the concept of industrial symbiosis takes whole networks of actors into consideration rather than just individual firms, it needs business models that emphasise the collaborating aspects of industrial symbiosis (Walls and Paquin, 2015). As earlier mentioned, knowledge on how to develop sustainable business models for interorganisational collaborations in line with industrial symbiosis networks is a previously highlighted knowledge gap within the industrial symbiosis literature (Walls and Paquin, 2015; Coelho and Ruth, 2006; Woodard, 200I). Increased knowledge could entail greater opportunities to facilitate further development of excess heat utilisation collaborations - both regarding excess heat-based systems of district heating and the utilisation of low-grade excess heat.

One way to facilitate further utilisation of excess heat could be through a shift in business focus, from the product (excess heat) to the service (heating) (cf. Baines et al., 20I7; cf. Tukker, 2004). Applying an Integrated Product and Service Offering (IPSO) approach, as one out of several elements of the business model, could be such a way. The IPSO is part of a research field of studies on how to alter the view of how products are used by providing products integrated with services. Collaborations between businesses on lowgrade excess heat - such as the activities described above like facilities with cooling systems and various food cultivation productions where heat distribution-related issues are outside the core business between the actors involved - most probably entail a lack of knowledge on such issues. The lack of knowledge regarding both technical issues related to the capturing and distribution of the excess heat as well as issues regarding 
how to formulate business agreements could, however, entail new business opportunities for actors with an understanding of heat-related issues. A third-party with knowledge related to the technical aspects of distribution as well as knowledge about how to develop a suitable business model could possibly facilitate these kinds of excess heat collaborations between actors outside the traditional heating market. This thirdparty's business offering would, in line with the IPSO concept (see Oliva and Kallenberg, 2003; Maussang et al., 2006; Tukker and Tischner, 2006; Lelah et al., 20II; Lindahl et al., 20I4; Mont, 2008), consists of integrated product service offerings of heating and would basically mean providing offerings based on the knowledge of how to provide the excess heat from one actor to another. However, as for development of interorganisational collaborations similar to industrial symbiosis, utilisation of excess heat in line with the IPSO also requires organisational conditions related to resource sharing (Fulford and Standing, 20I4; cf. Chertow, 2007; 2000). In addition, technical conditions related to the match of supplies and demands of excess heat are also important.

\subsection{Planning for new development of excess heat utilisation}

Through land use planning, there are significant opportunities to influence the design and location of planned areas (Ranhagen, 2008) (which influence the demand for heat) as well as industrial activities (generating excess heat) in ways that have the opportunity to facilitate further utilisation of both low- and high-grade excess heat. Planning of large technical systems, such as systems of district heating, are highly intertwined with land use planning (cf. Albrechts, 2004, 2006; cf. Poister and Streib, 1999).

Local authorities in Sweden have a strong position in spatial planning through their municipal plan monopoly (National Board of Housing, Building and Planning, 20I5). Local self-government provides a large range of freedom of action. In Sweden, the geographical area is divided into 290 municipalities with inhabitants, organisations, and large technical systems (Swedish Association of Local Authorities and Regions, 20I7). Each municipality has a local government - which is politically governed - and a local authority consisting of the local public administration (Swedish Association of Local Authorities and Regions, 2017). The local government consists of elected representatives and have independent power of taxation. The public administration consists of officeholders within different areas and with different expertise. The above-mentioned municipal plan monopoly means that local authorities have the main responsibility for designing land and water use within their geographical territory according to the provisions in the Plan and Building Act (PBA) (SFS 20I0:900). The PBA contains provisions on the planning of land, water and construction and obligates all local authorities to develop comprehensive planning for the municipality. The law also contains provisions concerning detailed development planning and building permits for all municipalities (National Board of Housing, Building and Planning, 20I6).

The earlier mentioned political trends towards privatisation have also changed the planning situation (Allmendinger, 2009). The spatial planning is affected by higher involvement of private stakeholders (Graham and Marvin, 200I). This relatively new order of land use planning affects the current district heating systems, which were developed in a context of strong public municipal influence and ownership. The technical aspects of district heating have not significantly changed for several decades, but now the systems are required to be run on the new terms of demand and more private institutional conditions. Strategic spatial planning processes in Sweden are often described as processes including developed participatory mechanisms, such as 
consultation processes (Busck et al., 2008; Maier, 200I). Previous strategic planning literature stresses the need for involving multiple stakeholders in a collaborative approach to build stakeholder commitment in the development of a strategic vision for spatial planning (Albrechts, 2006; Poister and Streib, 1999). The importance of this is also highlighted in multiple EU and international policies (Council of Europe, 2000, 2006a,b; Aarhus Convention, 1998; FAO, 2003; European Commission, 2004; Forest Europe, 20II).

\subsection{Objective and Research Questions}

Given the discussion above, this thesis investigates different types of interorganisational collaborations regarding the utilisation of excess heat, with a focus on Swedish excess heat utilisation mainly for district heating purposes.

The thesis analyses both existing and potential cases of excess heat utilisation collaborations, of both low- and high-grade excess heat, yet with a focus of high-grade excess heat. In order to propose different organisational implications for an increased utilisation of excess heat, it entails the identification of drivers and barriers using a combined perspective of industrial symbiosis and a business perspective. The business perspective is additionally used to identify important elements of interorganisational business models. The characteristics of the IPSO are applied to give suggestions for increased utilisation of excess heat. Also investigated is the municipal spatial planning practice - which forms the basis for the technical conditions behind the emergence of excess heat utilisation - in relation to the current Swedish spatial planning legislation and strategic spatial planning literature.

The overall objective is to identify challenges behind excess heat utilisation primarily for systems of district heating, and to propose practical suggestions to facilitate expanded excess heat utilisation in order to contribute to resource efficiency and a more circular economy. The objective is broken down into three different research questions, presented in the following sections.

\subsubsection{Research Question 1}

What are the main drivers and barriers behind the development of interorganisational collaboration on excess heat utilisation?

An increased utilisation of excess heat requires knowledge of both providers and users, or in other words, an answer to the questions: Who are they? In which areas do they operate? What are their drivers? What do they perceive as being barriers for entering a collaboration on excess heat utilisation? Increased knowledge of important aspects behind interorganisational business collaborations could entail greater opportunities to facilitate both low- and high-grade excess heat on both a small and larger scale.

The first research question focuses on organisational aspects such as business agreements and the relationship and interaction between the actors involved in interorganisational collaborations on excess heat. Elaboration of the first research question provides descriptions of different providers and users of excess heat, both existing and potential. The elaboration will also include a description and analysis of the most important drivers and barriers, mainly from an organisational viewpoint. Financial and technical barriers, however, are also addressed to some extent. These findings are 
needed to understand the context for further investigation of Research Questions 2 and 3.

\subsubsection{Research Question 2}

What are the important key elements of interorganisational business models for excess heat utilisation, and how can they facilitate increased value creation for individual actors and society at large?

The emphasis of the importance of business models taking several actors into account, together with findings from elaborating on Research Question I, provides the motivation for Research Question 2.

Can business models specifically designed for interorganisational business agreements facilitate the development of further excess heat utilisation? How could such business models be designed in order to meet the interests of both parties and to lay the foundation for long-term collaborations? These are the types of questions that elaboration on Research Question 2 will contribute with discussions on, both by existing examples of excess heat utilisation collaborations and through potential cases, both to gain knowledge on actual outcomes of such business collaborations and to gain knowledge on why business collaborations do not occur, even though the technical conditions for them exist.

\subsubsection{Research Question 3}

How could strategic spatial planning facilitate the conditions for further excess heat utilisation?

The technical conditions regarding supply and demand constitute the foundation of the utilisation of excess heat through interorganisational business collaborations. The supply and demand are regulated by how the society is planned. In order to facilitate the utilisation of excess heat, the spatial planning needs to be conducted based on knowledge on how to match the supply with the demand. Strategic planning processes involving multiple stakeholder participation are required in order for the planning process to be based on well-founded decisions regarding the technical conditions required for excess heat utilisation.

The third research question aims to explore how the spatial planning process could be developed, emphasising a more strategic planning approach, to facilitate further utilisation of excess heat.

\subsection{Scope}

This thesis focuses on organisational aspects behind the development of different excess heat utilisation collaborations. Although technical and financial aspects are also addressed, the main focus on organisational aspects entails less emphasis on the aspects of technical and financial character. The overall objective and research questions are designed to address different actors' perceptions of excess heat utilisation. The cases involve a variety of actors, all connected to excess heat utilisation but with different perspectives; energy companies, industries generating high-grade excess heat, facilities generating low-grade excess heat, facilities demanding low-grade excess heat, experts of 
utilisation of low-grade excess heat, branch organisations, municipal spatial planners, energy- and climate advisors, and developers.

The majority of the cases investigated involves collaborations on high-grade excess heat for district heating purposes between energy companies and large, energy-intensive industries. Cases involving collaborations on low-grade excess heat between smaller facilities, however, are also included. The different studies of high- and low-grade excess heat utilisation within each of the papers have been carried out from a Swedish perspective, under the prevailing Swedish conditions and current Swedish legislation. Nevertheless, they yield useful lessons can be applied internationally and to other areas of interorganisational collaboration and planning processes.

The different studies were carried out between 2009 and 2017. This time period entails a development, both regarding technological solutions related to distribution and utilisation, that especially focuses on low-grade excess heat. It also entails an increased knowledge and interest in solutions for increased utilisation among practitioners. Based on the five appended papers, this thesis aims to synthesise in order to provide a holistic and compiled, yet current view, of the research area in focus. 


\section{UTILISATION OF EXCESS HEAT - AN OVERVIEW}

This chapter presents a background on excess heat utilisation in a Swedish context. First, a brief historical overview of district heating, internationally and in Sweden, is presented. This is followed by a presentation of the situation, as of 20I7, regarding excess heat-based systems for district heating. Finally, the Swedish municipal spatial planning process, which impacts the supply and demand of excess heat, is described according to the Swedish spatial planning legislation described in the PBA. 


\subsection{Systems of district heating}

Despite the fact that the technology of district heating has been known and used for more than a century, district heating globally is a small niche technology - targeting specific customers with a demand for heat, with the specific technique of distribution in focus (Frederiksen and Werner, 20I4). The low global usage reflects the relatively sparse literature on district heating compared with other energy technologies. Further, a very small percentage of the information available is written in English, since district heating mainly occurs in Russia, Poland, Finland, Germany, Denmark and Sweden, and is an infrequent technology in both the US and Britain (Frederiksen and Werner, 20I4). In Europe, district heating covers Io percent of the total heating demand of industries, residential buildings and services (Werner, 20I6).

\subsubsection{Historical development}

The first heating systems similar to district heating were used during the Antiquity to heat bathhouses. Yet these early systems were used on a smaller scale and with a considerably lower efficiency (Sahlin, 2013). Systems of district heating more similar to the district heating of today were commercially established in the late I8oos. The first system, based on steam, was developed in the city of Lockport in the United States and soon the example spread to other cities. In I882, the New York City borough of Manhattan got district heating using a grid that is still in operation. After the Second World War, there was an increased need for electricity. Combined heat and power (CHP) was highlighted as an effective alternative with high efficiency and as an alternative generating both electricity and heat (Sahlin, 2013). The first district heating in Sweden was developed in Karlstad in 1948 (Swedish District Heating Association, 2009). Just over Io years later, in the I960s and I970s, the expansion of district heating began to take off in Sweden.

During this first period of expansion the systems were developed and controlled by units within the local authorities, and later as municipally owned energy companies on a breakeven cost price basis (Magnusson, 2013). The primary fuel was oil (Swedish District Heating Association, 2009). Later in the I970s during the oil crisis, when oil began to be replaced by the combustion of waste and coal, excess heat also began to emerge as a source of energy. At the same time, district heating in Sweden had its real breakthrough (Swedish District Heating Association, 2009). The housing shortage of the time was acute, caused by high levels of migration to cities. During these years, the million public housing program, which is the term for a housing construction project in Sweden between 1965 and 1974 with the objective to quickly build a million homes and improve housing standards, was completed and could be directly adopted and connected to district heating (Werner, 2007). Sales of district heating doubled and at the time, Swedish district heating plants delivered $35 \mathrm{TWh}$ per year (Magnusson, 2013). In the I980s, a slight decline was observed as several nuclear reactors began operating and electricity prices were relatively low.

In 1996 there was a deregulation of the Swedish electricity market, and the production and sales of electricity was opened up for competition on profit market terms. During this time, municipal energy companies were sold to private companies (Magnusson, 20I3). Since a large share of these energy companies provided both electricity and heating through CHP plants, the deregulated electricity market also affected the district heating market (SOU, 2005). These energy companies were now to be run as profit-driven companies compared to earlier municipal administrative bodies. This entailed possibilities of selling district heating in profit market terms compared to earlier municipal monopoly terms (Pädam et al., 20I3). Currently - in the year of 20I7 - around 7o percent of the district heating in Sweden is derived from private energy companies (SCB, 20I7). 
In the I990s, environmental and climate policy grew stronger (Sahlin, 20I3). Between I998 and 2008, the Swedish government set aside 8.2 billion Swedish SEK in grants for environmental improvements. These grants were managed through two investment programs: LIP (Local Investment Program), aimed at increasing ecological sustainability in general, and Klimp (Climate Investment Program), which targeted support for local investments that would reduce global warming. A large portion of the district heating developed during this time period was developed as a result of LIP and Klimp (Swedish Environmental Protection Agency, 20I0). The grants funded approximately I0-20\% of the total investment cost for the projects and the rest was financed by municipalities and/or energy companies. (Swedish Environmental Protection Agency, 20I2). Today, ever since the climate issue began to gain a stronger foothold in the 1990s, the production sites have been changing fuels, from fossil to more bio-based fuels, in order to reduce carbon dioxide emissions (Sahlin, 2013; Swedish District Heating Association, 2009).

In 20I5, a new initiative - the Climate Step (Klimatklivet, in Swedish) - was introduced to support local climate investments (SFS 2015:517). Since its introduction, more than one billion SEK has been awarded and by 2020, a yearly amount of 700 million SEK will have been distributed. In July 20I7, the Climate Step was modified through a new regulation (SFS 2017:815) with the objective, among other things, to increase the support of facilitating measures for excess heat utilisation.

District heating in Sweden consists of several local markets, both private and municipally owned, with natural monopolies. Natural monopolies often occur within infrastructure systems with large initial investment and capital costs (Gyberg et al., 2004). In these cases, the cost of the product often decreases with an increased number of customers, which in turn often results in one single actor on the market, constituting a natural monopoly. In the case of district heating, the owner of the district heating grids, which are the municipal or private energy companies, owns the legal rights for the production as well as the exclusive access to the distribution systems (Swedish Energy Agency, 2007). The privatisation also led to controversial price increases, directly effecting district heating customers. For this reason, national investigations regarding third-party access (TPA) have been carried out in order to investigate the effects of competition in district heating systems (SOU, 2005; 20II). The first of the two investigations, conducted in 2005, concluded that the introduction of TPA could result in negative environmental impacts and would probably not lower prices. Instead, the "district heating law" was introduced and entered into force in July 2008. This law aimed to strengthen the position of the customers. In the same phase, a district heating board with the commission to negotiate between dissatisfied customers and energy companies was also introduced (SFS 2008:263). The board could also be approached by dissatisfied actors wanting to deliver excess heat into the systems to get help in negotiations with energy companies. The second TPA investigation carried out during 201 r resulted in the decision that TPA should be introduced in systems where it was considered possible. This second investigation was however heavily criticised by numerous referral units, which ultimately led to the decision being put on hold. Yet, different measures to facilitate excess heat utilisation and to secure reasonable district heating prising for customers has been suggested by the Ministry of Enterprise, Energy and Communications. The measures related to excess heat utilisation and concerned accounting for potential excess heat utilisation during planning of new district heating systems and regulated system access for potential excess heat providers (Ministry of Enterprise, Energy and Communications, 20I2).

\subsubsection{The current systems}

The main purpose of district heating has always been to efficiently transfer heat in urban areas (Frederiksen and Werner, 20I4). Instead of each property having its own heat source, 
the heat is produced and provided from a local collective plant. As mentioned previously, traditional systems consist of production plants, distribution systems and the internal pipeline systems of the users. The heat is produced in the production plants, which are either connected to district heating or a CHP plant, a combined combustion facility for conversion of fuels into both electricity and heat (Frederiksen and Werner, 20I4).

One characteristic of district heating is the massive grids that are buried under streets, roads, and lawns (Swedish District Heating Association, 2009). The distribution grids consist of pipes containing a heat carrier, usually consisting of pressurised water. The heated water is spread in the distribution grid and further to the subscriber's central systems in buildings connected to the grid - residential and non-residential premises and industries. The pipelines consist of two pipes: the flow pipe (hot water under high pressure on the way to the customer) and the return pipe (cooled water sent back to the heating plant, where the water is heated again in a closed loop) (Swedish District Heating Association, 2009). The temperature of the water in the flow pipe is between $70^{\circ} \mathrm{C}$ and $90^{\circ} \mathrm{C}$. Each building connected to district heating has a heat exchanger that transfers heat to the radiators and hot water taps. The temperature of the water in the return pipe is between $40^{\circ} \mathrm{C}$ and $50^{\circ} \mathrm{C}$. On the way back to the district heating plant, the cooled water can be used to heat pavements and football fields, making them become ice-free. Back in the district heating plant, the water is heated up again and sent back into the district heating grid. The same technology is also used for systems of district cooling to meet cooling requirements. In these systems, the carrier instead consists of cooled water (Frederiksen and Werner, 20I4).

District heating mostly occurs in urban areas, where the residential and service-sector building heat market is the largest (Forsaeus Nilsson et al., 2008). This geographical concentration arises because the typical users of district heating are found in commercial, public, and multi-family residential buildings located in urban areas that have a high heat density, a situation that results in low distribution costs for district heating (Reidhav and Werner, 2005). The heat density, mentioned in the introduction, is especially important in the planning of new development in district heating (Swedish District Heating Association, 2009). Since the I960s, when the expansion of district heating reached its peak, the heat density has fallen. This decrease is mainly because district heating has, as already mentioned, been extended to less densely populated areas (Frederiksen and Werner, 20I4).

The Swedish heat market's turnover during a normal year is almost IooTWh. District heating accounts for over $50 \%$ of the market, electric heating for just under $30 \%$, oil for $5 \%$, and other heating sources (natural gas, wood, geothermal, and solar) for just over $10 \%$ (Frederiksen and Werner, 20I4). In Sweden, all major cities have district heating systems. More than half of the district heating supply goes to multi-family residential buildings, and up to $90 \%$ of the multi-family building market has district heating. The district heating market share for single-family homes, however, is considerably lower. This low share is due to the fact that the heat demand is lower in single-family areas, resulting in high distribution losses (Reidhav and Werner, 2005). As mentioned in the introduction, in central European countries, oil and natural gas are the traditional energy sources predominantly used for heat generation in the system (Frederiksen and Werner, 2014). In the northern parts of Europe, with a high demand for heat, district heating has a dominant position as it covers about 50 percent of the total heating demand in Denmark and Finland. Norway and Iceland constitute exceptions, where the electricity heating from hydropower in Norway and geothermal heating in Iceland dominate. Yet, the production of district heating in Denmark and Finland differs from Sweden in many aspects. In Denmark and Finland, 80 and 75 percent of the district heating is produced in CHP plants, respectively. In Finland and Denmark, the combustion of fossil fuels is still very common for heat production in CHP 
plants. In Sweden, about 35 percent of the district heating is produced in CHP plants, where 90 percent of the fuel consists of renewables. Forest and household waste constitutes a great majority of the fuels used for district heating in Sweden (Frederiksen and Werner, 20I4). These fuels are used in combination with excess heat from local industries together with coal, oil and natural gas as backup fuels for heating the heat medium in the distribution grid.

\subsection{Excess heat-based systems of district heating}

By connecting heating requirements with different available sources of heat, the demand for heating can be met with a lower resource utilisation than conventional heating boilers and air-conditioning units provide (Frederiksen and Werner, 20I4). Recovery of excess heat by district heating systems is currently one of the most cost-effective ways of utilising excess heat as a source of heating (Fahlen et al., 2012). In addition, an increased recovery of excess heat from industrial processes and thermal power generation has the potential to reduce primary energy demands (Persson and Werner, 2012). Recovery of industrial excess heat could also lead to the development of new district heating systems. The development of district heating systems based on excess heat has increased during the past decades (Frederiksen and Werner, 2014). Yet, as mentioned in the introduction, in Sweden there is currently a great unutilised potential of further development of excess heat-based systems of district heating. The difference between traditional systems of district heating and district heating systems based on excess heat is the energy used to heat the water in the district heating grids. Simply explained, traditional systems require a combustion plant while systems based on excess heat require a heat exchanger connected to the provider of the excess heat that transfers the excess heat in the effluent to usable energy storage for district heating.

Since the decision regarding TPA was put on hold, the current model for ownership of the distribution systems implies that actors with an excess of heat do not have the ability to directly sell and distribute heat through the existing infrastructure. The sales and distribution of excess heat must therefore be made via energy companies who own the grid.

Further development in excess heat-based systems of district heating could potentially have positive impacts on the currently more saturated district heating market. This is because excess heat is less expensive than primary energy, leading to the possibility of achieving profitability for systems of district heating despite reduced heating demand (Doménech and Davies, 20II). As mentioned in the introduction, the new EU directive on zero-energy buildings for new and significantly remodelled houses (Directive 2010/3I/EU) is expected to affect Swedish building regulations. These new building regulations could affect the choice of heating and the competitiveness of district heating in a positive manner (Göransson, et al., 20I3), since the directive implies measuring the total amount of primary energy used to produce one unit of energy, taking the whole energy system into account. It appears more beneficial for district heating and excess heat-based district heating in particular, since it lowers the use of primary energy compared to, for example, heat pumps.

\subsection{Utilisation of low-grade excess heat}

The problems associated with the current unutilised potential of excess heat are in some cases related to that actors with excess heat have a greater excess than the owner of the district heating grid needs, or that the excess heat is low-grade (Elamzon and Nordberg, 2014). There are techniques using heat pumps to upgrade excess heat with lower temperatures, but this technique is not always preferable from a financial point of view (Cronholm et al., 2009). Another problem relates to insufficient energy volumes, meaning that the excess of heat is sometimes too small in relation to the demand. To overcome this problem, collaborations between businesses as well as joint heating collaborations could 
provide conditions for sufficient energy volumes and return on investment when using unutilised excess heat (Elamzon and Nordberg, 2014). As mentioned in the introduction, there are also technologies under current development aiming at utilising excess heat to generate electricity (Swedish Energy Agency, 20I6). This method is based on a "chemical engine" that, simply explained, converts hot water to electricity. It is basically about chemical absorption. The method creates a closed thermodynamic cycle that releases or binds carbon dioxide. This process creates a gas expansion, which drives a power turbine generating electricity.

However, the currently most explored area of utilisation of low-grade excess heat is food cultivation processes (Swedish University of Agricultural Sciences, 2012). Walls and Paquin (2015) point out that low-grade excess heat can be redirected to greenhouses, and that this also entails benefits such as reductions of $\mathrm{CO}_{2}$ emissions from the industry, since emissions of carbon dioxide can be captured and utilised in the greenhouse. In addition, there is potential in combining the greenhouse production with other applications. In networks based on the concept of biological cooling and aquaponics, heat is utilised in a cascading system in order to provide heat in a descending scale; applications with the highest-grade heat requirements are provided first, and after use, the slightly cooled water is provided to the next application with lower-grade heating demands, etc. (David et al., 2015).

Another area of use for low-grade excess heat is for algae production. The production of algae has been shown to give effective production and environmental outcomes within the scope of industrial symbiosis synergies (Andersson et al., 20I4). The return rate from the land used producing algae is five times higher than for other sources of biofuel (Andersson et al., 20I4), and the cultivation provides four times more energy than what is needed as input (Karlsson-Ottosson, 2015). In addition, heated excess water is beneficial since it contains nutrients that otherwise would have needed to be provided by additional artificial fertilisers to improve the growth (Andersson et al., 20I4). This results in a reduced need for conventional heated excess water (excess heat) treatments. By utilising the heated excess water in algae ponds, carbon dioxide and industrial flue gas is consumed and captured by the algae, reducing emissions in a closed-loop system.

\subsection{Municipal spatial planning in Sweden}

Large technical systems - such as systems of energy, transportation, water supply, sewage, waste management networks and district heating - are developed in a planning context where overall strategies of future urban development are connected. With spatial planning for land and water use, this results in very complex processes dealing with large amounts of technical knowledge that must be coordinated between different actors, views, and values of society at large (Nilsson, 2007). Briefly described, spatial planning involves determining how land and water areas should be used as it basically concerns the location, intensity, form, amount, and harmonisation of land development required for various space-consuming functions, such as infrastructure systems, residential houses, municipal buildings, etc. (CEC, 1997; Chapin, 1965; Cullingworth, 1972). The governmental planning system in Sweden consists of three different levels: the national level, the regional level (counties), and the local level (local authorities). The national level has the responsibility for coordination of areas of national interest. These areas can be, for example, important areas for nature conservation and national defence, as well as of national importance for infrastructure. The regional level covers cross-municipal issues such as infrastructure, climate and regional residential supply.

The following sub-chapters provide a historical background of the Swedish local planning system, i.e. municipal spatial planning, in relation to the development of district heating. Chapter 2.4.I provides a historical perspective in order to clarify how the municipal influence 
of spatial development has changed over time, and how it has affected the development of district heating. The following chapter, 2.4.2, includes a more in-depth description of the objectives behind the current spatial planning, followed by a presentation of how it is described to be implemented according to the PBA.

\subsubsection{Historical glance back at the Swedish planning system}

The history of strong independent Swedish municipalities started in 1908, with the introduction of the Town Planning Act. This act was introduced in order to enhance the implementation of municipal plans (Blücher, 2006). Before the introduction of this act, there was no effective legislation concerning regulations on the implementation of municipal plans. Later, in 1947, this act was strengthened by the Building Act, which entailed stronger municipal control over spatial planning.

In 1952, a boundary reform with the objective to reduce the number of Swedish municipalities from approximately 2000 to 816 was implemented (Nelson, 1992). Later, through a second boundary reform in 1973 , the number was further reduced to 282 . The total number has since been modified, and today, as of 2017 stands at 290 . The boundary reforms were implemented in an attempt to increase administrative efficiency and standardisation of locally provided services, which in turn strengthened the planning monopoly further (Nelson, 1992). The implementation of the million public housing program during the years I965-I974 strengthened the monopoly even further, as it gave municipalities the main responsibility for the spatial planning and for providing good quality, spacious homes at reasonable prices. In order to achieve this, municipalities were given loans to buy land as well as rights to condemn the land acquired. It is argued that the planning monopoly reached peak power during this time period (Blücher 2006; Lind, 2002). The introduction of the above-mentioned measures entailed straightened municipal power in terms of financial resources and legal rights to develop future strategies. The combination of legal power, previous knowledge of how to build grid-based infrastructure systems of gas and electricity (Kaijser, 1986; 1994), and financial resources made the expansive phase of municipally developed district heating possible. At the time, district heating was developed in coevolution with the built environment of roads, water and sewage systems (Brattberg, 1996).

In 1987, the Planning and Building Act (PBA) (SFS 1987:I0) was implemented. This act was based on similar principles as the ones in the previous Building Act from 1947. Yet, the new act resulted in decreased municipal rights, especially in relation to private property owners, as new settlements are increasingly affected by private initiatives. The new act also contained extended requirements for stakeholder participation in the planning process. Even though the municipal planning monopoly still existed, its weakening entailed decreased municipal power (Strömgren, 2007).

\subsubsection{The current planning system}

The current spatial planning process in Sweden is regulated by the PBA (SFS 2010:900), introduced on May 2nd, 2OI in an effort to increase the role of comprehensive plans and to re-establish its central role in the planning practice of local authorities (Proposition 20IO/II:63; Fredriksson, 20II). Also emphasised were climate and environmental issues as part of the spatial planning, which in turn placed a greater responsibility on local authorities regarding these matters (Proposition 20IO/II:63). Similar to the previous PBA, it contains provisions on the planning of land, water and construction. Further, in early 2015, a new law on guidelines for municipal land allocation was introduced. This entailed reduced municipal rights regarding requirements for construction (SFS 2014:900), which means decreased opportunities for local authorities to directly influence the conditions for district 
heating - that, as earlier mentioned, requires a relatively high heat demand to be profitable from an economic perspective.

The spatial planning is also regulated by several other related laws with different implications for spatial change, for example the Environmental Code (SFS I998:808). At the local level, the planning system consists of regional planning, comprehensive planning, area regulations and detailed development planning (SFS 2010:900). The area regulations and the detailed development planning are legally binding, while the regional planning and the comprehensive planning can be seen as overall directives. Within the framework of spatial planning, the local authorities should also consider the municipal energy plan. According to the Law of Municipal Energy Planning (SFS I977:439), each municipality must have a current plan for the supply, distribution and use of energy. Within the framework of municipal energy planning, holistic energy planning and consideration for the environmental effects of the energy used should be taken into account from a local, regional and global perspective.

The main goal of spatial planning is vaguely described as the promotion of "progress towards equal and good living conditions, and a good and sustainable environment for the benefit of the people of today's society as well as that of future generations" (SFS 2010:900). According to the current PBA, various societal interests should be weighed against each other in an open and democratic process, while the rights of individuals should also be considered. All policies related to sustainability should also, according to the Swedish legislation (Elbakidze et al., 2015), be taken into consideration in the spatial planning, including the comprehensive plans at the local municipal level. Yet, all municipalities have different conditions in terms of political management, geography, population, established businesses, established large technical systems and other factors effecting the conditions of the planning. This, in turn, leads to different conditions regarding the management of natural resources concerning development in value-added production and networking (Elbakidze et al., 2015). Therefore, flexible spatial planning processes are required (Terryn et al., 20I6). As a further consequence of these differences, the collaborative learning process and knowledge sharing between the local authority and relevant external stakeholders within different spatial planning processes is encouraged to varying degrees within municipalities. Examples of relevant external stakeholders within the planning process are the County Administrative Board, the cadastral authority, energy companies and other interested parties, which are individuals and businesses that own land or other real estate in and around the area affected by the plan (SFS 20I0:900). Different local traditions and practices largely define which spatial planning policies are pursued and how they are carried out within municipalities and their different local governance (Evers and Tennekes, 20I6).

The PBA describes the spatial planning as a linear process including different steps and guidelines concerning related laws and stakeholder participation described above. The following paragraphs present the planning process based on how it is described in the PBA. Provided is a description of the comprehensive planning, followed by a description of development in detailed development planning.

\section{Comprehensive planning}

All spatial planning processes for land and water use should start with the development of a comprehensive plan (Figure I). According to the PBA, all local authorities must have an upto-date comprehensive plan covering the entire geographical area of the municipality (SFS 20I0:900). The main purpose of the comprehensive plan is to serve as guidance for decisions regarding land and water area use, as well as the built environment, for a period of 20-30 years (ibid.). In the process of developing the comprehensive plan several planning steps, all 
specified in the PBA, are included. Each local authority has the freedom to adapt the development process, its scope and its level of detail.

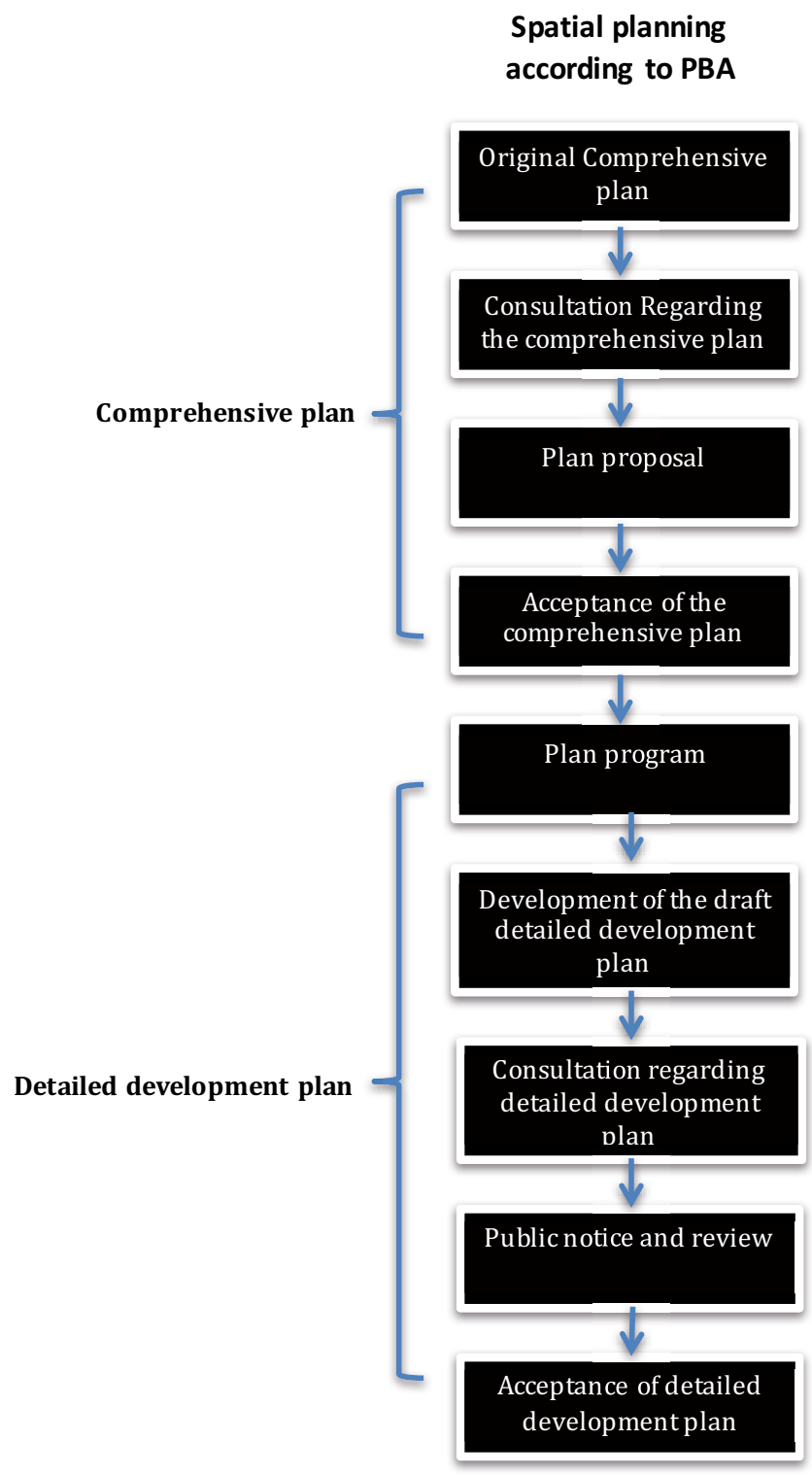

Figure I. The major steps in the planning processes described by the PBA (SFS 20I0:900).

At least once every fourth year, the local government should evaluate whether the comprehensive plan is up-to-date or if it needs to be modified (SFS 2010:900). Considering changes to the comprehensive plan, the local authority must consult with relevant external stakeholders. The consultation concerning the comprehensive plan should be an open 
dialogue where relevant external stakeholders should be invited to provide feedback that might affect the design of the plan. Before consultation, the local authority constructs a first draft of the modified comprehensive plan (ibid.). The local authority reports the results of the consultation, which eventually become the basis for the proposed comprehensive plan. Finally, the municipal council approves the comprehensive plan.

\section{Detailed development planning}

Before the development of a detailed development plan starts, the local authority decides whether a plan program is needed (SFS 20I0:900) (Figure I). The objective of a plan program is to broaden the detailed development plan to include relevant external stakeholders' experiences and opinions. Within the plan program, the local authority decides on a starting point and objective - considering location and design - for the detailed development plan. If a plan program is considered necessary, stakeholders are invited for consultations; if not, the development of a draft detailed development plan begins immediately.

As mentioned above, the detailed development plan is legally binding and regulates the use of land and water areas and the urban design of areas covering specific geographic areas in municipalities. Most commonly, the detailed development plan follows the guiding principles agreed on in the comprehensive plan; nevertheless, since comprehensive plans are not legally binding, the detailed development plans can theoretically sometimes conflict with the comprehensive plan (Lundström, 20I0; National Board of Housing, Building and Planning, 20I6). Despite the limited ability to directly control the energy use of buildings through the detailed development plan due to the regulations of reduced municipal rights regarding construction requirements (SFS 2014:900), the local authority can influence the energy performance of buildings in several ways. The local authority may, for example, set requirements resulting in high heat density by requiring densification of a planned area (Lundström, 20I0), which is a prerequisite for district heating (National Board of Housing, Building and Planning, 2016). The local authority may also control where certain types of industry facilities are located by regulating placement of such facilities.

The process of the consultation regarding the detailed development plan is very similar to the consultation process regarding the comprehensive plan, as it also is conducted in order to provide opportunities for relevant external stakeholders to provide feedback and to affect the design of the plan (SFS 2010:900). Similar to the consultation regarding the comprehensive plan, external relevant stakeholders are invited to participate in what is described as an open dialogue to discuss the proposed detailed development plan. The objective of the consultation process is to provide insight and an opportunity for all participants to provide knowledge that eventually leads to a good knowledge base for the final detailed development plan. The comments from the consultation participants, consisting of all relevant external stakeholders, should be compiled in a consultation report that the consultation participants - public, private, and individual - are given the opportunity to make additional comments on (SFS 20I0:900). The comments are compiled in another consultation report that eventually becomes the basis for the proposed detailed development plan (SFS 2010:900). The final decision regarding the approval of the detailed development plan is taken by the municipal council. 


\section{THEORETICAL BACKGROUND}

In this chapter, the different theories used to discuss the objective and the research questions of this thesis are presented. 
Based on the overview presented in chapter 2, three different focal areas, all related to excess heat utilisation, have been identified: interorganisational collaborations, business models for collaboration and municipal spatial planning.

For the first focal area, Interorganisational collaborations, it is of interest to understand the essential mechanisms behind the formation and development of networks in which different, normally unrelated actors collaborate. Previous research on the development of interorganisational collaborations on resource and by-product flows often highlights organisational aspects, related to communication, personal ties and business agreements on equal terms, as important in the development of such collaborations (see, e.g., Mauthoor, 2017; Yedla and Park, 2017; Walls and Paquin, 2015; Arnell et al., 2012; Park et al. 2008; Gibbs, 2003; Uzzi, I997; I996).

In this thesis, approaches from the multidisciplinary research field industrial symbiosis are used to explain the underlying organisational phenomena behind the development of excess heat collaborations. This is because industrial symbiosis concerns collaborations on resources between normally unrelated actors, similar to the studied collaborations on excess heat. Yet, one highlighted weakness with the industrial symbiosis concept is that it mainly considers factors related to the inputs and outputs of collaboration, and not the business agreements behind the collaborations where the actors are involved (Walls and Paquin, 2015; Tsvetkova and Gustafsson, 2012; Coelho and Ruth, 2006; Woodard, 200I). As mentioned in the introduction, interorganisational collaborations between normally unrelated actors require business models taking the collaborative aspects into consideration. Thus, there is a gap of knowledge on how to develop sustainable business models for interorganisational collaborations in line with industrial symbiosis networks (Tsvetkova and Gustafsson, 2012). Another factor highlighted as a knowledge gap is the weak emphasis in research on organisational aspects concerning industrial symbiosis networks (Walls and Paquin, 20I5). Therefore, in this thesis the industrial symbiosis perspective is complemented with a business model perspective in order to enable an analysis of the organisational changes required for a business model implementation for interorganisational excess heat collaboration.

For the second focal area, business models for collaboration, parts of the canvas model (Osterwalder and Pigneur, 20I0) that are compatible with industrial symbiosis and the objective concerning drivers and barriers behind the development of excess heat collaborations are used. The canvas model is widely used to analyse businesses and to clarify actors' needs (Osterwalder and Pigneur, 20I0). Such clarifications can be used to improve communication and business relationships between actors. The canvas model can thus be used to help explain the important factors behind a sustainable business agreement on excess heat supply. In addition, parts of the Integrated Product and Service Offering (IPSO) concept are applied in order to complement the industrial symbiosis perspective further, and to investigate how specific measures related to IPSOs could facilitate excess heat utilisation.

For the third and last focal area, municipal spatial planning, research on strategic spatial planning is mainly used to examine how district heating issues are addressed in the municipal spatial planning of new areas, and how Swedish planning legislation could facilitate the expansion of new excess heat-based systems for district heating. This last focal area is complemented with industrial symbiosis and IPSOs in order to enable a deeper analysis of the organisational aspects of strategic spatial planning. 
In the following sub-chapters, the different theories used to discuss the aim and the research questions corresponding to each focal area are further presented. First, the perspective of industrial symbiosis is introduced. Subsequently, the main features of the canvas model are illuminated, followed by a presentation of the IPSO in particular. Finally, earlier research within the research field of strategic spatial planning is summarised and presented.

\subsection{Industrial symbiosis}

Industrial symbiosis has been developed as a subset of industrial ecology, which is a research field based on the ideology of nature (Chertow, 2007). Industrial ecology uses nature as a reference to study resource productivity and environmental burdens of industrial and consumer products and their production and consumption systems. The industrial symbiosis concept implies an idea of expanding the system boundary from a single business or value chain to a system involving a network of actors in proximity. Chertow (2000) defines it as different stakeholders sharing and exchanging resources, including energy, to create collective environmental and financial benefits. According to Deutz (2014), industrial symbiosis is "a flow of underutilised resource(s) (comprising substances and/or objects and/or energy), from an entity which would otherwise discard them, to another entity which uses them as a substitute for new resources". Industrial symbiosis focuses on cyclical flows of resources through networks of businesses within wider system boundaries. It can make resource use more efficient by forming close working agreements between normally unrelated industrial companies or other organisations (Jensen et al., 20II). The business agreements can, for example, involve reuse of one company's by-products as raw material for another company. It can also involve the sharing of manufacturing capacity, water, steam supplies and excess heat as well as logistics and expertise (Chertow, 2007; Jensen et al., 20II).

There are many forms of industrial symbiosis collaborations, a common classification is the division of planned and unplanned (Baas, 20II; Ashton and Bain, 20I2; Hein et al., 20I5). Unplanned industrial symbiosis is the basis for self-organisation, whereas planned industrial symbiosis refers to conscious efforts of identifying and locating companies from different industries in order to share resources across and among them (Chertow, 2007). Collaborations evolving spontaneously have shown to be more functional and durable than collaborations that are specifically engineered as industrial symbiosis collaborations (Chertow, 2007). Successful cases of industrial symbiosis have served as inspiration for planned attempts to create eco-industrial parks. However, many attempts to implement the lessons learned in the form of eco-industrial parks have to a large extent failed (Chertow, 2007; Gibbs and Deutz, 2007). These failures have been explained in a variety of ways, yet the problem, which is widely held to be one of the primary barriers to development, apparently involves difficulties generating organisational conditions related to communication, personal ties and business agreements on equal terms, which are important conditions for companies that want to share production processes (Gibbs, 2003). These kinds of planned synergies require a more fruitful ecoindustrial strategy to build upon existing waste and energy interchanges on a wider spatial scale (Chertow, 2007; Gibbs and Deutz, 2007). Social factors such as personal relationships, close contact and common interests are argued to bind industrial symbiosis networks together (Baas and Boons, 2004). These factors also enable access to important information across the business boundaries (Baas and Boons, 2004). 
The strongest drivers behind industrial symbiosis synergies are the need to improve profitability and the need to improve competitiveness (Ehrenfeld and Gertler, 1997). Regardless of the driving forces behind the development of such synergies, interorganisational collaborations in line with industrial symbiosis have been shown to result in significant financial and environmental benefits both for the companies involved and society at large (Hein et al., 2015; Hellweg and Canals, 20I4; Doménech and Davies, 2009; Park and Behera 2015; Nicolas et al. 2015; Deutz and Gibbs, 2008; Chertow, 2000; Senlier and Albayrak, 20II). The benefits are connected to sustainable use of natural resources, collaborations on local resource potentials leading to increased productivity and increased urban quality, and so forth (Şenlier and Albayrak, 20II). Yet, one critical factor related to potential benefits is how they are communicated. Further, Mirata and Emtairah (2005) stress the need to communicate potential benefits to private stakeholders, namely company managers, and public stakeholders, that is politicians and political officials, within the sustainability management field.

Industrial symbiosis networks are complex because they rely on collaboration, which often deals with difficulties connected to social factors (Walls and Paquin 2015). The greatest barrier behind the development of industrial symbiosis is often described as risks related to financial aspects (Walls and Paquin, 2015). Longer repayment periods compared to other options is one example keeping companies from engaging in industrial symbiosis networks (Chertow, 2000). Another factor, which is described as bringing resistance towards entering interorganisational collaborations, is that industrial symbiosis collaborations normally consist of activities outside the core aspects of the businesses involved. In addition, despite the well-known societal benefits of industrial symbiosis, private actors sometimes have difficulties in understanding the company-specific benefits (Chertow, 200o). Further, private actors play a central role in these networks since they often constitute actors providing and/or using material flows. In some cases, there are challenges related to commitment of the private actor, where "business as usual" constitutes a barrier (Chertow, 2000). The multi-party planning of industrial symbiosis also constitutes a barrier, as it consumes a lot of both time and effort. Concern of being dependent on someone else is also a highlighted problem (Walls and Paquin, 2015). Another factor highlighted as a barrier can be that the goal of the activities connected to industrial symbiosis contradicts certain political goals (Fichtner et al., 2005). Yet, Horváth and Harazin, (2016) argue that the social benefits of industrial symbiosis could be further developed through local authorities. In the development of industrial symbiosis networks between businesses and local authorities, local authorities can either be passive or proactive by encouraging new businesses through investments in necessary infrastructure, or by participation in activities concerning local business development and so on (Horváth and Harazin, 20I6). Chertow (2007) concludes that typical barriers often are business related. For companies to engage in industrial symbiosis activities - which often develop around non-core businesses - there is a need for corporate strategies (Deutz and Gibbs, 2008).

Collaborations based on exchanges of energy and resources among companies and other organisations require embedded relations based on trust and personal ties, rather than explicit contacts (Uzzi, 1997). Uzzi (1996) defines embeddedness as "the process by which social relations shape economic action in ways that some mainstream economic schemes overlook or missspecify when they assume that social ties affect economic behaviour only minimally or, in some stringent accounts, reduce the efficiency of the price system". Three organisational conditions are highlighted as being especially important: (I) trust, 
(2) fine-grained information transfer, and (3) joint problem solving (Uzzi, 1997). Similar organisational conditions are also highlighted as important by others (see, e.g., Mauthoor, 2017; Yedla and Park, 2017; Walls and Paquin, 2015; Park et al. 2008). These conditions allow companies to adapt more quickly and to react with greater flexibility to environments characterised by continuous change and complexity. All of these features have also proven to be important preconditions for the decision-making process for joint collaboration projects, wherein knowledge gained via the involvement of the stakeholders within the collaboration is required to both understand and realise the common goals and objectives in practice (Albrechts, 2006). These conditions allow companies to adapt more quickly to environments characterised by continuous change and complexity. Companies and other organisations involved in embedded networks tend to have a greater chance of gaining advantages compared to other forms of governance explicitly focused on internal processes (Uzzi, I996). In order to facilitate industrial symbiosis activities, a business model visualising outcomes of possible scenarios could help in the building of confidence among the actors involved (Şenlier and Albayrak, 20II).

\subsection{Business model concept}

The primary barrier behind industrial symbiosis networks involves difficulties generating intercompany business interaction (see, e.g., Arnell et al., 2012; Gibbs, 2003; Chertow, 2007; Gibbs and Deutz, 2007; Bryson et al., 2015). Business models involving concepts taking interaction between normally unrelated companies into account, in line with industrial symbiosis activities, has proved to facilitate interorganisational collaborations on none-core activities (see, e.g., Tsvetkova and Gustafsson, 20I2; Zott and Amit, 2008; Bertels et al, 2015; Boons and Lüdeke-Freund, 2013).

The business model concept is an emerging concept that has, since the late I99os, been used extensively in academia and industry to describe how organisations can create and capture different values (Boons and Lüdeke-Freund, 2013). The common, central idea of all business models is to include and connect relevant factors for a business idea to be realised. A business model should be simple, relevant and intuitively understandable without over-simplifying how the enterprises function. It should help clarify the value creation and increase the understanding of the often complex realities of companies (Osterwalder and Pigneur, 20I0). Its main purpose is to assist companies and/or other organisations to align their activities and to illustrate potential trade-offs by mapping value propositions, infrastructure, customers and finances (Osterwalder and Pigneur, 20I0). A typical business model normally uses four concepts: value proposition, supply chain, customer interface, and a financial model (Boons and Lüdeke- Freund, 20I3). Researchers within the field have presented various propositions of how business models can be designed (see Zott et al., 20II; Osterwalder and Pigneur, 20I0; Richardson, 2008).

One of the most frequently used models to build or analyse business models is the canvas model by Osterwalder and Pigneur, (2010). The canvas model, developed in 2004, consists of the nine building blocks shown in Table I (Osterwalder, 2004). The canvas model can be used by companies to fill in their company-specific information related to the nine building blocks, namely customer segments, value proposition, channels, customer relationships, revenue streams, key resources, key activities, key partners and cost structure. This way of applying the model helps to visualise and explain the value of each and every building block, and shows how they relate to and complement each other 
for a higher value.

Table I. Description of the nine basic building blocks described by Osterwalder and Pigneur (2oIo).

\begin{tabular}{ll}
\hline The nine building blocks & Descriptions \\
\hline Customer segments & $\begin{array}{l}\text { The heart of any business model, since no company would survive without } \\
\text { profit. } \\
\text { Value propositions }\end{array}$ \\
$\begin{array}{l}\text { Products and services that create value for a specific customer segment by } \\
\text { solving a customer problem or satisfying a customer need. }\end{array}$ \\
Channels & $\begin{array}{l}\text { Communication, distribution, and sales channels describe how the } \\
\text { company reaches its customer segments. These channels play an important } \\
\text { role in the customer experience. }\end{array}$ \\
Customer relationships & $\begin{array}{l}\text { Can be both automated and of a more personal nature. Different customer } \\
\text { relationships are often driven by different motivations, such as upselling } \\
\text { and customer acquisition and retention. }\end{array}$
\end{tabular}

Revenue streams

Covers the revenue a company generates from each customer.

Key resources

A precondition for the value proposition, the market, the relationship with customers and the revenues.

Key activities

Defines the important activities behind a successfully operated company.

Key partnerships

Partners and suppliers that make the business model function well. For example, companies enter collaborations as a way to acquire resources, reduce risk, or optimise their business models.

Describes all the costs involved within the operation of a business model.

These nine building blocks can all be categorised into four concepts, similar to the ones described by Boons and Lüdeke-Freund (2013). The four concepts are product, customer interface, infrastructure management and financial aspects. The first category, product, focuses on the market and the value proposition offered to it. The second, customer interface, comprises distribution channels for delivery and how to establish long-term sustainable relationships with the target customer. The third category, infrastructure management, defines the logistics and infrastructure related to the business and how they are dealt with. It also describes arrangements of activities, capability to execute the activities needed, resources through value configuration, and partnerships for value creation. Finally, the financial category comprises the cost structures and revenue models for the financial sustainability of the business model.

There is an emerging consensus that business models should provide a holistic description of how to create value through interaction with the surrounding environment (Zott et al., 20II). In order to do so, however, the business model must go beyond the individual business boundaries of the firm (Zott and Amit, 2008). This interaction is claimed to have the opportunity to create higher growth, yet also a higher rate of risk (Bertels et al, 20I5). The risk of failure, however, does not correspond to how far from the core business the new activity is. According to Bertels et al. (2015), it often depends on false assumptions about factors such as the distribution channels and cost structure. Companies interested in entering interorganisational collaborations on a none-core business should critically and closely evaluate the seemingly easy factors and 
all assumptions of non-core business models. Bertels et al. (2015) note that the additional elements added to business models, including none-core activities, increases the complexity for analysis. Informal relationships and governance structures are claimed to be critical in the success of a business model (Zott et al., 20II). The broadened perspective, that is that a business model should include collaboration as a key aspect, is shown in a few examples below.

A study by Short et al. (20I4) applies a business model suggested by Richardson (2008) that combines the research fields of industrial symbiosis and business models. It shows that a combination of both concepts contributes to a wider system perspective, taking the important aspects from both concepts into consideration (Short et al, 20I4). Other examples of business models inspired by the canvas model, developed in order to analyse networks of collaborating actors, are models developed by Tsvetkova and Gustafsson (2012) as well as by Boons and Lüdeke-Freund (2013). The model developed by Tsvetkova and Gustafsson (2012) is based on the concepts of value proposition, customer, capabilities and revenue. The studied case followed the principles of industrial symbiosis and was for that reason more complex than the traditional supply chain, as it could be described as a value network consisting of multiple value chains. Because of the complexity, a more boundary-spanning business model was required. The model presented by Boons and Lüdeke-Freund (2013) includes the four concepts of value proposition, supply chain management for upstream relationships in the network, customer interface managing downstream relationships, and lastly a financial model managing costs and benefits. The focus of this business model is on the company and its collaboration partners, as it takes the distribution of costs and benefits between different actors involved in interorganisational collaborations into consideration.

Similar to the examples described above, this thesis uses the canvas model in a general way, and in combination with industrial symbiosis, to get a generic understanding of how a business model perspective could contribute to a deeper understanding of the drivers and barriers behind the studied collaborations on excess heat supply. The nine building blocks which constitute the canvas model are used to complement the industrial symbiosis perspective - which mainly consider factors related to the inputs and outputs of collaboration (Coelho and Ruth, 2006) - by focusing on the basic steps behind the collaborating companies' and organisations' business strategies and agreements.

\subsection{Integrated Product and Service Offerings (IPSOs)}

Collaborations on low-grade excess heat, where heat-related issues are outside the core business of the actors involved, might be hindered because of a lack of knowledge on heat-related issues. This lack of knowledge does, however, entail business opportunities for a third-party with an understanding of heat-related issues. Such an actor could possibly facilitate these kinds of excess heat collaborations by providing services constituting knowledge related to the technical aspects of heat distribution, as well as knowledge about how to develop suitable business models. Examples of similar service approaches in adjacent areas are found within the IPSO literature. Therefore, this thesis uses parts of the IPSO concept to elaborate on possible implications for excess heat collaborations, mainly without the involvement of energy companies. It is also used to discuss local authorities as promoters of excess heat collaborations. Below follows a general description of the concept, and how certain parts of the concept are used in this thesis. 
The IPSO entails a shifted (servicification) focus from products to services (Baines et al., 2017; Tukker, 2004), meaning the customer is shifting from owning physical products to getting access to the functionality of products (Oliva and Kallenberg, 2003). The concept of the IPSO is further used to design products in order to, for example, minimise downtime on the products by making them easy to maintain (Kindström and Kowalkowski, 2009). This requires that the IPSO provider strive to achieve the most costefficient way, from a life cycle perspective, to design and deliver the offering (Tukker, 2004). Prolonged durable design of the product (Lelah et al.,20II; Lindahl et al., 20I4; Mont, 2008) could also bring about positive effects of production efficiency and the processes related to it, which in turn also results in an enhanced product from a life cycle perspective. Since the provider of the service often has better knowledge of ingoing products and their functions, and thereby the ability to control the use of the product in an improved way as compared to customers owning the product, the IPSO approach can also bring decreased environmental impacts related to the use of energy and other resources from the usage phase (Lelah et al., 20II; Lindahl et al, 20I4; Mont, 2008). This is especially important as the environmental impact from the usage phase of many products is often the greatest, since the usage phase often corresponds to the greater part of the life cycle were the energy use also is the greatest. The life cycle perspective often has a great focus as the IPSO strives to use a minimum of resources for a maximum utilisation of the elements in the offering (Meier et al., 20I0). In this way, the IPSO provider has the possibility to increase the value of the IPSO for its customers by integrating different products in new ways (Brady et al., 2005).

The servicification of different customer activities from the demand side is another example illustrating change in the traditional customer of a product (Arai and Shimomura, 2005). The focus of dematerialisation that the IPSO brings is an important aspect of competitiveness (Meier et al., 20IO), which can be seen as a driver for the development of technologies (Lindahl et al., 2006) such as how to facilitate low-grade excess heat. The overall objective of the concept corresponds to the cornerstones of both industrial ecology and the circular economy (Finger et al., 2005).

In the context of this thesis, increased utilisation of excess heat for heating purposes could be seen as way to decrease the environmental impact from heating. Excess heat supply solutions can, from an IPSO perspective, also be seen as services rather than products. As mentioned, this thesis uses selected parts of the IPSO concept related to the shifted focus and the third-party IPSO provider. For the first focal area, interorganisational collaborations, the IPSO is used to analyse how a shifted focus from product heat to service heating could facilitate interorganisational collaborations on excess heat without the involvement of energy companies. Further, possible implications of involving a third-party IPSO provider are discussed. The third focal area, municipal spatial planning, also uses parts of the perspective related to implications of an IPSO provider to analyse the implications of local authorities as third-party promoters of excess heat collaborations within the stakeholder participation processes of spatial planning.

\subsection{Strategic spatial planning}

The strategic spatial planning literature does not provide a single universal definition of what the concept of strategy and strategic spatial planning comprises (see, e.g., Albrechts, 2004; Mäntysalo 2013; Van den Broeck 2013). Instead, a fairly broad cumulative view of the concept is presented. Yet, Albrechts, (2004) presents the main characteristics of the 
concept described in the strategic spatial planning literature; strategic spatial planning shall have a critical view of the environment to enable and determine opportunities and threats; it is supposed to study external trends, forces and resources available; it shall identify and gather major relevant societal stakeholders (public and private); it shall allow for a broad and diverse involvement during the planning process; it shall develop realistic and long-term visions and strategies; and finally, it shall be focused on decisions, actions, results and implementation and incorporate monitoring feedback and revision. This broad view of strategic spatial planning implies that it is a set of different concepts, procedures and tools. According to Ziafati Bafarasat (20I5), strategic spatial planning "mediates between the respective claims on space of the state, market, and community around three considerations: stakeholder involvement, policy integration, and implementation". Albrechts (2006) chooses to define it as an approach that is focused on framing decisions, actions, projects, results, and implementation.

For this thesis, a definition based on existing strategic spatial planning literature is applied, where strategic spatial planning involves relevant societal stakeholders, both public and private, in order to gather knowledge from different views of society as a basis for decision-making and the development of long-term visions and strategies. Included are also monitoring feedback and revision in order to allow for a learning process based on the outcomes of planning.

Strategic spatial planning is important from an overall societal point of view, and can be seen as a tool to facilitate the integration of financial, environmental, cultural and social policy agendas. Led by the public sector, strategic spatial planning also has the ability to rescale these issues from international and national levels to regional and local levels (Albrechts, 2004; Albrechts et al., 20I0). In Sweden, the process of comprehensive planning constituting the overall municipal planning is the most important instrument from a strategic point of view (Magnusson, 20I3). The comprehensive plans, however, are vaguely specified in order to provide local authorities possibilities to change directions from the intentions of the comprehensive planning. The objective behind vaguely written and non-legally binding comprehensive plans is to allow for alternative planning approaches (Nyström, 2003).

Strategic planning is dependent on politically legitimate decision-making and the realisation of stated goals (Albrechts, 2006). It depends on effectively communicating goals and objectives, and the effective disclosure of goals and objectives requires the understanding that there are many ways to achieve them (Emmelin and Kleven, 1999). As for strategic spatial planning, the effectiveness of the planning process is determined by whether and how the planning involves the relevant tasks, for example, conducting comprehensive planning and detailed development planning that involve consultation with relevant external stakeholders. The efficiency of the spatial planning is, on the other hand, determined by whether and how the tasks are conducted in a suitable way, with respect to, for example, time and financial aspects. As previously mentioned, since comprehensive plans are not legally binding they might also conflict with detailed development planning; one common reason for this is the other public or private actors' will to implement projects in conflict with the guidelines of the comprehensive plan (Emmelin, 20IO).

Strategic spatial planning is supposed to aim at achieving greater understanding of the current and future problems in order to make well-founded decisions (Faludi, 2000). 
Situated knowledge from different views of society is important in order to reach an understanding and to realise the goals and objectives of the planning. This knowledge can be gained through participation of different stakeholders with expertise in their specific fields (Ivner et al., 20I0; Ziafati Bafarasat (2015). Strategic spatial planning processes rely heavily on a structure built on intensive interaction with a wide range of disciplines and stakeholders reflecting the diversity of the local society (Bryson et al., 2015; Salet, 20I4; Innes and Booher, 2004). Stakeholders' expertise also creates an awareness of both drivers and barriers to the measures specified in the plans. Albrechts (2004; 2013) describes the key concepts behind strategic spatial planning as being an open dialogue, collaboration and consensus building. As mentioned in Chapter 2.4.2, the new PBA, implemented in 20II, emphasises the strategic aspects of spatial planning. Stated is that "Priority must be given to usage that promotes good management in view of the public interest" (SFS 20I0:900). In order to consider public interests, the importance of consultation processes involving relevant societal actors is also stated: "The purpose of the consultation is to deliver as good a basis for decision as possible, and to provide opportunities for transparency and influence" (SFS 2010:900). Two important conditions for spatial planning processes to be strategic are communication and understanding between the actors involved (Bryson et al., 20I5). These conditions are important prerequisites for a broad and anchored strategy, both among the politicians, external relevant actors, and the wider community (Bryson et al., 20I5; Börjeson et al., 2006).

Because of expertise from several societal stakeholders involved in spatial planning, where politics and the economy are linked, a multidimensional approach is required (Bryson et al., 2015; Albrechts, 2006; Poister and Streib, 1999; Mäntysalo, 2000). The planning process shall be characterised by collaborative learning amongst different actors and stakeholders (Faludi, 2000; Granados Cabezas, 1995; Albrechts, 2004). Healey (2009) argues that spatial planning that reaches implementation is rarely a product of single individuals, and that it develops as a result of stakeholder participation and governance, which is a prerequisite for a plan to be embedded in the governance culture. Another dimension of stakeholder participation is that it also entails possibilities to create new partnerships among the participating actors (Von Malmborg, 2004; Vedung 2006).

Even though there is literature presenting methods to be used by municipalities in order to enhance stakeholder participation, there are critics who state that the methods are poor in providing practical advice on how to actually involve stakeholders (Jank, 2000; Ling et al., 2002; Khan, 2004; Ivner, 2009, Ivner et al., 2010). Besides, increased participation involving multiple stakeholders representing different areas of society tends to create challenges and increase complexity. Clashes over conflicts of interests, power games, or fragmentation by civil servants or politicians are other features observed involving stakeholder participation (Khakee, 2000; Pacione, 20I4). Developing spatial plans that eventually are implemented is a very difficult assignment, since it requires both analytical abilities and design skills along with sensibility (Healey, 2009). Healey (2009) further notes that strategic spatial planning involving knowledge from societal stakeholders needs to grasp relations between actors, people and places through time.

\subsection{Theoretical synthesis}

The scope of this thesis - involving studies of interorganisational collaborations between normally unrelated actors, business models for collaboration and municipal spatial 
planning - requires a broad theoretical framework to address the overall aim and research questions related to practical suggestions for increased excess heat utilisation. The theoretical perspectives presented above are used in a synthesised way to enable a both deeper and broader analysis: they are deeper as the theories complement each other in ways that enable different perspectives of the different focal areas studied, and broader as they partly overlap each other in ways that enable a deeper understanding of the important linkages between the focal areas.

The first focal area, interorganisational collaborations, mainly relies on industrial symbiosis, but a business perspective is added in order to deepen and broaden the analysis by illustrating the implications of tentative value creation.

The business model perspective is further used as the main theoretical perspective in the studies of the second focal area, business models for collaboration. This is complemented with the industrial symbiosis perspective to enable a deepened and broadened analysis of organisationally important conditions for business models for collaboration between normally unrelated actors. In addition, parts of the IPSO perspective are also used to enable an analysis of how a shifted business focus could potentially facilitate further excess heat collaborations.

The third focal area, municipal spatial planning, mainly uses the strategic planning literature to discuss how the municipal spatial planning process could be conducted with a stronger strategic emphasis on stakeholder participation. For this focal area, industrial symbiosis - to discuss organisationally important conditions of stakeholder participation - and IPSOs - to discuss local authorities as third-party promoters of interorganisational collaborations on excess heat utilisation - are added to deepen and broaden the analysis. 


\section{METHODOLOGY}

This chapter presents the methodological overview. It starts with a description of the research process and the overall research design, followed by a presentation of the contribution of each paper. Next, an overview of the methods for data collection and the research's analytical approaches is put forward. This is followed by a section presenting the appended papers. The chapter concludes with a discussion of the research quality. 


\subsection{Research process}

In this section, the research process is explained through the different appended papers of this thesis. The research conducted applies a multidisciplinary, mainly social science perspective on excess heat utilisation for increased environmental performance.

My research journey started with an investigation of the development of systems of district heating. Because of a strong environmental focus, the research soon developed into concentrating on district heating systems based on excess heat, as these systems are generally considered resource efficient with a lower environmental impact compared to traditional systems of district heating based on primary energy. Since these systems require interorganisational collaboration between normally unrelated actors providing excess heat and actors demanding excess heat, the first paper was written in an attempt to gather knowledge about important conditions behind the development of such collaboration. The focus was on drivers and barriers behind the development of these systems. Because of the comparably little emphasis on organisational aspects for this matter in previous literature, the focus of the first paper was on important organisational conditions behind interorganisational collaborations on excess heat between industries providing excess heat and energy companies demanding excess heat. This paper applied a theoretical framework consisting of industrial symbiosis, as described in Chapter 3.I. In addition, the canvas model was used to complement the industrial symbiosis concept, which mainly considers factors related to the physical inputs and outputs of collaboration - by-products, services and knowledge - and not the business agreements between the collaborating actors (see Chapter 3.2). The canvas model was used in a general way to get a generic understanding of how a business model perspective could contribute to a deeper understanding of the drivers and barriers behind the studied collaborations on excess heat supply. This first paper (Paper I) showed a fairly consistent picture of the importance of organisational factors behind these collaborations. Jointly developed business agreements on equal terms were highlighted as one important factor behind the development of long-term, durable collaborations.

Based on the key findings about the importance of organisational conditions from the first paper, the second and third papers (Papers 2 and 3) aimed at further examining the development of interorganisational business models suitable for excess heat collaborations. Besides studies of high-grade excess heat utilisation between industrial firms and energy companies, these papers also included studies of utilisation of lowgrade excess heat. Low-grade excess heat is often derived from less accessible sources in more sparsely populated areas, often without the infrastructure of district heating. The reason for involving studies of low-grade excess heat was to enable an analysis of whether and how collaborations involving high-grade excess heat and low-grade excess heat differ. The IPSO perspective (see chapter 3.3) was applied to complement the industrial symbiosis perspective, since earlier research used within the first paper highlighted the business perspective as a missing parameter in studies of similar cases (see Chapter 3.I). The main findings of Papers 2 and 3 showed possible facilitating implications of introducing a third neutral IPSO provider, with the objective to contribute knowledge and objectivity to facilitate further excess heat collaborations between actors whose core businesses normally did not relate to heating issues.

Early in the research process, and even before the focus on excess heat, I discovered that the infrastructure of district heating systems plays an important role for the technical conditions behind the development of excess heat collaborations. Therefore, the fourth 
paper (Paper 4) was developed in parallel and focused on the development of district heating infrastructure systems. Through analyses of the Swedish spatial planning practice combined with studies of the Swedish planning legislation and scientific planning literature, the paper resulted in practical suggestions on how to develop the spatial planning process to facilitate the expansion of district heating in the planning of new areas. As mentioned, this paper applied a theoretical framework consisting of strategic planning since the features of strategic planning are being highlighted as important features for long-term sustainable planning (see Chapter 3.4). The paper was subsequently supplemented with additional empirical data to further elaborate on the results and add another perspective on planning, namely that of excess heat-based systems of district heating. Paper 4 shows that district heating, and excess heat-based district heating in particular, could be facilitated by more strategic spatial planning processes with a greater emphasis on stakeholder participation.

The last paper, paper 5 was developed to compile, complement and further elaborate on the results of the different practical suggestions for increased utilisation of excess heat presented in Papers I-4. The previous papers identified different areas influencing further excess heat utilisation: interorganisational collaborations between normally unrelated actors, business models for collaboration, positive impacts of a third-party and strategic municipal spatial planning. Based on this, for Paper 5, additional empirical data was collected from actors representing different societal views on excess heat with the objective to fill some of the knowledge gaps identified in Papers I-4. Paper 5 applied the perspectives of industrial symbiosis (see Chapter 3.I), strategic planning (see Chapter 3.4) and, to a minor extent, IPSO (see chapter 3.3). The key findings show how strategic spatial planning processes conducted with broad stakeholder participation could facilitate both technical conditions in terms of supply and demand of excess heat, and how development of new excess heat collaborations could be facilitated through a broad stakeholder participation. The paper further concludes that local authorities have unique possibilities to promote excess heat collaboration through municipal spatial planning processes.

The results from the appended papers were later compiled and cross-analysed based on the theoretical framework of this thesis. This resulted in a deepened and broadened understanding of the overall results.

To conclude, the research conducted in this thesis has a strong empirical foundation consisting of interview studies with actors representing different areas of society with different perspectives on excess heat. Each of the appended papers contributes to the overall objective and research questions of this thesis in one way or another.

\subsection{Overall research design}

This thesis is a synthesis of five papers (Papers I-5), all written during my time as a $\mathrm{PhD}$ student. Since all cases studied are unique, with distinct conditions and circumstances, the thesis does not strive to describe a general situation. Still, it contributes with valuable conclusions about the effects of these conditions and circumstances, and how they could be managed to facilitate the conditions for increased excess heat utilisation. The methodological approaches of the five papers are all qualitative, as they all focus on understanding and explaining the phenomena studied. Qualitative approaches are suitable for studies aiming to achieve understanding of the study objects, and have the ability to "go where quantitative methods cannot" regarding achieving a deeper 
understanding about the phenomena studied (Yin, 2009; Denzin and Lincoln, 2005; Ahrne and Svensson, 20II). For the cover essay, the overall methodological approach is also qualitative, since it strives to develop an understanding of how different practical suggestions could facilitate the utilisation of excess heat within different areas and for different purposes.

The different studies of excess heat collaborations are focused on different themes and cases. In order to enable a synthesis of the papers a common denominator for all the papers has been identified; the focus on organisational factors behind excess heat utilisation. Each paper relates to the organisational factors of communication, trust and information transfer. The papers also relate to collaboration in different ways, either by interorganisational collaborations on excess heat or by collaboration among different societal stakeholders within the framework of spatial planning.

The selection of study objects for this thesis consists of a set of excess heat utilisation cases. Two different types of excess heat utilisation cases, existing and potential, have been studied. The reason behind studies of both existing and potential cases was to enable an analysis of potential differences in the perception of drivers and barriers behind interorganisational collaboration on excess heat. The study objects can also be further divided into excess heat utilisation cases, with and without the involvement of district heating distribution infrastructures. This enabled an analysis of how different technical conditions impact the development of excess heat utilisation.

Empirical data collection from real cases has been conducted in order to identify and understand the important conditions behind excess heat utilisation. One advantage of studying real cases is that the collaborations and organisational factors are investigated in terms of their consequences in relation to the context that they appear in (cf. Ritchie and Spencer, 2002). For the cases investigated within the framework of this thesis, the organisational factors are studied in relation to the other prevailing conditions of technical and financial character. The study of actual cases can also be used to identify different kinds of drivers and barriers behind the emergence of excess heat utilisation, and thus point at practical suggestions for increased utilisation. Yet, one critique concerning studies of real cases is that it is difficult to ensure whether the studied cases give a representative view of the general situation. As a consequence of this, all qualitative research should strive to use triangulation (Bowen, 2009). In order to triangulate, there is a need to conduct comprehensive studies. For this reason, the studies for data collection conducted within this thesis consist of extensive literature, document and interview studies (the different methods used for data collection are further described in Chapter 4.4.I). Qualitative research studies also require critical assessments in order to establish the purpose and veracity of the content in which the studies are carried out (Yin, 2009).

\subsection{Contribution of each paper}

In order to elucidate the research questions of this $\mathrm{PhD}$ thesis, theories and results from the five appended papers (Papers I-5) have been extracted. Table 2 presents how the five appended papers (I-5) contribute to the three research questions. 
Table 2. Contribution of Papers I-5 to Research Questions I-3. A LARGE X signifies a major contribution to the research question, while a small $\mathrm{x}$ signifies a medium or minor contribution.

\begin{tabular}{lccccc}
\hline & Paper 1 & Paper 2 & Paper 3 & Paper 4 & Paper 5 \\
\hline RQ1 & $\mathrm{X}$ & $\mathrm{X}$ & $\mathrm{X}$ & $\mathrm{X}$ & $\mathrm{X}$ \\
RQ2 & $\mathrm{X}$ & $\mathrm{X}$ & $\mathrm{X}$ & - & $\mathrm{X}$ \\
RQ3 & - & - & - & $\mathrm{X}$ & $\mathrm{X}$ \\
\hline
\end{tabular}

The first research question of this thesis aims at identifying the main drivers and barriers behind the development of interorganisational collaboration on excess heat utilisation. This is mainly explored empirically through Papers I and 5 (see Table 2). In paper I, the identified drivers and barriers behind excess heat utilisation among energy companies, industrial firms and local authorities are studied in both existing and potential cases of excess heat utilisation. Paper I uses an industrial symbiosis approach and a business model perspective in order to analyse the results (see Table 3). Paper 5 consists of studies of existing cases and uses industrial symbiosis, parts of an IPSO and strategic planning.

To further understand the importance of business models for collaboration, to answer the second research question, discoveries from Papers I, 2 and 3 were mainly used (see Table 2). Papers 2 and 3 consist of a combination of both existing and potential excess heat utilisation cases, both with and without the involvement of energy companies. For these papers, the theoretical field of industrial symbiosis was complemented with the perspective of integrated product and service offerings (IPSO) (see Table 3). In Papers 2 and 3, the IPSO is mainly used to analyse the utilisation of low-grade excess heat for purposes other than district heating. For this thesis, however, parts of the IPSO is also used in analyses of the role of local authorities within municipal spatial planning.

The lessons learnt within Papers 4 and 5 (see Table 3) studying Swedish spatial planning processes in combination with Swedish spatial planning legislation and strategic planning literature helped in answering the third research question (see Table 2) about how strategic municipal spatial planning could facilitate conditions for the development of excess heat-based systems for district heating.

For Paper 5, industrial symbiosis, strategic planning and, to a minor extent, IPSO were applied (see Table 3) to further develop some of the practical suggestions for increased utilisation of excess heat presented in Papers I-4. This last paper (Paper 5) supplies additional knowledge about the role of local authorities in order to contribute new findings, with the objective to fill some of the identified knowledge gaps within Papers I4. Paper 5 mainly contributes to Research Questions I and 3 (see Table 2).

\subsection{Overview and motivation of methods and analytical approaches}

The five papers which form the basis of this thesis applied a variety of methods. Table 3 presents an overview of these methods along with the theories used for each appended paper.

This thesis applies a multidisciplinary approach, where different theories are used. The broad theoretical foundation (see Table 3) enabled a broad analytical approach. All studies have used a thematic analytical approach. 
Table 3. Description of methods for data collection and theories used for each appended paper.

\begin{tabular}{lll}
\hline Paper & Methods for data collection & Theoretical foundation \\
\hline $\mathbf{I}$ & Literature, Documents, Interviews & Industrial Symbiosis, Business perspective \\
$\mathbf{2}$ & Literature, Documents, Interviews & Industrial Symbiosis, IPSO \\
$\mathbf{3}$ & Literature, Documents, Interviews & Industrial Symbiosis, IPSO \\
$\mathbf{4}$ & Literature, Documents, Interviews & Strategic planning \\
$\mathbf{5}$ & $\begin{array}{l}\text { Literature, Documents, Group } \\
\text { interview, Interviews }\end{array}$ & Industrial Symbiosis, Strategic planning, IPSO \\
\hline
\end{tabular}

\subsubsection{Methods for data collection}

This section presents the data collection methods used in this research. For further details of the methods used for each paper, see the appended papers (Papers I-5).

\section{Literature studies}

Literature studies can be used in the mapping of knowledge situated in a research field (Yin, 2009). The different text sources, such as scientific articles or books, should be relevant in relation to the research questions, providing information to enable an analysis. Comparing different sources of literature within a specific topic can provide interesting results - for example, similarities and differences between different interorganisational collaborations. For these types of literature studies, it is important to not only describe the differences, but also to try to explain what they may be due to. The majority of the appended papers of this thesis have used literature studies of different scientific fields in order to analyse the results (Table 3).

For Paper I, literature studies were conducted within the scientific field of industrial symbiosis (see Table 3 and Chapter 3.I). As mentioned in Chapter 3.I, there was an identified knowledge gap in the literature of industrial symbiosis. Therefore, the literature study for Paper I was complemented with literature of the canvas building blocks in the formation of business models (see Chapter 3.2). This enabled an analysis of how the canvas could be used to gain a deeper understanding of the importance of wellfunctioning business agreements.

For Papers 2 and 3, the literature study of industrial symbiosis was complemented with IPSO literature (see Table 3, Chapter 3.I and 3.3). The IPSO perspective was applied to complement the industrial symbiosis perspective with a more business-oriented view. The purpose of this was to enable practical suggestions of how to develop interorganisational collaboration on excess heat between companies and organisations with businesses normally not related to heating issues.

In Paper 4, scientific literature within the field of strategic planning (see Table 3 and Chapter 3.4) was used to further elaborate on the findings from Paper I, and to enable an analysis of the potential of Swedish municipal spatial planning processes to become more strategic in terms of planning to match the supply and demand of excess heat (see Chapter 3.I).

For Paper 5, literature within the field of industrial symbiosis, strategic spatial planning and IPSOs (see Table 3, Chapter 3.I, 3.3 and 3.4) was studied. The literature study was conducted to enable an analysis of how stakeholder participation within the framework 
of municipal strategic spatial planning could be developed in order to facilitate both the technical conditions - in terms of supply and demand of excess heat - as well as the conditions of organisational character - concerning interorganisational collaborations in which providers and users of excess heat utilisation collaborations are involved.

\section{Document studies}

Document studies have also been conducted for all of the papers appended to this thesis (see Table 3). These types of studies are based on existing printed data (cf. Patel and Davidson, 2003). Examples of documents studied for this thesis are municipal reports, operational descriptive reports, annual activity reports, consultancy reports, performance reports and national laws and regulations. Document studies do, similar to literature studies, require critical assessments in order to establish the purpose and veracity of the content in which the studied documents appear (Yin, 2009). The reliability in the facts presented must be considered by the researcher to form an objective perception (Patel and Davidson, 2003). Further, it is appropriate to start with the most general information to form a basic idea, and then seek more specialised literature for a deepened understanding (Andersen, 1994). For all the documents studied in this thesis the purpose for which the documents were produced, if the material was sufficient and who developed it was, have been considered.

Document studies require comprehensive sources of documentation. Yet, the availability of published material may in some cases be very extensive, and in some cases scarce. It is, therefore, important that data is carefully selected (Patel and Davidson, 2003). For the document studies of company-specific information about the cases investigated in this thesis, the information from the different companies' websites varied. For some of the cases with limited documented information, additional information was provided upon request by representatives from each organisation.

The first paper (Paper I) used studies of operational descriptive reports, annual activity reports, consultancy reports, performance reports and other related background information - such as electronic, local and national news articles - of the cases studied (see Table 3). As for the first paper, Papers 2 and 3 also used document studies of the companies and organisations which constitute the actual objects of study (see Table 3 ).

For Paper 4, the Swedish spatial planning legislation was examined (see Table 3). For this paper, the Plan and Building Act (PBA), as well as associated regulations, were mainly used in the mapping of the spatial planning process. Yet, some additional related legislation, such as the Environmental Code and the Law of Municipal Energy Planning, was also used. One advantage of studying documents rather than conducting interviews in the mapping of the generic process regulated by legislation is that these types of documents have generally been reviewed before publication and describes a standardised planning process (cf. Merriam, 1994).

The document study conducted for Paper 5 consisted of municipal reports, operational descriptive reports, annual activity reports, consultancy reports, performance reports and national laws and regulations (see Table 3 ). 
One limitation connected to document studies is that documents are normally written based on a specific context and purpose (May, 200I). In addition, the organisational issues studied within this thesis are hard to capture in studies of documents.

\section{Interviews}

Interview studies comprise the backbone of data collection for this thesis, since interviews can be used to examine issues that go beyond the contents of literature and documents (cf. Rowley, 20I2). For this reason, all papers have used interviews. Interviews with actors involved in the processes studied enabled a deeper understanding of considerations made and underlying conflicts behind decision making processes compared to annual reports and protocols (Richards, 1996).

All the interviews have been semi-structured, meaning they are based on open-ended interview questions that allow respondents to speak freely on specific themes. The openended interview questions also allow for follow-up questions that encourage interviewees to expand on their responses (May, 200I). For all the interview studies, interview guides with basic questions were formulated in advance. Interviews should have an objective approach (Eklund, 20I2), and it is important not to influence the respondent's statement by showing approval or disapproval. The interviews conducted within the framework of this thesis have been built up according to a funnel model. First, general and neutral questions were asked. These first questions asked were open questions; nevertheless, they were based on themes related to the research questions. This approach does, however, open up the possibility of receiving spontaneous information about attitudes and emotions (Eklund, 2012). The conversations during the interviews have therefore been directed by follow-up questions. The first questions were followed by more in-depth questions. These questions have been more concrete and focused in order to provide answers to the research questions, which according to Eklund (20I2) is one way for the interviewer to direct the interview. All interviews have been completed with the question: "Is there something that you want to add or develop further?", to provide the respondent with an opening to add additional information that might be of interest. All interviews have been recorded and transcribed. With the exception of repetitions and irrelevant sounds such as coughs from the respondents, all interviews have been transcribed word for word. All respondents have also been offered the opportunity to review the transcript from their interview. Interviews, however, always risk being interpreted differently by different interviewers (Kvale and Brinkmann, 2008; Yin, 2009). For this reason, the interview results have been carefully presented to clearly distinguish the respondents' answers from the interviewer' analysis of them.

For the first paper (Paper I) on drivers and barriers behind the development of excess heat-based systems for district heating, a total of 26 interviews was performed (see Table 4). The respondents all had experiences of excess heat utilisation and consisted of mangers at different levels from each company and organisation. The interviews were conducted to reach a deeper understanding of each specific company and organisation than what was provided by the document study. Yet, most important, the interviews allowed answers to questions about the organisational aspects behind the development of excess heat-based systems for district heating. 
Table 4. Number of respondents for each paper, representing different private/public organisations (more detailed information about the respondents is provided within each of the appended papers).

\begin{tabular}{|c|c|c|c|c|c|c|}
\hline \multirow[t]{2}{*}{ Type of company/organisation } & \multicolumn{6}{|c|}{ Number of respondents from each private/public organisation } \\
\hline & Paper I & Paper 2 & Paper 3 & Paper 4 & Paper 5 & Total \\
\hline Energy companies & 5 & 2 & 3 & 6 & 2 & I8 \\
\hline Industrial firms & 19 & 2 & 2 & & 2 & 25 \\
\hline $\begin{array}{l}\text { Facilities demanding low-grade } \\
\text { excess heat }\end{array}$ & & I & I & & & 2 \\
\hline $\begin{array}{l}\text { Facilities generating high-grade } \\
\text { excess heat }\end{array}$ & & & 2 & & & 2 \\
\hline $\begin{array}{l}\text { Experts on low-grade excess heat } \\
\text { utilisation }\end{array}$ & & I & I & & 2 & 4 \\
\hline Municipal spatial planners & & & & I3 & 4 & 17 \\
\hline $\begin{array}{l}\text { Municipal energy and climate } \\
\text { advisors }\end{array}$ & & & & 6 & & 6 \\
\hline Developers & & & & $\mathrm{I}$ & & I \\
\hline Local authorities & 2 & & & & & 2 \\
\hline $\begin{array}{l}\text { Swedish District Heating } \\
\text { Association }\end{array}$ & & I & I & & & 2 \\
\hline $\begin{array}{l}\text { Swedish Association of Local } \\
\text { Authorities and Regions }\end{array}$ & & & I & & & I \\
\hline $\begin{array}{l}\text { Competence centre for timber } \\
\text { products }\end{array}$ & & & I & & & I \\
\hline Total: & 26 & 7 & 12 & 26 & IO & $8 \mathrm{I}$ \\
\hline
\end{tabular}

For Papers 2 and 3, a total of I9 semi-structured interviews was performed (see Table 4). As for the first paper, the respondents consisted of managers at different levels from the studied companies and organisations. The respondents within these papers represented companies and organisations with either an excess of heat or a need for heat. The interviews were conducted in order to reach a deeper understanding about organisational aspects behind the development of excess heat-based systems for district heating.

Interviews were also used in Paper 4 (see Table 4) in order to map the spatial planning practices within the six studied municipalities. A total of 26 semi-structured interviews were conducted. The respondents consisted of local authority spatial planners, representatives from energy companies and energy and climate advisors. In one of the cases, the interview study was complemented with a developer. The mapping as a result of the interviews enabled a comparison of planning processes as described in Swedish legislation and the actual planning practice within the six studied municipalities. The interviews also contributed to a deeper understanding about organisational aspects of multiple stakeholder participation in the planning of new areas.

One of the main critical issues regarding interviews concerns the relation between the respondent and the interviewer (see, e.g., Kvale and Brinkmann, 2008; May, 200I). Some of the criticism concerns possibilities of respondents ending up in disadvantageous positions in relation to the interviewer. This, however, mostly concerns interviews with individuals on sensitive topics concerning private matters. The respondents interviewed within this thesis represent organisations in a professional context, not related to private matters. My experience is that the majority of the respondents have been well aware of how to express their views on the questions asked. 
Conducting interviews requires an interviewer well versed in the respondent's background and the context in which he/she is active in; the reason for this is to get access to the knowledge desired (Kvale and Brinkmann, 2008), and for the interview questions to be relevant in relation to the background and context of the respondent. My experience is that well-prepared interviews, both regarding carefully prepared interview guides and carefully executed document studies, result in open and relaxed interviews which in turn result in access to the information needed.

Another aspect relating to the relation established between the respondent and the interviewer concerns the importance of maintaining a certain kind of distance. May (20I0) argues that on the one hand, the feeling of trust and safety is important to allow freely speaking respondents. Yet, on the other hand, a certain amount of distance is also required to allow the interviewer to assess and analyse the interview results with an objective approach. Excessively close personal relationships can affect objectivity in a negative way. The relationships between the interviewer and respondents in the interview studies conducted for this thesis have been of a professional nature, and the interviewer has no personal relation to any of the respondents.

Some interviews conducted within this thesis have been face to face, and some by telephone. There are clear pros and cons with both approaches. Face-to-face interviews are often emphasized as the most appropriate form of interviews as they, in contrast to interviews conducted by telephone, contain information beyond the spoken word (Kvale and Brinkmann, 2008). This concerns information gained through body language and other visual impressions, which could affect the interviewers' overall impression. Applying this reflection on the interviews conducted for this thesis, my interpretation is that the questions asked and issues discussed have not been affected by visual impression to a significant extent. Given the scope and overall objective of this thesis, information beyond the spoken word is considered less relevant.

Benefits of interviews conducted by phone is that they are less time consuming compared to face-to-face interviews, which often require time spent on travel. The added value of the telephone interviews conducted within the studies of this thesis is the greater number of interviews. The extensive empirical material, partly due to telephone interviews, has contributed to an increased and broader understanding, which in turn contributed to increased credibility and validity of the studies.

\section{Group interview - influenced by focus group methodology}

For Paper 5, a group interview influenced by the methodology of focus group interviews was conducted (see Table 3). Wibeck (2010) defines the method of focus groups as a research technique with three different aspects: (I) a method aimed at data collection for research purposes, (2) data collection by group interaction, and (3) a method for data collection where the subject addressed is determined by the researcher. The conducted group interview meets all of these criteria, yet it was more guided by the interviewer than a traditional focus group interview. Since part of the objective with the group interview was to confirm and follow up on the results from the previous studies conducted for Papers I-4, the different topics discussed were introduced by the researcher through a short presentation of previous results. For a traditional focus group interview, such background information is not normally presented (cf. Wibeck, 20IO). 
The reason for choosing a group interview was to trigger a discussion between experts in the area of excess heat utilisation. According to Bryman and Bell (20II), the value of this method is that discussions and aspects are generated as a result of the group dynamic that would not appear during individual interviews. For instance, respondents often comment beyond their original answer after hearing each other's answers, which is something that enhances the quality of the data (Patton, 2002).

The discussions that took place during the group interview were characterised by more elaborated reasoning compared to the individual interviews performed for this thesis. The group discussions contributed to a broad view of the prevailing conditions of drivers, barriers, challenges and practical suggestions. The participating respondents represented different professional societal actors with different perspectives on the utilisation of excess heat for heating purposes. The respondents consisted of representatives from an energy company with a demand for high-grade excess heat, an industry with an excess of high-grade excess heat, one expert on low-grade excess heat, and one municipal spatial planner (comprehensive planning).

For Paper 5, additional semi-structured interviews to complement the group interview were conducted (see Table 4 ). The objective with the interviews performed was to gain a deeper understanding of different societal actors' perceptions of different measures for increased utilisation of excess heat. The participating respondents consisted of representatives similar to the ones participating in the group interview: an energy company with a demand for high-grade excess heat, an industry with an excess of highgrade excess heat, one expert on low-grade excess heat, and municipal spatial planners at both the comprehensive and detailed development planning levels.

The reason for choosing spatial planners with different views - that is, comprehensive planners and detailed development planners - was to gain a broad perspective capturing the whole planning process.

\subsubsection{Analytical approach}

Thematic analysis is an analytical approach used in all the appended papers. This approach is widely used for identifying, analysing and reporting themes and patterns within data, normally consisting of literature, documentation and interviews (Tuckett, 2005). It can be used to organise and describe the data in rich detail. Further, it can be used to interpret various aspects of the research topic (Boyatzis, 1998). The different themes identified when conducting thematic analysis capture important aspects about the data in relation to the research questions, and represent some level of patterned response or meaning within the data set (Braun and Clarke, 2006). Ideally, the themes identified will occur a number of times across the data set. Since this is a qualitative analysis, there is not any direct answer to the question of how frequently occurring a theme needs to be displayed in order for it to be considered a theme. According to Braun and Clarke (2006), a theme might be given considerable space in some data items, and little or none in others, or it might appear in relatively little of the data set. The themes identified within the different studies of this thesis have mainly been occurring with a high frequency. On some occasions, themes more rarely occurring but still considered as particularly interesting have been identified.

For Paper I, themes within the scientific literature from the research field of industrial symbiosis and business models for collaboration were identified. These themes 
concerned drivers and barriers behind development of interorganisational collaborations. As mentioned, a document study was also conducted in order to get a deeper understanding of the energy companies and industrial firms constituting the actors investigated through the interview study. The studied documents consisted of operational descriptive reports and annual activity reports. The case-specific knowledge gained through the documents indirectly affected the interview questions formulated for the interview study. The identified themes on drivers and barriers did, however, frame the scope and the themes further elaborated on in the interview study. Further themes were identified when analysing the results from the interview study and resulted in a categorisation of financial, technical organisational and environmental drivers and barriers.

For Papers 2 and 3, the earlier described document and literature studies were used together with results from the interview study. The compiled and analysed findings resulted in themes related to important organisational aspects behind the utilisation of excess heat between normally unrelated actors, with a specific emphasis on collaborations without the involvement of distribution systems for district heating. The identified themes were important conditions behind the development of interorganisational business agreements on equal terms, and opportunities and challenges of third-party IPSO providers to facilitate collaborations between actors whose core businesses normally do not concern heating issues.

One of the main themes from Paper I was further investigated in Paper 4. As mentioned, besides organisational conditions, Paper I also identified technical conditions, concerning supply and demand, as important for the development of excess heat utilisation. Based on this, Paper 4 aimed at studying municipal spatial planning, which has a great impact on excess heat supplies and demands. The document study on Swedish planning legislation, the literature study about strategic spatial planning and the interview study on actual planning processes were compiled and thematically analysed in order to identify similarities and differences between planning theory, legislation and practice. The analysis of participatory mechanisms of spatial planning resulted in identification of the theme early and broad participation of relevant stakeholders.

For the last paper, Paper 5, thematic analysis was used to identify themes concerning the different practical suggestions of further utilisation of excess heat identified in Papers I4. The literature study on industrial symbiosis, business model perspective, IPSOs and strategic spatial planning, with an emphasis on stakeholder participation, as well as the document study on Swedish planning legislation and the interview study on the different practical suggestions proposed in Papers I-4, were compiled and analysed. The identified themes concerned the lack of political emphasis on excess heat issues and the role of local authorities as promoters of excess heat collaborations between normally unrelated actors.

\subsection{Appended papers}

This section briefly presents the five appended papers, to include their different objectives and methods. More detailed descriptions of the methods used for each paper can be found in each appended paper. 


\subsubsection{Paper 1 - Excess heat supply collaborations within the district heating sector: Drivers and barriers}

Päivärinne, S., Hjelm, O. and Gustafsson, S. (2015). "Excess heat supply collaborations within the district heating sector: Drivers and barriers". Journal of Renewable and Sustainable Energy, Volume 7, Issue 3, 20I5, Pages 033II7-I-I6.

This paper aimed at investigating drivers and barriers behind the development of excess heat-based systems for district heating. Increased knowledge of these important aspects could mean greater opportunities to develop such systems. This paper examined both existing and potential interorganisational collaborations between industrial producers of excess heat and users of excess heat, specifically energy companies. The focus of the study consisted of two Swedish cases of existing collaboration between energy companies and pulp and paper industries, as well as I6 industrial firms that all had unutilised excess heat as a by-product. Combining both existing and potential cases, this study strived to identify necessary conditions for the emergence of collaborations. In order to increase the knowledge about drivers and barriers behind development of these systems, the analytical part of this paper combined the theoretical field of industrial symbiosis with a business model perspective.

This paper confirmed that trust, joint problem solving, and fine-grained information transfer were important elements in the development of interorganisational collaborations. In addition, the results added honesty and shared visions on common goals as important for the development of well-functioning collaborations. All these features have proved to be central in the decision-making process for joint collaboration projects, where knowledge through participation of stakeholders is required to understand the common goals and objectives and to translate them into practice. Financial aspects were shown to be both the main drivers and the main barriers when it comes to the emergence and development of long-term sustainable excess heat supply collaborations.

The author of this thesis conducted the empirical data collection and wrote the paper. Guidance and support was provided by the co-authors.

\subsubsection{Paper 2 - Exploratory study of combining Integrated Product and Services Offerings with Industrial Symbiosis in order to improve Excess Heat utilization}

Päivärinne, S. and Lindahl, M. (2015). "Exploratory study of combining Integrated Product and Services Offerings with Industrial Symbiosis in order to improve Excess Heat utilization". Procedia CIRP, Volume 30, 20I5, Pages I67-I72.

This paper explored the implications of combining an integrated product service offering (IPSO) perspective with the perspective of industrial symbiosis to facilitate increased utilisation of excess heat. In order to do so, four different excess heat cases that originated from an industrial symbiosis perspective were investigated; in addition, a representative from a branch organisation was also interviewed. All the cases were related to excess heat in one way or another. The first case was an existing example of an 
excess heat supply collaboration between a pulp mill and an energy company. In this specific case, there was also a nearby greenhouse which was provided with heat from the mill. The second case was an oil refinery with a large unutilised excess of heat. Case number three was an energy company, which fairly recently started a project called Open District Heating. Its project was based on the idea that the energy company offers anyone the opportunity to sell and deliver heat on its district heating grid. The fourth case was based on ongoing studies and preliminary results of a research project which aimed to explore the increased use of low-grade heat for food production. The last respondent represented the Swedish District Heating Association, which is a branch organisation for the district heating sector when dealing with the government, parliament and authorities, for example in investigations and consolation responses.

Based on an IPSO-focused literature review, the five excess heat cases were analysed in order to identify potential pros and cons, if an IPSO perspective was applied, in order to further improve excess heat utilisation. The paper was based on interviews with respondents from the five different cases.

The paper concluded that applying the IPSO concept, in combination with industrial symbiosis, has the potential to facilitate and improve excess heat utilisation. This is because applying an IPSO approach when developing customised business offerings could help shift focus from the product (excess heat) to the service (heating), as a way to fulfil a user's initial need and thereby make it more attractive within a wide area of operations.

The author of this thesis conducted the empirical data collection and wrote the paper. Guidance and support was provided by the co-author.

\subsubsection{Paper 3 - Combining Integrated Product and Services Offerings with Industrial Symbiosis - a study about opportunities and challenges}

Päivärinne, S. and Lindahl, M. (20I6). "Combining Integrated Product and Services Offerings with Industrial Symbiosis - a study about opportunities and challenges". Journal of Cleaner Production, Volume 127, 20 July 20I6, Pages 240-248.

The overall objective of this paper was to examine opportunities and challenges in combining integrated product and service offerings (IPSOs) with industrial symbiosis. In order to do so, several excess heat supply collaborations were examined. This paper builds on the five cases from Paper 2. Yet, for this study the respondents from Cases I-5 were contacted a second time with the objective to verify and further elaborate on the results from the previous study. Cases I-5 represented five different societal actors in terms of being both providers and users of excess heat. For this study, the empirical data from Cases I-5 was complemented with an additional five cases (Cases 6-IO), all originating from an industrial symbiosis perspective. Similar to the first five cases, the additional cases (Cases 6-IO) also consisted of both providers and users of excess heat, representing different societal actors. These cases were selected to verify and complement the findings. All ten cases were selected by two different desktop studies, one specifically for the first five cases (Cases I-5) and one for Cases 6-IO. 
This paper identified a number of different potential opportunities and challenges in combining IPSOs with industrial symbiosis from an excess heat supply collaboration perspective. The validity and reliability of the method in relation to the selected examples and sample size were found to be viable, since the collected data from the different examples proved to be consistent and possible to categorise. The main opportunities were associated with how the IPSO and industrial symbiosis perspectives complement each other through their different ways of addressing collaborations of excess heat supply. The combination of the two perspectives resulted in an increased combined understanding of both the practical and organisational factors related to excess heat supply collaborations.

The author of this thesis conducted the empirical data collection and wrote the paper. Guidance and support was provided by the co-author.

\subsubsection{Paper 4 - Strategic spatial planning - a missed opportunity to facilitate district heating systems based on excess heat}

Päivärinne, S. Hjelm, O. and Gustafsson, S. (20I7). "Strategic spatial planning - a missed opportunity to facilitate district heating systems based on excess heat". Manuscript, submitted to European Planning Studies.

The overall objective of this paper was to explore how the implementation of strategic spatial planning could facilitate the conditions for excess heat-based systems for district heating. This was based on an investigation of the current planning practice in Sweden. The paper builds on two complementary studies, conducted in 2009 and 2016, of the spatial planning process in six municipalities. In an attempt to add to suggestions for improved strategic spatial planning processes, the study used a qualitative approach. The main focus of the interviews in this study was on the final decision regarding what type of heating system the planned area finally gets. The analysis of the results was based on Swedish planning legislation according to the PBA (SFS 2010:900) and previous research on strategic planning. The results were based on the interview material from the respondents' answers, in combination with the national planning legislation described in the PBA.

The paper suggested that greater integration between the local authority spatial planners and external relevant stakeholders should start at the comprehensive planning level. Such an approach would require a greater openness among business people and politicians to allow others to participate. This could be one way to implement strategic spatial planning to increase the opportunities for district heating systems based on excess heat. Moreover, the results indicated that the planning practice could be improved if energy companies and actors with an excess of heat, together with other stakeholders, are invited earlier in the formation of the detailed development plans to share their knowledge and thereby improve the possibilities for implementation of excess heat-based district heating. These characteristics of strategic planning based on well-founded decisions are important not only in a Swedish context, but also in an international one. Strategic planning is also an interesting approach from a broader perspective. Examples of this could be other kinds of planning processes in which knowledge from several societal actors is required, or for other issues within the framework of spatial planning. 
The author of this thesis conducted the empirical data collection and wrote the paper. Guidance and support was provided by the co-authors.

\subsubsection{Paper 5 - Local authorities as promoters of interorganisational collaborations of excess heat utilisation}

Päivärinne, S. (20I7). "Local authorities as promoters of interorganisational collaborations of excess heat utilisation". Manuscript.

This last appended paper aimed at investigate the role of local authorities as promoters of interorganisational collaborations on excess heat utilisation within the framework of strategic municipal spatial planning. The study is focused on whether and how broad stakeholder participation in municipal spatial planning processes - involving both potential providers and users of excess heat - could facilitate the technical and organisational conditions required for interorganisational collaborations on excess heat utilisation to develop. It builds on the qualitative studies of five different categories of respondents, namely energy companies demanding excess heat, industries providing excess heat, municipal spatial planners at the comprehensive plan level, municipal spatial planners at the detailed development plan level and experts on low-grade excess heat utilisation, all with different perspectives. A group interview influenced by the methodology of the focus group interviews, including one respondent from each category, comprised the basis for the empirical data collection. In addition, individual semi-structured interviews were performed with all respondent categories as a complement to the group interview.

The analysed results showed that excess heat utilisation is currently a non-existing issue within municipal spatial planning. Broad stakeholder participation early and throughout the entire planning process is required to facilitate both the technical conditions - regarding supply and demand - and the organisational conditions required for interorganisational collaborations on excess heat supply between normally unrelated actors. Through the comprehensive function of local authorities and the participatory mechanisms of municipal spatial planning, local authorities have unique possibilities for initiating contacts between actors providing and actors demanding excess heat. Yet, this requires stakeholder participation involving these actors, and currently potential excess heat providers are excluded from the stakeholder participation. To facilitate conditions for increased utilisation of excess heat there is a need to bring the issues of excess heat utilisation to the political agenda. This would create the political legitimacy required to make excess heat a prioritised issue within municipal spatial planning.

The author of this thesis independently developed the paper idea, conducted the empirical data collection and wrote the paper. Some guidance and support was provided by supervisors Olof Hjelm and Sara Gustafsson.

\subsection{Research quality}

This section presents an overall discussion about the research quality of this thesis. Since the overall methodological approach of this thesis is qualitative, an evaluation method adapted to qualitative research is applied in the judgement of the quality of the research. The evaluation method, described by Guba and Lincoln (1989), is based on the 
assumption that reality is constructed through interaction between the researcher and the respondents, and uses the four concepts of credibility, transferability, dependability and confirmability. These concepts are used to enable a critical view of the conducted interview, literature and document studies. Nevertheless, additional related evaluation literature is also used (see, e.g., Denzin, I978; Bassey, 198I; Brewer and Hunter, 1989; Firestone, 1993; Miles and Huberman, 1994; Merriam, I998; Rowley, 2012; Stake, 2013).

Below, the meaning and description of how the research within this thesis corresponds to the four concepts - credibility, transferability, dependability and confirmability - are presented.

\subsubsection{Transferability, dependability, credibility and confirmability}

The transferability of a study relates to "the extent to which the findings of one study can be applied to other situations" (Merriam, 1998). This is a relevant question for all of the studies within this thesis and for the thesis in its entirety, as the conditions for the utilisation of excess heat differs between different countries as well as within Sweden, which is the focus of this thesis.

Even though the organisational conditions studied within this thesis depart from a Swedish perspective with a focus on excess heat collaborations, the findings concerning interorganisational collaborations and business agreements are general and transferable for collaborations in a broader context, for other forms of interorganisational collaborations, in other contexts and for other countries. Besides the unique conclusions from this thesis, the findings show many similarities with other studies investigated within the literature studies of other interorganisational collaborations, in other contexts and other countries. The same relates to strategic planning, which can be applied to different planning processes, for example in the planning of long-term goals and strategies within companies or other organisations. This makes many of the elements brought to light in this thesis - such as how to frame decisions, actions, projects, results and implementation by taking knowledge from several relevant stakeholders into account - relevant in a broader context. Certain aspects specific to Sweden and/or the utilisation of excess heat, such as technical conditions or Swedish planning legislation, are obviously not directly transferable to collaboration studies in a wider context.

To overcome difficulties regarding the generalisation of qualitative studies, the contexts and limits of the study must be explicitly described in order to enable the reader to determine whether it is possible to transfer the results to other situations (Bassey, I98I; Firestone, 1993). The transferability of this thesis is validated through contextual information about the cases studied. Information about details of the methods for data collection, the time period for data collection and number of participants involved is provided.

The dependability of a study largely requires the same methodological features as required for the transferability of a study. Yet, in contrast to transferability, the dependability of a study implies that it should be replicable; this means that by using the same methods, another study of similar cases should achieve similar results (Lincoln and Guba, 1985).

The contextual details of the methods used are also relevant for the dependability of the thesis. For the conducted studies in this thesis, the respondents have not been mentioned 
by name. One obvious consequence of this is that it will be difficult to conduct the exact same interview again. Yet, the professional position of each respondent is stated in most cases in each paper, which makes it possible to conduct interviews with respondents at the same professional position representing a similar case, which in turn would entail possibilities of achieving similar results using the same method for studies of similar cases with similar respondents.

According to Merriam (1998), the credibility of a study relates to the question "How congruent are the findings with reality?" One way to ensure that the collected data is credible is to verify the results by asking the respondent for a judgement of the data collected. For this thesis, the studied documentation has been verified by the respondents. The respondents from the different interview studies have also been asked to review the transcribed interviews to enable corrections.

To increase the credibility of the thesis and overcome uncertainties concerning how well the selected cases for each study present a general situation, multiple cases are included. The appended papers involve different cases of the same phenomenon. Compared to single-case studies, multiple-case studies involving different cases improve the trustworthiness and thus credibility of the results (Stake, 20I3). The credibility is also affected by the selection and number of respondents in each study. According to Rowley (2012), a typical study should include at least six to eight focused one-hour interviews. In addition, this thesis uses triangulation by applying several methods, theories and sources of information collected from the literature, documents and interview studies. Triangulation is a common strategy to enhance the credibility of qualitative research (Denzin, 1978). This thesis uses a variety of different methods, sources and theories that complement one another. The use of several methods and the diversity it brings can compensate for the individual shortcomings of a specific method (Brewer and Hunter, I989).

The credibility is also ensured by the fact that each research question of this thesis relies on results from several studies. That the results from all studies of interorganisational collaborations are relatively consistent increases the dependability of the thesis. In the context of this thesis, all respondents in the interview studies for Papers I-5 were, as mentioned, given the opportunity to review the transcript in order to add or correct information. The respondents have also been given the opportunity to withdraw their participation. Yet, for the different studies conducted within this thesis, not one of the respondents withdrew. For the interview studies in Papers I, 3 and 4, the interview questions were sent to the respondents in advance. This was especially important for the study conducted in Paper I, since some of the developments of the excess heat-based district heating systems started more than 18 years ago. In this case, the respondents needed time to go through the documentation and to refresh their memory in order to prepare answers. This contributed to the credibility by increasing the conditions for important information to not be omitted or incorrectly remembered.

Confirmability refers to the degree to which the results could be confirmed by others (Miles and Huberman, 1994). The results, therefore, should be clearly based on the expertise of the respondents and empirical data, rather than based on the preferences of the researcher. The empirical data of this thesis have, as mentioned, been carefully presented in order to clearly distinguish the empirical results and analysis. All of the appended papers include carefully translated quotes and summarised findings from the 
interview studies, which contributes to an increased confirmability. Yet, it should be noted that the reader is only provided with summarised extracts from the original transcripts.

Something that is also emphasised in terms of the confirmability of a study is that the researcher when presenting the research, should highlight their own position concerning the objective and analysis of the results when relevant (Miles and Huberman, 1994). Concerning this thesis, the researcher's view of excess heat utilisation is presented in Chapters I and 2, which present the resource efficiency potential of utilising excess heat from an environmental, financial and societal viewpoint. 


\section{RESULTS AND DISCUSSION}

This chapter presents and discusses the aggregated main results from the five appended papers, divided into three main subheadings according to each research question: Section 5.I Drivers and barriers behind development of interorganisational collaborations on excess heat utilisation, Section 5.2 Important key elements of interorganisational business models, and Section 5.3 Implications of applying strategic spatial planning into the Swedish spatial planning process in order to facilitate utilisation of excess heat. 


\subsection{Drivers and barriers behind development of interorganisational collaborations on excess heat utilisation}

The drivers and barriers for the studied excess heat collaborations have been categorised into four different themes that became clear during analysis: financial, technical, organisational and environmental (Table 5).

Table 5. Financial, technical, organisational and environmental drivers and barriers behind development of excess heat collaborations.

\begin{tabular}{|c|c|c|}
\hline & Drivers & Barriers \\
\hline Financial & $\begin{array}{ll}\text { - } & \text { Financial profitability } \\
\text { - } & \text { Investment grants } \\
\text { - } & \text { Marketing advantages } \\
\text { - } & \text { Reduced cost for customers }\end{array}$ & $\begin{array}{ll}\text { - } & \text { Lack of financial funding } \\
\text { - } & \text { Large investment costs } \\
\text { - } & \text { Financial risks }\end{array}$ \\
\hline Technical & $\begin{array}{ll}\text { - } & \text { Existing distribution system } \\
\text { - } & \text { Reasonable distance } \\
\text { between supply and } \\
\text { demand } \\
\text { - } \quad \text { Match of supply and } \\
\text { demand } \\
\text { - } \quad \text { Sufficiently high-grade heat } \\
\text { - Availability of technical } \\
\text { solutions }\end{array}$ & $\begin{array}{ll}\text { - } & \text { Lack of existing distribution system } \\
\text { - } & \text { Distance between supply and demand } \\
\text { - } & \text { Supply and demand not matching } \\
\text { - } & \text { Not sufficiently high-grade heat } \\
\text { - } & \text { Varying seasonal heat demand } \\
\text { - } & \text { Lack of available technical solutions } \\
\text { - } & \text { Lack of knowledge about the amount } \\
\text { of excess heat }\end{array}$ \\
\hline Environmental & $\begin{array}{ll}\text { - } & \text { Reduced environmental } \\
\text { impact } \\
\text { - } & \text { Environmental image } \\
\end{array}$ & - \\
\hline Organisational & $\begin{array}{l}\text { - } \quad \text { Personal relationships } \\
\text { Business agreements based } \\
\text { on; humility, honesty, } \\
\text { transparency, trust, fine- } \\
\text { grained information } \\
\text { transfer, joint problem } \\
\text { solving, and shared visions } \\
\text { of common goals }\end{array}$ & $\begin{array}{ll}\text { - } & \text { Lack of knowledge - heating issues } \\
\text { - } & \text { Lack of knowledge - business } \\
\text { - } & \text { Lackeement } \\
\text { - } & \text { Communication difficulties } \\
\text { - } & \text { Non-core business }\end{array}$ \\
\hline
\end{tabular}

\subsubsection{Financial aspects}

The results confirm previous research (see, e.g., Ehrenfeld and Gertler, I997; Walls and Paquin, 20I5) as they show that financial aspects appear to be the most important, and both a driver and barrier (Papers I, 2, 3 and 5) for development of interorganisational collaborations between normally unrelated actors. All respondents' perceptions were that both parties involved in collaboration must have potential financial gains in order to be willing to enter collaboration. For the realised cases, collaboration would never have taken place if it had not been financially viable for both parties (see Papers I, 2, 3, and 5). For actors demanding heat, the potential financial benefits of excess heat collaborations consisted of access to cheaper heat, since excess heat is normally less expensive than primary energy. For actors providing heat, the financial benefits constitute potential financial returns for a product considered a waste product. Yet, even though excess heat is waste for the actors providing it, it is a valuable resource for energy companies and should therefore be priced accordingly, allowing both parties to gain financially (see Paper I).

The risks related to the financial aspects concerning long repayment periods described by Chertow (2007) were something also highlighted by the actors involved in the cases investigated within this thesis. One aspect that became clear during the interviews was 
that it was not given how the investment costs should be allocated between the collaborating actors. A general measure was that the financial risks and investments made should reflect the potential benefits of the collaboration (see Papers I and 5); this meant that the actor investing a greater share also got a greater share of the potential financial return

The industries providing excess heat from the existing cases were initially concerned about the breakdown of investment costs related to the technical equipment, which was needed to supply their excess heat (see Paper I). In one of the cases, an industry respondent expressed that since providing heat was not part of their core business, they were initially not interested in investing. As a result of increased production, the industrial partner in another case was faced with significant investment costs in the beginning of the collaboration, as the industry needed to invest in a solution for cooling their increased amount of excess heat. Therefore, in this case, it appeared beneficial to share most of the investment costs. Most of the industry respondents, representing both existing and potential collaborations, believed that securing long term-financial investments in excess heat utilisation collaboration should be relatively easy. The problem, however, related to the traditional investment calculations and did not appear to apply to these types of long-term investments with long repayment periods.

One observation made in Papers I,2,3 and 5 was that the existing excess heat utilisation cases had been awarded national investment grants in conjunction with the early development of collaboration. All respondents believed that the investment grant they were awarded contributed to the project's relatively fast progress. According to one respondent representing one of the energy companies (see Paper I), the grant also contributed to expansion of the district heating grid. Other respondents believed that the investment grant inspired confidence in investing and expanding the district heating system to a greater extent than they perhaps would have done otherwise, and that investment grants often help persuade politicians to realise projects. The results from Paper 4 showed that energy companies required predetermined financial revenue from a sufficient number of heat customers corresponding to the investment costs before they were willing to invest in the construction of new district heating systems, or in the expansion of existing grids. Regardless of the ownership of the energy company, the investment had to be financially justifiable for the energy company to expand its operations. The studied excess heat collaborations have led to better financial conditions for the energy companies compared to what they would have had using primary energy (see Papers I and 5). Another perceived benefit was that all parties involved promoted the collaboration on excess heat utilisation as a good environmental investment and thus gained market advantages, in terms of increased number of costumer connections, over other competitors at the heating market (see Paper I). In one of the realised cases (see Paper I), a positive development was that the district heating grid was expanded to serve a community located about six kilometres south of the original grid. In another realised case (see Paper I), an assessment made by the local authority showed that the project had led to clearer environmental measures within the region. In that same case, the number of connections to the district heating grid increased more than expected.

According to Chertow (2007) and Ehrenfeld and Gertler (1997), the timing of development of interorganisational collaborations is of great importance. One financial aspect effected by the timing is the current energy prices. An energy market based on fossil fuels, is more beneficial for excess heat utilisation. One significant challenge today 
is that the energy market in Sweden is currently based on comparably green and cheap energy, meaning decreased potential financial gains compared to initial high energy prices. The current high use of renewables and biofuels also entails less improved environmental performance in comparison with a conversion from fossil fuels to excess heat. In terms of drivers and barriers, the current use of comparably green and cheap energy can be seen as weakened financial and environmental drivers for actors with the potential of developing interorganisational collaborations on excess heat.

\subsubsection{Technical aspects}

Technical conditions served as both important drivers and barriers behind excess heat utilisation collaborations (Table 5). For the potential cases, the main technical barrier was identified as the absence of a nearby existing district heating grid; the industries highlighting this as a problem were all located outside urban areas. Even though access to an existing district heating grid was described as an important driver, this does not necessarily mean that collaborations develop (Gibbs, 2003; Chertow, 2007; Gibbs and Deutz, 2007). In contrast, Paper I provided an example of a collaboration on excess heat between a paper mill and an energy company, which developed the other way around. In this case, the supply of excess heat from the mill resulted in the development of a new district heating grid.

Other technical conditions - such as a reasonable distance between the supply and the demand of excess heat, sufficiently high temperatures and the availability of technical solutions - were also examples of conditions serving as both drivers and barriers (see Table 5). A lack of knowledge of the amount of produced excess heat was yet another technical barrier preventing heat supply collaborations.

The fact that Sweden is a country with large variations in seasonal temperatures resulting in a varying heat demand throughout the year - was described as another problem that complicated collaboration between excess heat providers and the district heating sector. This is because excess heat is a by-product of industrial production, which is normally not affected by variations in seasonal temperatures but by demand for the products produced.

In relation to the problem described above, some of the respondents representing facilities for food cultivation processes, such as greenhouses demanding low-grade excess, have experienced problems with deliveries of heat via traditional district heating systems. Greenhouses were described as challenging customers for energy companies, as their rapid fluctuations (the heat demand is drastically affected by sunshine, clouds or rain) of large heat demand quantities affect the entire district heating system. One of the respondents representing a greenhouse (see Paper 3) argued that rapid fluctuations of heat demand often demand interlayer, day-to-day storage or long-term stocks in order to smoothen the varying heat demand from the providers' perspective. The technical issue concerning interlayer to enable heat storage was also described as a financial matter - the storage requires financial investments, which in turn requires cheap heat in order to motivate the investments made to enable storage. Cheaper, low-grade excess heat would therefore be preferable to use for applications of different food cultivation processes not necessarily in need of high-grade excess heat (see Paper 5).

Less densely built areas outside city centres, without existing systems of district heating and a combination of a low demand for heat and large unutilised heat sources associated 
with, for example, industrial activities and/or facilities generating low-grade excess heat, are well-suited for large-scale food production in the form of greenhouse crops (Swedish University of Agricultural Sciences, 20I2; Walls and Paquin, 2015). This could be an example of when separate solutions not connected to existing district heating infrastructure for distribution are preferable (Swedish University of Agricultural Sciences, 20I2; Walls and Paquin, 20I5; David et al., 2015). Yet, the location of different food cultivation facilities affects the competitiveness of the cultivators in terms of transport possibilities, since extensive transportation is both more expensive and timeconsuming.

\subsubsection{Environmental aspects}

Improved environmental performance was also described as a driving force, yet not as strong as the financial aspects. Results from Papers I and 5 showed that as long as collaborations did not involve financial losses there may be factors such as environmental considerations, environmental profiling, and energy strategies, other than those of a financial nature, which ultimately determined whether actors decided to enter collaborations on excess heat (see Table 5). In line with previous research (see, e.g., Domenech and Davies, 2009; Chertow, 2007; 2000), the results show that the financial and environmental factors are related as the studied cases resulted in both improved financial and environmental performance for all actors involved.

\subsubsection{Organisational aspects}

The compiled results from the appended papers provided a quite consistent image of the main reasons behind the large unutilised potential of excess heat. One important reason for this was the fact that excess heat utilisation requires interorganisational collaboration across individual business boundaries (see, e.g., Uzzi, 1996; 1997; Baas and Boons, 2004; Chertow, 2007). Results, mainly from Papers I and 5, showed that organisational conditions such as humility, honesty, transparency, trust, fine-grained information transfer, joint problem solving, and shared visions concerning common goals were important for collaborations to overcome technical and financial barriers. These features led to greater efficiency as well as environmental and financial gains for the companies involved and for society - outcomes previously also highlighted by, e.g., Uzzi (1996; 1997); Deutz and Gibbs (2008); Doménech and Davies (2009).

Personal relationships in business collaborations are an aspect recognised to be important (Baas and Boons, 2004; Doménech and Davies, 20II). Nevertheless, there was a difference in the respondents' perceptions of the importance of organisational aspects. Actors with experiences of initiating and developing collaborations on excess heat tended to have a greater understanding of the importance of continuous and clear communication across their business' boundaries. All actors in the existing cases mentioned the importance of organisational conditions. Some felt that transparency and openness contributed to a greater consensus for matters concerning the collaboration as well as better understanding of each other's different businesses. As noted by the respondents, establishing personal contacts and relationships requires communication and sharing of information - a time-consuming undertaking. Some respondents believed that personal contacts with someone from the other organisation within the collaboration could provide insight, generating access to informal information leading to a greater understanding of each other's activities. This is held to be especially important, since one of the main difficulties related to interorganisational collaborations was described as being a lack of understanding and knowledge of each other's different 
activities (see Paper I). This was further explained as a cause of a lack of trust and communication between the involved actors.

Communication built on trust and honesty is an important condition in decision-making processes for joint collaboration projects. The reason for this is to understand the common goals and objectives and to translate them into practice (Albrechts, 2006). Further, Chertow (2007) believes that the typical barriers often are business related, meaning difficulties in initiating the fundamental business agreement, which is supposed to be formulated based on the common goals and objectives of the collaboration.

In line with Uzzi (1996; 1997), the results from Papers I and 5 also showed that it has been of importance for the parties involved in a collaboration to show humility from the outset so that all parties involved felt equally important to the success of the project. Humility appeared to be especially important for companies involved in collaborations outside their core businesses, in these cases meaning not normally related to heating issues. Chertow, (2000) noted that private actors in particular seem to have greater difficulties in understanding company's specific benefits. Papers I, 2, 3 and 5 showed that initially, there were often signs of unwillingness to enter excess heat collaborations from the industry's side, since heat does not belong to the core business of traditional industries (see also Chertow, 2000). The reluctance normally consisted of fear that the core business would be disturbed. The results from the studies of existing cases showed that personal relationships sometimes helped in overcoming issues like the one described above.

Actors in the potential cases without ongoing collaborations did not recognise the importance of organisational aspects in the same way. Perhaps this is due to the character of these aspects, which could be described as "soft" aspects of humility and trust, difficult to quantify in relation to the "hard" aspects of financial and technical character, which can be easily quantified. There is a general tradition of "hard" aspects being emphasised as more important than "soft" ones (Berglund, 2002). This might be due to the "soft" aspects appearing more abstract, and thus more difficult to understand since they are not measurable in the same way as the "hard" ones. The different perceptions about the importance of certain organisational aspects could be seen as an indication that the importance of them is difficult to understand before they are experienced.

At the time of the interviews, all industries representing potential excess heat collaboration cases had recently investigated their ability to supply excess heat (see Paper I). How thoroughly the possibilities were examined, however, differed significantly. In about half of the cases, the initiative originated from top management, while for the other half, the question was a bottom-up initiative. In some cases, the industries had experienced resistance from energy companies (see Paper 2). For example, Paper 3 showed an example where the reluctance was derived from an energy company. In this specific case, there was an oil refinery with large amounts of high-grade excess heat approaching the local energy company, which at that time faced an expansive phase and hence was in need of heat. Despite the good financial and technical conditions for utilising the excess heat in the district heating grid, for both the oil refinery and the energy company, the energy company instead built a separate combustion plant. The reason for this was explained to be that the energy company wanted full control over production and deliveries, and did not want to be dependent on the activities of another actor. 


\subsection{Important key elements of interorganisational business models}

Business agreements between collaborative actors across traditional business boundaries have been shown to constitute the foundation of collaboration (see Papers I and 5). Respondents representing both existing and potential collaborations describe clear business agreements that both parties agree on as important for development of long-term durable excess-heat collaborations. Clear business agreements are described as defining how different financial and technical commitments aims to be adopted and allocated among the collaborative parties (see Paper I).

By jointly developing business agreements, the risks concerning misunderstandings and passiveness can be prevented (Zott et al., 20II; Bertels et al, 20I5). This early interaction and developments of common goals and objectives entails knowledge transfer, something previously argued to facilitate the creation of mutual understanding, which in turn creates trust (Uzzi, 1996; 1997). Collaborative business agreements on equal terms for increased value also tended to create humility amongst the collaborative actors towards each other's different business activities (see Paper I). Humility has proved to increase the creation of honesty and further trust, which was necessary in order for the collaborative actors to be transparent. These conditions, which characterise collaborations based on embedded relationships (see Papers I and 5) (Uzzi, 1997), also increased the conditions of joint problem solving. Paper I provided an example of this. The study of two existing excess heat collaborations consisted of spontaneously developed collaborations, which are held to be more functional, long-term and durable than planned attempts to create interorganisational collaborations (see, e.g., Chertow, 2007; Gibbs and Deutz, 2007; Baas, 20II; Ashton and Bain, 20I2; Hein et al, 20I5). Despite the fact that the development of the two studied cases differed, there were many similarities in terms of perceived drivers and barriers behind them. In one of the cases, the collaborating parties developed common goals and a clear vision from an early stage, which resulted in the early creation of trust the collaboration developing more quickly. In the other case, the energy company had a clear vision of a desirable outcome, which resulted in them taking a proactive role in forwarding the development. The result of the proactive role of the energy company was that the industry felt left out, and was not persuaded to enter collaboration on excess heat together with the energy company. This led to the process having to start all over for a second time. When the industry finally became involved in the development of the goals, trust was created. The trust led to a greater transparency, contacts were initiated and information was exchanged, which in turn resulted in collaboration finally taking off. These cases provided examples of collaborations which included the financial, technical and organisational conditions highlighted as important behind development of interorganisational collaborations (see Papers I, 2, 3 and 5).

Business models characterised by widened system boundaries beyond the traditional business boundaries of single businesses can be helpful to visualise and clarify roles and determine how to allocate risks, costs and financial returns associated with collaboration (Şenlier and Albayrak, 20II). Such business models can provide a more holistic view of how companies can work together to create greater value through interaction with the surrounding environment. Interorganisational collaborations in line with industrial symbiosis activities on none-core businesses are facilitated by business models that take interaction between companies into account (Zott et al., 20II; Tsvetkova and Gustafsson (2012); Zott and Amit (2008); Bertels et al. (2015); Boons and Lüdeke-Freund (2013). 
A broader understanding of interorganisational collaborations in line with industrial symbiosis activities is provided in studies that combine symbiotic activities and business models as a financially-related expression (Short et al., 20I4). The study presented by Short et al. (2014) shows, similar to Paper I, that interorganisational collaborations can be applied in business model evolutions. Symbiotic exchanges - for example, exchanges of excess heat - are most potent for business model innovation when they go to the core of the business model (Short et al., 20I4). This means introducing changes in the value proposition (new coproducts and new customers) and value creation system (new resources and activities, including technology, production processes, and relationships), as well as creating new sources of value capture for the firm (new revenue streams). The new opportunities for value creation in applying a business model perspective on industrial symbiotic activities such as excess heat utilisation also implies enhanced positive environmental outcomes. This is because the combined perspectives allow a broadened uptake of industrial symbiotic activities, which could accelerate sustainability initiatives by bringing a stronger business development focus (Short et al., 20I4).

\subsubsection{Implications of applying the IPSO approach in order to facilitate utilisation of excess heat}

The identified implications of applying an IPSO approach on interorganisational collaborations on excess heat reveal a number of different potential opportunities and challenges (see Papers 2 and 3). The approach has the potential to improve efficiency, which can lead to positive environmental and financial effects for both the companies involved in collaboration and for society at large (Mont et al., 2006).

Broadly, the heat-related services provided by an IPSO provider could consist of offerings that bridge the gap between providers and users of excess heat, and that deal with the practical issues related to collaboration. The potential services an IPSO provider would provide are the I) mapping of supplies and demand, initiating collaboration; 2) provision of knowledge related to the distribution of excess heat; and 3) provision of business agreements. All these issues are connected to the main barriers behind development of excess heat supply collaborations (see Papers I, 2, 3, and 5). The IPSO, however, would differ depending on the prevailing conditions. For example, the IPSO could differ between urban areas, with the constant supply and demand of heat from multiple stakeholders - and from more sparsely populated areas, in which both the supply and the demand for heat is less. The general consensus among the respondents from Papers 2, 3 and 5 was that the involvement of a third-party could have a potential positive impact, in particular to coordinate and initiate collaborations. However, the perception of how the IPSO provider would operate and the effects it would have differed between the respondents in the different cases, given their different prevailing conditions concerning the supply and demand of excess heat.

In order to simplify the analysis of the results from Papers 2 and 3, the different excess heat collaborations have been divided into different explanatory case types. The overall objective behind typologies is to classify heterogeneous quantities into relatively homogenous groups (Manuela Rozalia, 2009). Typology classifications are normally made based on a series of variables or interdependent relations. For this thesis, prospective cases in urban areas with a number of providers and users, as well as an energy company with the knowledge and existing infrastructure system required for distributing heat, have been categorised as Type I. Prospective cases outside urban areas, 
without the involvement of an energy company and the infrastructure of district heating, have been categorised as Type 2. The classifications of the two types of cases have been based on the type of collaborative actors (with or without the involvement of energy companies), quantity of the excess heat (large or small quantities), quality of the excess heat (high or low-grade), and localisation (urban or rural areas). The typology contributed valuable findings, despite the fact that all cases related to the two case types to varying degrees, and that there were cases in between the two categorisations. The categorisation was used to illustrate two contrasting extremes in order to highlight differences and to enable a generalisation of different conditions, which is an important scientific contribution in the context of studies involving different cases (cf. Manuela Rozalia, 2009).

An important condition to facilitate the conditions of excess heat utilisation that were equally independent of the prevailing technical conditions - differing Type I and Type 2 cases - was the knowledge of the product (which is excess heat), the service (consisting of the distribution of the heat), and how to integrate them to increase the value of the service for the customers.

Table 6. Possible opportunities and challenges of involving a third-party IPSO provider (Paper 3).

\begin{tabular}{|c|c|c|}
\hline$\overline{\text { Type I }}$ & Possible opportunities & Possible challenges \\
\hline & $\begin{array}{ll}\text { - } & \text { Neutral third-party (provider) } \\
\text { - } & \text { Increased willingness to enter collaboration } \\
\text { - } & \text { Decrovider) } \\
\text { - } & \text { Financial profit (provider/user) } \\
\text { - } & \text { Positive environmental impact (provider/user) } \\
\text { - } & \text { Marketing opportunities (provider/user) } \\
\text { - } & \begin{array}{l}\text { Increased excess heat collaborations } \\
\text { (provider/user) }\end{array}\end{array}$ & $\begin{array}{l}\text { - An additional party to take into account } \\
\text { (user) } \\
\text { - } \quad \text { Disruption of the core business (provider) } \\
\text { - } \quad \text { Claims a share of the profit (provider/user) }\end{array}$ \\
\hline Type 2 & Possible opportunities & Possible challenges \\
\hline & $\begin{array}{ll}\text { - } & \begin{array}{l}\text { Neutral third-party with knowledge } \\
\text { (provider/user) }\end{array} \\
\text { - } & \text { Facilitates collaboration (provider/user) } \\
\text { - } & \text { Decreased workload (provider/user) } \\
\text { - } & \text { Financial profit (provider/user) } \\
\text { - } & \text { Positive environmental impact (provider/user) } \\
\text { - } & \text { Marketing opportunities (provider/user) } \\
\text { - } & \text { Increased excess heat collaborations } \\
\text { (provider/user) }\end{array}$ & $\begin{array}{l}\text { - An additional party to take into account } \\
\text { (provider/ user) } \\
\text { - } \\
\text { Disruption of the core business (provider) } \\
\text { user) } \\
\text { - Claims a share of the profit (provider/user) } \\
\begin{array}{l}\text { Difficulties linked to the creation of } \\
\text { knowledge and understanding required } \\
\text { (provider/user) }\end{array}\end{array}$ \\
\hline
\end{tabular}

For the investigated cases categorised as Type I, including an energy company with the experience, knowledge and infrastructure required to distribute excess heat, the energy company could constitute the IPSO provider, meaning that the involvement of a thirdparty might not be necessary. For prospective Type 2 cases on, for example, food production, it is likely that there is only one provider and one or maybe two users of the excess heat. If the heat source, consisting of some sort of industrial activity, is located outside an urbanised area, it is not certain that there is any existing distribution system for the excess heat. For cases like these, where energy companies do not constitute one of the collaborating actors, the results showed that there was often a lack of knowledge concerning heat-related issues (see Papers 2 and 3). This makes a third-party IPSO provider particularly important as a knowledge broker of such collaborations. For Type 2 cases, a third-party IPSO provider could serve as a promoter of collaborations as it 
enters from the outside to create a service offering based on the providers' and the users' needs, which also is the main opportunity identified by the respondents (see Papers 2, 3 and 5). In cases lacking a distribution system, part of the third-party IPSO providers' task would be contributing with knowledge in developing such an infrastructure. Innovative solutions as such could be seen as a result of the increased value of applying the IPSO approach (see, e.g., Brady et al., 2005), as IPSOs have proven to often serve as a driver for technology development (Lindahl et al., 2006). The business agreement developed by the IPSO provider could specify the allocation of the cost. A third-party IPSO provider can be considered neutral in the sense that it does not take sides with any of the two initial parties. However, in financial terms the IPSO provider is driven by the occurrence of excess heat collaborations, gaining a share of the financial returns.

In parallel to the results which showed a reluctance, particularly from the excess heat providers' side, to enter collaborations outside their core business, a previous study by Zander et al. (20I6) shows that there is a greater willingness to share information among actors involved in collaborations outside their core business because it does not concern the core competence of the business. In line with the cases in this thesis (see Papers I, 2, 3 and 5), the shared investments associated with the collaborations studied by Zander et al. (2016) were only considering none-core businesses. Based on this, a third-party IPSO provider with a core business of developing business collaborations on excess heat could help in overcoming the difficulties concerning the reluctance of entering collaborations. The results indicated the core business issue as especially important for collaborations where both participating actors lack heat-related issues as part of their core business. Other opportunities mentioned as potential gains of an IPSO provider are potential marketing, financial and environmental opportunities, both for the actors involved and for society at large (Mont et al., 2006; Domenech and Davies, 20II).

The main challenges associated with applying a third-party IPSO provider related to the decreased potential financial returns for the initial (providing and using) actors within the collaboration, due to that a share of the financial return would cover the costs for the IPSO provider (see Papers 2 and 3). Another potential challenge noticed during the interviews conducted for Papers 2, and 3 is associated with potential difficulties for the IPSO provider to gain a deeper understanding of both actors' activities required for the collaboration to be successful. As mentioned in Chapter 3.3, implementation of IPSOs is also associated with difficulties related to organisational changes of the companies applying the IPSOs (Lingegård and Lindahl, 20I5). Yet, since IPSOs in these cases would be applied on new business collaborations without existing organisational structures, the difficulties related to organisational changes would not be as pronounced. Besides, the challenges of entering collaborations on excess heat could be outweighed by the potential opportunities of involving an IPSO provider (see Papers 2, 3 and 5). Reduced workload, related to the findings of Walls and Paquin (2015), and a neutral third-party with knowledge of heat distribution and how to develop business agreements that consider the interests from both the supply and demand side are factors highlighted as potential opportunities (see Papers 2 and 3 ).

One of the cases investigated in Papers 2 and 3 provided services in line with IPSOs. This particular case was an energy company that offers anyone with an excess of heat the opportunity to sell and deliver heat on its district heating grid. In IPSO terms, the energy company in this case constitutes the IPSO provider without being a third-party. The project, called open district heating, was based on an open business model where actors 
provide excess heat into the district heating system at a fixed price. In line with the IPSO approach (see cf. Olivia and Kallenberg, 2003; Mont, 2008; Lelah et al., 20II; Lindahl, et al., 20I4), the project had a shifted focus from heat production - which normally is the heart of an energy company's business - to the service of distributing heat. According to the criteria of the typology, this particular case can be categorised as a Type i case.

The example described above constituted a collaboration involving an energy company based in an urban area with several providers of excess heat and with a high demand for heat. For rural areas without the same conditions, this example would not be applicable. For this example, the energy company provided services similar to the ones identified as necessary by an IPSO provider, yet since the energy company constituted one of the initial actors it was not neutral in the same sense that a third-party would be. The energy company described above did manage to map the supply and demand relatively easily due to the large flows of supply and the high demand that exist in urban areas. Still, this innovative way of conducting business on excess heat-based district heating indicated a driven engagement within the company organisations of the energy company.

Despite the often more beneficial conditions concerning knowledge, resources, existing distribution infrastructure and supply and demand of excess heat that the involvement of an energy company in urban areas often brings, the potential benefits of bringing a third neutral party has also been shown to be desirable for some cases involving energy companies (see Table 6). The perceived potential opportunities are mainly highlighted by actors providing excess heat and concern the IPSO providers' task of taking the providers' needs into consideration (Walls and Paquin, 20I5). This is especially vital for cases lacking the previously highlighted important organisational conditions (see, e.g., Gibbs, 2003; Baas and Boons, 2004; Chertow, 2007; Gibbs and Deutz, 2007). In cases like these, a neutral party could possibly increase the building of trust by communicating both parties' different views and interests (Walls and Paquin, 20I5) - a condition that could increase the willingness to enter collaboration among these actors.

Another example of a company providing services in line with IPSOs is the Swedish enterprise Bizcat (Bizcat, 20I7). Bizcat provide services in the initial phases of district energy projects. They provide district energy planning, pre-feasibility and feasibility studies including technical, financial and business solutions. Their business idea constitutes coordination of ready propositions for their costumers to invest in, meaning conducting the planning before the actual implementation. This way of providing services separates Bizcat from the previous example as Bizcat enter collaborations as a third-party. The business idea could be applied to Type 2 cases, without the involvement of energy companies, in order to map supply and demand and to initiate collaboration, provide knowledge related to the distribution of excess heat and provide knowledge on how to formulate business agreements.

Given these identified tasks of an IPSO provider for increased utilisation of excess heat, some of the tasks could be suitable for energy companies, while others seem to be more related to local authorities. Energy companies have the technical skills concerning knowledge of how to distribute heat, while local authorities within the municipal organisations have a more holistic view and a greater mandate - through, for example the plan monopoly (National Board of Housing, Building and Planning, 2015) - and resources to act as promoters by mapping resources and demand. Another aspect that speaks for better suitability of local authorities is related to difficulties gaining financial 
returns. Regardless of whether energy companies are municipally or privately owned, they always have requirements for financial returns, long or short-term, of their investments. Local authorities do not have that same requirement, especially not in the short term, since they are supposed to have a wider system view taking benefits of the larger society into account (Horváth and Harazin, 20I6). Yet, even though local authorities are considered to have an important role they do not have the mandate to act operatively. This is because the divisions responsible for development of energy system infrastructures have gone from being controlled by units within the local authorities, and later as municipally owned energy companies on a break-even cost price basis, to private actors. This development towards privatisation has, as earlier mentioned, resulted in decreased municipal influence (see SOU, 2005; Pädam et al., 2013). Energy companies do, on the other hand, have a wider freedom to act as operational business promoters. Given the discussion above, it is not clear who would be most suitable as an IPSO provider of excess heat utilisation. Yet, it is clear that the IPSO provider needs to be flexible in order to provide IPSO solutions suitable for different cases involving different types of actors with different prevailing financial, technical and organisational conditions.

\subsection{Implications of applying strategic spatial planning in the Swedish spatial planning process to facilitate the utilisation of excess heat}

Local authorities' ability to directly influence spatial development through spatial planning has been reduced from a historically strong influence during the time of the implementation of the million public housing program during the years 1965-1974. This time period is argued to be when the planning monopoly reached peak power (Blücher 2006; Lind, 2002). The incremental weakening of the municipal plan monopoly since then is the main reason for local authorities' decreased direct influence. The latest example is the new law on guidelines for municipal land allocation from 2015 (SFS 20I4:900), which caused decreased opportunities for local authorities to directly influence the conditions for district heating. Considering development of district heating, the opportunities for local authorities to influence have been directly affected by the privatisation of energy companies and developers, as a direct consequence of the deregulation of the electricity market in the I990s (SOU, 2005; Pädam et al., 20I3).

Yet, even though the conditions have changed, the results from Papers 4 and 5 showed that local authorities - within the framework of the participatory mechanisms of the municipal spatial planning - still have opportunities to facilitate further development of district heating and excess heat utilisation. This is mainly due to the PBA (SFS I987:IO), implemented in 1987, which contained extended requirements for strategic spatial planning processes. Stakeholder participation was emphasised as parts of the planning process - a requirement which was further strengthened by the current PBA (SFS 20I0:900), introduced in 20II. Strategic spatial planning processes should focus on framing decisions, actions, projects, results, and implementation (Gibelli, 2003). Applied to Swedish municipal spatial planning practice and planning for the expanded utilisation of excess heat in particular, this requires involvement and knowledge sharing from several societal actors, including actors demanding excess heat and potential providers of excess heat. Broad stakeholder participation is required in order to create well-informed decisions about actions and projects and to reach broad-anchored strategies among politicians, external relevant stakeholders, and the wider community. Broad-anchored strategies are important conditions for substantiated implementation to 
be realised (Bryson et al., 20I5; Börjeson et al., 2006).

Strategic and farsighted comprehensive planning as a tool to regulate the design of built environments is desirable in order to avoid using primary energy where there are already existing sources of excess heat. The process of keeping the comprehensive plans up to date were described as ongoing (see Paper 5). Changes were continually made through specifications of chosen areas. These continuous changes were described as consequences of a growing need to expand and exploit areas covered by the comprehensive plan. In some of the investigated cases, energy companies were involved in dialogues concerning these plans, in others not. Initiatives of exploitation were most often derived from either local authorities or from developers approaching the local authority with suggestions on areas for exploitation (see Papers 4 and 5).

From a utilisation perspective, potential providers and users of excess heat should preferably participate in the planning process during the comprehensive planning by providing input on how to conduct planning to facilitate utilisation. Certain areas in close proximity to existing facilities generating excess heat could, for example, be earmarked for residential areas or for food production, depending on the amount of supply and whether the excess heat is low or high-grade (see Paper 5). Strategic comprehensive planning processes could also be about coordinating new sources of supply and demand. Yet, one aspect highlighted as a problem related to the input of supply and demand of excess heat at the comprehensive planning level is the farsighted planning characterising comprehensive planning - it can be difficult to predict future supply and demand in advance (see Paper 5).

Developing plan programs is another way to initiate earlier stakeholder participation. As mentioned in the background chapter, plan programs are not compulsory. It is, however, preferable to develop plan programs for planning processes involving many stakeholders and opposing interests (proposition 2009/IO:I70). The plan program was not mentioned as a step in the planning process by any of the respondents representing municipal spatial planners, energy companies or climate and energy advisors in Paper 4 . The results from Paper 5 provided a similar picture - plan programs were usually not developed. According to the spatial planners within Paper 5 , the main reason for this was time pressure as a result of the political agenda, which normally consists of a desire to quickly exploit in order to create economic growth. Stakeholder participation in general creates complex processes that are both resource and time consuming (Khakee, 2000; Pacione, 20I4). Problems related to political goals that contradict industrial symbiotic activities are previously highlighted by others (see, e.g., Fichtner et al., 2005). Fichtner et al. (2005) further describe resistance as a result of increased workload, and time pressure as another barrier related to symbiotic activities.

The consequence of not implementing plan programs is that an important opportunity for energy companies, other actors demanding heat or potential providers to influence the detailed development plan is lost. According to Mäntysalo (200o), spatial change depends on skilled planning, politically legitimate decision making, and the realisation of stated goals. A multidimensional approach is required because of the subsystems of expertise, where politics and economics are linked. The plan program would entail opportunities for potential providers and users of excess heat to participate in the planning process. Besides, local authorities have a unique position in using the plan program to establish contacts with and between relevant external stakeholders. The 
interaction it brings would in turn stimulate communication and collaboration earlier in the process (cf. Von Malmborg, 2004). Plan programs could contribute to that stakeholder knowledge would be exploited earlier in the process.

According to the results (see Papers 4 and 5), the conditions for excess heat-based district heating in planned areas were mainly based on the outcomes of the detailed development planning - and only indirectly decided through the comprehensive planning. In the detailed development planning processes, the local authority spatial planners contacted external relevant stakeholders, including energy companies, for consultation regarding the draft of the detailed development plan. Actors with an excess of heat were not contacted at this stage.

The analysed results (see Paper 4) showed that the contacted stakeholders only had the opportunity to influence the first draft of the detailed development plan once all decisions, in principle, were already made. The energy companies' only task as remittance bodies was to determine the profitability of district heating in the planned areas. The respondents representing energy companies all expressed that they found it difficult influencing the detailed development plans in ways to facilitate the conditions for district heating at this stage of the planning process. A majority of the respondents from the energy companies (see Papers 4 and 5) felt they had a limited influence regarding the location of planned areas, which is something that is especially difficult to change late in the planning process. The fact that potential providers of excess heat were not included at all implies lost opportunities for gaining knowledge about existing supplies of excess heat, which in turn leads to lost opportunities to facilitate the conditions for excess heat utilisation. This suggests that the planning processes concerning the detailed development plans were not based on the interaction and exchange of knowledge - which are held to be important aspects in the decision-making process of strategic planning (see, e.g., Friedmann, 2004; Albrechts, 20I3; Healey 2009; Tewdwr-Jones, et al., 20IO; Albrechts and Balducci, 20I3; Hillier, 2013; Kunzmann, 20I3; Mazza, 2013). A consequence of the late involvement was the lost opportunity for the spatial planners to gain expert knowledge in order to make informed decisions. This way of conducting spatial planning means that important knowledge from relevant societal stakeholders risks getting lost.

Addressing issues related to the utilisation of excess heat within the municipal spatial planning of new areas requires an understanding, among all participants, of the practical meaning of the goals and objectives (Ivner et al., 20IO). These goals and objectives need to be accepted as legitimate by the involved actors. They also need to have broad support in the community (Jersenius and Smideman, 1995). According to Innes and Booher (2004), a structure built on interactions among stakeholders, reflecting the diversity of the local society, is necessary. Acceptance and action on the part of private actors is important when implementing plans (Ling et al., 2002; Rydén, 2006). The acceptance has proved to be affected by to which extent external relevant societal stakeholders are involved in the development of the plans. Involvement further entails opportunities to learn about potential problems and benefits associated with the plan under consideration (Ivner et al., 20IO).

The results of the studied planning processes within the framework of this thesis revealed less linear processes compared to how it is described in the PBA. The stakeholder participation was not as widespread, which in turn led to less influence from 
the local authorities. This can be considered a problem given that local authorities, through their overall functions regarding planning of municipal spatial development, constitute important key actors in the adoption and implementation of local energy and climate strategies (Fenton et al., 20I4). Based on this, it can be concluded that planning processes with a broad and early participation of different societal stakeholders are important for the formulation, understanding, acceptance and fulfilment of goals and objectives. Albrechts (2006) argues that the participation of different societal stakeholders provides the knowledge required to both understand the goals and objectives and to put them into practice. Applying this on the results from Papers 4 and 5 , it can be concluded that the current spatial planning processes in the investigated municipalities need to apply earlier and broader participation of societal stakeholders in order to create opportunities for knowledge to be exchanged in the creation of shared visions of common goals and objectives. This, however, requires political anchoring (see Paper 5).

The historical development of district heating is a clear example of the importance of political anchoring in order for an issue to have an impact. As mentioned, before the development towards privatisation, from 1965 until I974, local authorities had the most power and financial resources. The fact that district heating was a politically prioritised issue that impacted the spatial planning made the major expansion of district heating possible (Magnusson, 2013).

Learning from past experiences related to the importance of politically-anchored policies reaching impact on excess heat utilisation, there are indications that the utilisation of excess heat has begun to become a politically prioritised issue. One example is the measures suggested by the Ministry of Enterprise, Energy and Communications, in connection with the latest TPA investigation in 20II. These measures concerning accountings of potential excess heat utilisation during the planning of new district heating systems and regulated system access for potential excess heat providers (Ministry of Enterprise, Energy and Communications, 2012) could potentially highlight existing supplies of excess heat in an efficient manner. The revision of the Climate Step, which partly aimed to further increase the support of facilitating measures for excess heat utilisation (SFS 2017:815), is another example.

The results from Papers 4 and 5 do, however, show that these relatively new political initiatives for increased utilisation have not yet begun to have an impact on the municipal spatial planning. The measures suggested by the Ministry of Enterprise, Energy and Communications do not seem to be implemented properly in the municipal spatial planning. The reintroduced financial investment grants are, to some extent, an important driver behind development of excess heat collaborations (see Paper I). Nevertheless, collaborations between normally unrelated actors providing and using excess heat require the previously highlighted organisational conditions - trust, finegrained information transfer, joint problem solving, honesty, and shared visions of common goals - in order to develop into functional and long-term, durable collaborations (see Paper I).

The results from Papers 4 and 5 showed that enhanced strategic municipal spatial planning processes with a greater focus on broad stakeholder participation have the possibility of providing a facilitating forum in the creation of the highlighted organisationally important conditions between providers and users of excess heat. The 
interaction that stakeholder participation entails has proved to often create contacts between the participating actors (Von Malmborg, 2004; Vedung 2006). These contacts, in turn, could be a catalyst for new collaborations on excess heat supply (see Paper 5).

Excess heat utilisation, however, has been shown to be a current non-existing issue within the spatial planning (see Papers 4 and 5). This is probably because excess heat utilisation is a relatively new political issue that has not yet impacted the planning practice. Besides, other political interests related to fast exploitation processes often conflict with more time-consuming strategic planning processes (see Paper 5). Exploitation is highly desirable because of the increased opportunities of employment and immigration - creating economic growth - it entails. Since the initiative of exploitation often comes from developers approaching the local authority with suggestions on areas for exploitation, there have been indications that the political will of exploitation sometimes conflicts other interests in terms of environmental goals (see Paper 5).

Increased utilisation of excess heat requires political legitimacy that impact the spatial planning processes (see Paper 5). Strategic spatial planning processes led by the public and developed though the interaction of societal stakeholders is required for the goals and objectives of the planning to be anchored amongst the increasingly larger shares of private stakeholders influencing the outcome of planning.

There are, however, recognised challenges concerning the increased complexity of broad stakeholder participation (Khakee, 2000; Pacione, 20I4). Many different interests to consider tend to create more time and resource-consuming planning processes as a consequence of conflicts of interest. Besides, strategically-framed decisions, actions, projects, results and implementation also require monitoring, feedback, adjustment, and revision, both in the short and long term (Bryson and Roering, 1988; Faludi and Korthals Altes, 1994; Mintzberg, 1994; Bryson, 1995; Poister and Streib, 1999; Gibelli, 2003; Bryson et al, 2015). 


\section{CONCLUSIONS AND IMPLICATIONS}

This chapter starts with a presentation of the main conclusions regarding answering the research questions (6.I - 6.3). This is followed by a reflection on the theoretical contribution (6.4) of the thesis. Finally, proposed practical suggestions for increased excess heat utilisation are presented (6.5). 


\subsection{Main drivers and barriers behind the development of interorganisational collaborations on excess heat utilisation}

The compiled and analysed results show that potential financial gains are the most important drivers behind collaborations on excess heat utilisation. Additional financial and technical conditions, such as investment capital and a supply of excess heat matching the demand, are examples of other important drivers.

Utilisation of excess heat can be seen as a way to overcome some of the problems related to the financial obstacles facing the declining district heating market. This is because the utilisation of excess heat - compared to primary energy as a source of energy - positively influences the profitability of district heating. Nevertheless, the utilisation of excess heat is largely influenced by the substantial costs for technical investments, which constitute the main barrier.

It can also be concluded that interorganisational collaborations on excess heat - of both small and large flows, and of both low and high-grade - highly depend on the organisational factors forming the basis of such collaborations. In order for these collaborations to develop into long-term, durable collaborations, the organisational conditions of humility, honesty, transparency, trust, fine-grained information transfer, joint problem solving, and shared visions of common goals are required. In addition, these organisational conditions can compensate for shortages of certain conditions related to technical and financial character.

\subsection{Important key elements of interorganisational business models}

Business models for collaboration have the potential to increase value creation for both providers and users of excess heat. Such business models also have the potential to facilitate the creation of organisationally important conditions.

An IPSO provider with the main goal of mapping supply and demand and promoting collaboration can be useful both for collaborations involving energy companies, categorised as Type I cases, and for collaborations without the involvement of an energy company, categorised as Type 2. Yet, the function of a third-party can be particularly useful in cases categorised as Type 2. For these cases, the function of a third-party needs to go beyond the function of IPSO providers operating in Type I cases. For Type 2 cases, the contribution of the third-party most often needs to include formulating business agreements and contributing knowledge about issues related to the technical aspects of distribution - knowledge which is the typical property of energy companies.

One aspect of introducing an IPSO provider is that it is not obvious who it should be or who is the most suitable. There are a number of case-specific factors to take into account for the application of an IPSO to be successful.

\subsection{Implications of strategic planning for increased utilisation of excess heat}

Strategic planning processes based on knowledge through stakeholder participation are important in order to formulate well-founded goals and objectives. More extensive consultation processes, in terms of broader stakeholder participation, are expected to result in increased knowledge on how to plan to facilitate the use of excess heat. It also has the potential to promote new development of collaborations on excess heat, both 
with and without the involvement of third-party IPSO providers. If conducted strategically, the municipal spatial planning processes would provide an overall view that could be used to map current and future supply and demand of excess heat.

The required knowledge of Type 2 cases regarding technical aspects related to distribution, which are typical properties of energy companies active within the district heating sector, could also be shared within the framework of strategic spatial planning during the different consultation processes. In addition, involving both potential providers and users of excess heat in interactive stakeholder participation processes could constitute a forum for facilitating contacts between these actors, leading to the development of further excess heat collaborations.

Excess heat utilisation does, however, require political legitimacy impacting the spatial planning processes in order to be taken into account. This would allow excess heat utilisation a greater priority within the municipal spatial planning and mitigate the current conflict regarding time-consuming stakeholder participation processes and rapid exploitation processes.

\subsection{Contribution to research}

This thesis contributes with knowledge of how industrial symbiosis principles could be closely aligned with the business model perspective and strategic planning. These perspectives combined can be applied to facilitate the integration of financial, environmental, cultural and social policy agendas.

The three research fields used in the thesis overlap one another, yet most importantly they have been shown to complement each other as well. The different fields combined provide a wide system perspective on innovation as they seek to contribute both environmental and financial benefits at both a company and a societal level. They are used to analyse the three identified focal areas of interorganisational collaborations, business models for collaboration and municipal spatial planning, all of which relate to different aspects of excess heat utilisation.

A common denominator identified in the analysis of the collaborations required for each of the focal areas is the importance of organisational conditions. Each of the theoretical fields used to analyse the findings for each focal area show why collaboration is important, and how the identified organisational conditions affect the outcome of collaboration. The wide system perspective has provided an understanding of how the different areas of excess heat utilisation relate to one another, and the importance of them to be combined in order for excess heat utilisation to increase.

\subsection{Practical suggestions for increased excess heat utilisation}

Increased excess heat utilisation contributes to a circular economy since by-products are reused, generating flows that are more cyclic. Further, the perspectives of energy use deserve a strong focus in the circular economy. Aspects to consider when trying to increase excess heat utilisation are presented below.

To start, financial investment grants in conjunction with early development of collaboration can serve as catalysts for utilisation as a way to overcome financial barriers associated with the substantial costs of technical investments. The fact that all existing excess heat utilisation collaborations studied within this thesis were awarded national 
investment grants indicates the importance of such grants.

Further, strategic spatial planning processes governed by local authorities can be used to promote excess heat utilisation between normally unrelated actors. Contacts between these actors can be initiated and the creation of organisationally important conditions stimulated through the collaborative mechanisms of stakeholder participation.

Another suggestion is for local authorities to develop a function in line with the function of a third-party IPSO provider. The main objective with this function would be to promote and develop collaboration projects on excess heat utilisation. This function would preferably be involved in the consultation processes of the municipal spatial planning to initiate the first contacts. Alternatively, municipalities could encourage development of private companies offering services on excess heat utilisation.

Also, from a strategic perspective it would be preferable if the spatial planning units within municipalities would enhance their focus on learning and monitoring by following up on the planning process. This approach would entail opportunities for local authorities to gain greater knowledge about how to create strategic spatial planning processes based on broad participation. Evaluations by following up the planning process through feedback, adjustment, and revision would most probably result in more efficient strategic planning processes. Nevertheless, this way of conducting spatial planning requires political legitimacy. 


\section{FURTHER RESEARCH}

This chapter presents a discussion regarding further research. 
This research has had the utilisation of excess heat as its main focal point. For the parts addressing the importance of proper business models for interorganisational collaborations on excess heat, it is interesting to examine important components of business models for collaboration. Further research in this area could be to develop business models so that they better capture value creation between collaborating businesses. It is also interesting to understand how single businesses can internalise these values, and how they could be divided between the collaborating partners.

Another area of further research could be quantitative evaluations of excess heat utilisation, both from an environmental and a financial perspective, using life-cycle assessment and life-cycle cost analysis. An expanded system boundary could, for example, take other heating solutions into account in order to allow an analysis of different heating solutions' suitability - both environmentally and financial - for different areas.

Since IPSOs of excess heat utilisation is an area not particularly emphasised in previous research, there are great opportunities for further research. This thesis has identified a number of possible opportunities and challenges of an IPSO for excess heat utilisation addressed from the financial, technical and organisational perspectives. Further studies of actual implementation would be desirable in order to get a deeper understanding of the impacts in terms of the increased utilisation and improved financial and environmental gains an IPSO approach would bring.

The role of local authorities as promoters of excess heat utilisation collaborations is another interesting area to explore further. Research linking areas such as waste recycling schemes, integrated urban technology systems, waste management and sewage treatment for district heating systems - in a broader context where local authorities are key actors - is an area previously highlighted as poorly understood. Further research within this area for a greater understanding of how local authorities could act as promoters supporting development of industrial ecosystems entails opportunities for industrial development in line with the circular economy concept. 
8. REFERENCES 
Aarhus Convention. (1998). Convention on the Access to Information, Public Participation in Decision-making and Access to Justice in Environmental Matters. Geneva, United Nations Economic Commission for Europe.

Ahrne, G., Svensson, P. (20II). Handbok i kvalitativa metoder. Malmö: Liber.

Albrechts, L. (2004). Strategic (spatial) planning re-examined. Environment and Planning B: Planning and Design, 3I, 743-758.

Albrechts, L. (2006). Shifts in strategic spatial planning? Some evidence from Europe and Australia. Environment and Planning A, 38, II49-II70.

Albrechts, L. (2013). Reframing Strategic Spatial Planning by Using a Coproduction Perspective. Planning Theory I2, 46-63.

Albrechts, L., Balducci, A. (2013). Practicing Strategic Planning: In Search of Critical Features to Explain the Strategic Character of Plans. The Planning Review, 49, I6-27.

Albrechts, L., Healey, P., Kunzmann, K., (20I0). Strategic spatial planning and regional governance in Europe. Journal of the American Planning Association, 69, II3-I29.

Allmendinger, P. (2009). Planning theory. 2. ed. Basingstoke: Palgrave Macmillan.

Andersen, H. (1994). Vetenskapsteori och metodlära, en introduktion. Lund: Studentlitteratur.

Andersson, V., Broberg, S., Hackl, R., Karlsson, M. and Berntsson, T. (2OI4). Algae-based biofuel production as part of an industrial cluster. Biomass and Bioenergy, 7I, II3-I24.

Arai, T., Shimomura, Y. (2005). Service CAD system-evaluation and quantification. Ann. CIRP, 54, 463-466.

Arnell, J., Bolin, L., Holmgren, K., Staffans, L., Adolfsson, I., Lindblad, M. (20I2). Förutsättningar för ökad nytta av restvärme (in Swedish), 20I2: Swedish district heating association. 2012; 94.

Ashton, W., Bain, A. (2012). Assessing the "short mental distance" in eco-industrial networks. Journal of Industrial Ecology I6, 70-82.

Baas, L. (20II). Planning and Uncovering Industrial Symbiosis: Comparing the Rotterdam and Östergötland regions. Business Strategy and the Environment 20, 428440.

Baas, L.W. and Boons, F.A. (2004). An industrial ecology project in practice: exploring the boundaries of decision-making levels in regional industrial systems. Journal of Cleaner Production, I2, I073-I085.

Baines, T., Bigdeli, A.Z., Bustinza, O.F., Guang Shi, V., Baldwin, J., Ridgway, K. (20I7). Servitization: Revisiting the State-of-the-Art and Research Priorities. International Journal of Operations and Production Management, 37, 256-278. 
Bassey, M. (198I). Pedagogic research: On the relative merits of search for generalisation and study of single events. Oxford Review of Education, 7, 73-94.

Berglund, J. (2002). De otillräckliga - En studie om personalspecialisternas kamp för erkännande och status. Avhandling Handelshögskolan, Stockholm.

Bertels, H. M., Koen, P. A., Elsum, I. (20I5). Business models outside the core - Lessons learned from success and failure. Research-Technology Management.

Bizcat. (20I7). A touch of Swedish experience. Avaliable: http://www.bizcat.se/start.html

Blomqvist, L., Nordhaus, T., Shellenberger, M. (2012). Planetary Boundaries: A review of the Evidence. Technical report, The Breakout Institute.

Blücher, G. (2006). I900-talet - det kommunala planmonopolets århundrade. In Planering med nya förutsättningar: Ny lagstiftning, nya värderingar, Gösta Blücher och Göran Graninger (eds.), I33-I55. Vadstena: Stiftelsen Vadstena forum för samhällsbyggande.

Boons, F. and Lüdeke-Freund, F. (2013). Business models for sustainable innovation: State-of-the-art and steps towards a research agenda," Journal of Cleaner Production. 45, 9-I9.

Bowen, G.A. (2009). Document Analysis as a Qualitative Research Method. Qualitative Research Journal, 9, 27-40.

Boyatzis, R. E. (1998). Transforming qualitative information: Thematic analysis and code development. Thousand Oaks, CA: Sage.

Brady, T., Davies, A. and Gann, D.M. (2005). Creating value by delivering integrated solutions. International Journal of Project Management. 23, 360-365.

Braun, V. and Clarke, V. (2006). Using thematic analysis in psychol- ogy. Qualitative Research in Psychology, 3, 77-IOI.

Brattberg, L. (1996). Miljonprogrammet som stadsplaneuppgift. In En miljon, Martin Rörby (ed.), 47-5I. Stockholm: Arkitekturmuseet.

Brewer, J., Hunter, A. (1989). Multimethod research: a synthesis of styles, Newbury Park: Sage, Sage Library of Social Research Series, I75.

Bryman, A., Bell, E. (20II). Business research methods. Oxford University Press, Oxford, UK.

Bryson, J. M., Crosby, B. C., Middleton Stone, M. (2015). Designing and Implementing Cross-Sector Collaborations: Needed and Challenging. Public Administration Review, $75,647-663$.

Bryson, J. M. (1995). Strategic Panning for Public and Non-profit Organizations, San Francisco, CA: Jossey-Bass. 
Bryson, J. M., Roering, W.D. (1988). Initiation of strategic spatial planning by governments Public Administration Review.

Busck, A., Hidding, M., Kristensen, S., Persson, C., Prestholm, S. (2008). Managing rural landscapes in the Netherland, Denmark and Sweden: comparing planning systems and instruments in three different contexts. Danish Journal of Geography, I08, I-I6.

Börjeson, L., Höjer, M., Dreborg, K.-H., Ekvall, T., Finnveden, G. (2006). Scenario types and techniques: Towards a user's guide. Elsevier, 38, 723-739.

CEC. (1997). The E.U. Compendium of Spatial Planning Systems and Policies, in: official, L.O.f.t., Communities, p.o.t.E. (Eds.).

Chapin, F.S. (1965). Urban Land Use Planning, Urbana, IL: University of Illinois Press.

Chertow M.R. (2000). Industrial symbiosis: Literature and taxonomy. Annual Review of Energy and the Environment. 25, 313-337.

Chertow, M.R. (2007). "Uncovering" industrial symbiosis. Journal of Industrial Ecology II (I), II-30.

Chertow, M., Ashton, W., Espinosa, J. (2008). Industrial symbiosis in Puerto Rico: Environmentally related agglomeration economies. Regional Studies: the journal of the regional studies association 42, I299-I3I2.

Coelho, D., Ruth, M. (2006). Seeking a unified urban systems theory. In: Mander, U., Brebbia, C.A., Tiezzi, E.E. (Eds.), Hen Sustainable City IV. WIT, press Southampton UK, pp. I79-I88.

Council of Europe. (2000). European Landscape Convention. Treaty Series no. I76. Council of Europé, Firenze.

Council of Europe. (2006a). Community Strategic Guidelines for Rural Development. Council Decision 2006/I44/EC. Council of Europe, Brussels.

Council of Europe. (2006b). European Conference of Ministers responsible for Regional Spatial/Planning. CEMAT, Lisbon.

Cronholm, L., Å., Grönkvist, S., Saxe, M. (2009). Spillvärme från industrier och lokaler. [Excess heat from industries and premises]. Report: 2009:I2, ISBN 978-9I-738I-027-2. Stockholm, Sweden.

Cullingworth, J.B. (1972). Town and Country Planning in Britain in: Unwin, A.a. (Ed.), London.

David, C. L., Fry J. P., Li, X., Hill, E. S., Genello, L., Semmens, K., Thompson R.E. (20I5). Commercial aquaponics production and profitability: Findings from an international survey. Aquaculture, 435, pp. 67-74. 
Denzin, N. K., Lincoln, Y.S. (2005). Introduction: The decipline and practice of qualitative research, in N. K. Cenzin and Y. S. Lincoln (eds.) Handbook of Qualitative Research (3 ${ }^{\text {rd }}$ ed.) Thousand Oaks, CA: Sage Publications.

Denzin, N. K. (1978). Sociological Methods. New York: McGraw-Hill.

Deutz, P. (20I4). Food for thought: seeking the essence of industrial symbiosis. In: Salomone, R., Saija, G. (Eds.), Pathways to Environmental Sustainability. Springer, pp. 3II.

Deutz, P. and Gibbs, D. (2008). Industrial ecology and regional development: Ecoindustrial development as cluster policy. Regional Studies, 42, I313-1328.

Di Maio, F., Rem, P.C., Baldé, K., Polder, M. (2017). Measuring resource efficiency and circular economy: A market value approach. Resources, Conservation and Recycling I22, I63-I7I.

Di Maio, F., Rem, P.C. (2015). A robust indicator for promoting circular economy through recycling. Journal of Environmental Protection 6, I095-IIO4.

Directive 2010/3I/EU on the energy performance of buildings. (recast) - I9 May 2010.

Doménech, T., Davies, M. (2009). The social aspects of industrial symbiosis: the application of social network analysis to industrial symbiosis networks. Prog. Industrial Ecology International Journal, 6 (I), 68-99.

Doménech, T., Davies, M. (20II). The role of embeddedness in Industrial Symbiosis Networks: Phases in Evolution of Industrial Symbiosis Networks. Business strategy and the Environment. 20, 28I-296.

Ehrenfeld, J., Gertler, N. (1997). Industrial Ecology in practice: the evolution of interdependence at Kalundborg. Journal of Industrial Ecology I(I), 67-80.

Eklund, G. (2012). Intervju som datainsamlingsmetod. Pedagogiska fakulteten Åbo Akademi, Vasa.

Elamzon, J. and Nordberg, G. (20I4). Potential för spillvärme - Skånes och tre fallstudier potential för ökad energiåtervinning. Länsstyrelsen Skåne and Ramböll. Available at: http://www.sbhub.se/dokumentation/seminariepresentationer/spillvarme [2017-03-07]

Elbakidzea, M., Dawsonb, L., Anderssona, K., Axelssona, R., Angelstama, P., Stjernquistb, I., Teitelbaumc, S., Schlyterb, P., Thellbrod, C. (20I5). Is spatial planning a collaborative learning process? A case study from a rural-urban gradient in Sweden. Land Use Policy, 8, 270-285.

Ellen MacArthur Foundation (2015). Growth within: A circular economy vision for a competitive Europe, Available at: http://www.ellenmacarthurfoundation.org/ booksand-reports\# [Accessed 3ith January 20I7].

Emmelin, L. (20I0). Fysisk planering - att planera för förändrad markanvändning. In 
Planera för friluftsliv - natur, samhälle, upplevelser, Lars Emmelin, Peter Fredman, Ebba Lisberg Jensen \& Klas Sandell (eds.), 305-320. Stockholm: Carlssons.

Emmelin, L., Kleven, T. (1999). A paradigm of Environmental Bureaucracy? Atttitudes, thought styles, and world views in the Norwegian environmental administration., in: 599, N.s.P.S. (Ed.).

European Commission. (2004). EU Water Initiative - Water for Life. Office for Official Publications of the European Communities, Luxembourg.

European Commission (20I4). Green Principles of EU Industrial Policy. Technical report, European Commission

European Commission (2015). Resource Efficiency.

http://ec.europa.eu/environment/eussd/.

European Commission (2016). Closing the loop - New circular economy package. Briefing. EPRS. European Parliamentary Research Service. PE 573.899.

Evers, D. And Tennekes, J. (2016). Europe exposed: mapping the impacts of EU policies on spatial planning in the Netherlands. European Planning Studies, 24, I747-I765.

Fahlen, E., Trygg, L. and Ahlgren, E. O. (2012). Assessment of absorption cooling as a district heating system strategy-A case study. Energy Conversion and Management 6o, II5-I24.

Faludi, A., Korthals Altes, W. (I994). Evaluating communicative planning: a revised design for performance research. European Planning Studies 2(4), 403-4I8.

Faludi, A. (2000). The performance of spatial planning. Planning practice and research. I5, 299-3I8.

FAO (Food and Agriculture Organization of the United Nations). (2003). Sustainable Forest Management and the Ecosystem Approach: Two Concepts, One Goal. Working Paper FM 5. Forest Resources Division, Rome.

Fenton, P., Gustafsson, S., Ivner, j., Palm, J. (20I4). Stakeholder participation in municipal energy and climate planning - experiences from Sweden. Local Environment, 2I, 272-289.

Fichtner, W., Tietze-Stöckinger, I., Frank, M. and Rentz, O. (2005). Barriers of Interorganisational Environmental Management: Two Case Studies on Industrial Symbiosis. Progress in Industrial Ecology - An International Journal. 2, 73-88.

Finger, M., Groenewegen, J., and Künneke, R. (2005). The quest for coherence between institutions and technologies in infrastructures. Journal of Network Industries. 6(4), 227259.

Firestone, W. A. (1993). Alternative arguments for generalizing from data as applied to qualitative research. Educational Researcher, 22, 16-23. 
Forest Europe, UNECE and FAO. (20II). State of Europe's Forests 20II. Status and Trends in Sustainable Forest Management in Europe. Rome, Italy.

Forsaeus Nilsson, S., Reidhav, C., Lygnerud, K.S. (2008). Sparse district-heating in Sweden. Applied Energy 85 (2008).

Fulford, R., Standing, C. (20I4). Construction industry productivity ant the potential for collaborative practice. International Journal of Project Management, 32, 315-326.

Frederiksen, S. and Werner, S. (20I4). Fjärrvärme och Fjärrkyla. ISBN: 9789144085296. Lund: Studentlitteratur, 2014.

Fredriksson, C. (20II). Planning in the 'New Reality'. Doctoral Dissertation in Planning and Decision Making Analysis. Kungliga Tekniska Högskolan, Stockholm, Sweden.

Friedmann, J. (2004). Strategic Spatial Planning and the Longer Range. Planning Theory and Practice, 5, 49-67.

Geng, Y., Doberstein, B. (2008). Developing the circular economy in China: Challenges and opportunities for achieving "leapfrog development". The international Journal of Sustainable Development and World Ecology, I5 (3), 23I-239.

Gibbs, D. (2003). Trust and networking in inter-firm relations: the case of Eco-Industrial Development. Local Economy I8(3), 222-236.

Gibbs, D., Deutz, P. (2007). Reflections on implementing industrial ecology through ecoindustrial park development. Journal of Cleaner Production I5(I7), I683-I695.

Gibelli, M.C. (2003). Flessibilita e regole nella pianificazione strategica; buone pratiche alla prova in ambito internazionale, Milan: Franco Angel.

Graham, S., Marvin, S. (200I). Splintering Urbanism: networked infrastructures, technological mobilities and the urban condition. London: Routledge.

Granados Cabezas, V. (1995). Another methodology for local development? Selling places with packaging techniques: a view from the Spanish experience of city strategic planning. European Planning Studies. 3, I73-I87.

Guba, E., Lincoln, Y. S. (1989). Fourth generation evaluation, Newbury Park: Sage.

Gyberg, P., Karlsson, M., Palm, J. (2004). Drivkrafter till förändring - Essäer om energisystem i utveckling. Program energisystem, Arbetetsnotat NR. 27, Linköping University.

Göransson, A., Sköldberg, H., Unger, T., Wahlström, Å., Filipsson, P., Sundström, T. (3013). Reglerna för nära-nollenergihus. [Regulations for zero energy buildings] Report 20I3:I8, ISBN 978-9I-738I-II6-3, Svensk Fjärrvärme AB, Stockholm, Sweden.

Healey, P. (2009). In Search of the "Strategic" in Spatial Strategy Making. Planning Theory and Practice, I0, 439-57. 
Hein, A.M., Jankovic, M., Farel, R., Yannou, B. (2015). A conceptual framework for ecoindustrial parks. In: Proceedings of the ASME 2015 International Design Engineering Technical Conferences \& Computers and Information in Engineering Conference IDETC/CIE 20I5, pp. 987-988.

Hellweg, S., Canals, L. I. (20I4). Emerging approaches, challenges and opportunities in life cycle assessment. Science 344, IIO9-III3.

Hillier, J. (20I3). On Relationality and Uncertainty. The Planning Review, 49, 32-39.

Hirvonen, J., Kayo, G., Hasan, A., Sir, K. (20I4). Local sharing of cogeneration energy through individually prioritized controls for increased on-site energy utilization. Applied Energy, 135, 350-363.

Horváth, G.A., Harazin, P. (2016). A framework for an industrial ecological decision support system to foster partnerships between businesses and governments for sustainable development. Journal of Cleaner Production, II4, 2I4-22.

Innes, J., Booher, D. (2004). Reframing public participation: strategies for the 2Ist century. Planning Theory \& Practice, 5, 419-436.

Ivner, J. (2009). Energy planning with decision-making tools: experiences from an energy-planning project. Local Environment, I4, 833-850.

Ivner, J., Björklund, A.-E., Dreborg, K.-H., Johansson, J., Viklund, P., Wiklund. (20IO). New tools in local energy planning: experimenting with scenarios, public participation and environmental assessment. Local Environment 15.

Jank, R., ed. (200o). Advanced local energy planning (Alep) - a guidebook. Paris: International Energy Agency.

Jensen, P.D., Basson, L., Hellawell, E.E., Bailey, M.R., Leach, M. (20II). Quantifying 'geographic proximity': experiences from the United Kingdom's national industrial symbiosis programme. Resour. Conserv. Recycl. 55 (7), 703-712.

Jersenius, H., Smideman, B. (I995). Planera och bygga tillsammans. Förändringsarbete med planeringsboksmetoden i områden med många fastigheter, in: Byggforskningsrådet (Ed.), Stockholm.

Kaijser, A. (1986). Stadens ljus: etableringen av de första svenska gasverken. Doctoral Dissertation, Linköping University.

Kaijser, A. (I994). I fädrens spår: den svenska infrastrukturens historiska utveckling och framtida utmaningar. Stockholm: Carlsson.

Karlsson-Ottosson, U. (20I5). Svensk algodling slukar koldioxid. Ny Teknik. http://www.nyteknik.se/energi/svensk-algodling-slukar-koldioxid-6343238 [20I7-02-I9]

Kates, R W., Clark, W. C., Corell, R., Hall, J. M., Jaeger, C. C., Lowe, I., McCarthy, J. J., Schellnhuber, H. J., Bolin, B., Dickson, N. M., Faucheux, S., Gallopin, G. C., Grübler, A, Huntley, B., Jäger, J., Jodha N. S., Kasperson, R. E., Mabogunje, A., Matson, P., Mooney, 
H., Moore, B., O’Riordan, T., Svedin, U. (200I). Sustainability Science. Science 292(55I7), 64I-642.

Khakee, A. (2000). Samhällsplanering. Nya mål, perspektiv och förutsättningar. Lund: Studentlitteratur.

Khan, J. (2004). Local politics of renewable energy. Project planning, siting conflicts and citizen participation. Lund: Lund University.

Kindström, D., Kowalkowski, C. (2009). Development of industrial service offerings: a process framework. Journal of Service Management, 20, I56 - I72.

Komiyama, H., Takeuchi, K. (2006). Sustainability Science: Building a New Discipline. Sustainability Science I(I), I-6.

Kunzmann, K.R. (2013). Strategic Planning: A Chance for Spatial Innovation and Creativity. The Planning Review, 49, 28-3I.

Kvale, S., Brinkmann, S. (2008) Interviews: Learning the Craft of Qualitative Research Interviewing, $2^{\text {nd }}$ Edition. Thousand Oaks, CA: Sage.

Lelah, A., Mathieux, F., and Brissaud, D. (20II). Contributions to eco-design of machineto-machine product service systems: the example of waste glass collection. Journal of Cleaner Production. I9(9-IO), I033-IO44.

Lincoln, Y. S., Guba, E. G. (1985). Naturalistic inquir, 75, Sage.

Lind, H. (2002). Market-oriented land use planning: A conceptual note. Planning and Markets, 5(I).

Lindahl, M., Sundin, E., Öhrwall Rönnbäck, A., Ölundh, G., Östlin, J. (2006). Integrated product and service engineering e the IPSE project. In: Proceedings: Changes to Sustainable Consumption, Workshop of the Sustainable Consumption Research Exchange (SCORE!) Network (www.score-network.org), Supported by the EU's 6th Framework Programme. Copenhagen, Denmark.

Lindahl, M., Sundin, E., Sakao, T. (20I4). Environmental and economic benefits of Integrated Product Service Offerings quantified with real business cases. Journal of Cleaner Production. 64(0), 288-296.

Ling, E., Mårtensson, K., Westerberg, K. (2002). Mot Ett Hållbart Energisystem. Fyra Förändringsmodeller. Malmö: Malmö Högskola.

Lingegård, S., Lindahl. M. (2015) Integrated Product Service Offerings for rail infrastructure - Benefits and challenges regarding knowledge transfer and cultural change in a Swedish case. Journal of Cleaner Production, 98, I66-I74.

Lundström, M. J. (20I0). Planering och hållbar bebyggelseutveckling i ett energi- och klimatperspektiv. [Planning and sustainable building development in an energy and climate perspective]. KTH, Stockholm, Sweden. 
Magnusson, D. (2013). District heating in a Liberalized Energy Market: A New Order? Planning and Development in the Stockholm Region, 1978 - 20I2. Doctoral Dissertation in Technology and Social Change, Linköping University.

Maier, K. (200I). Citizen participation in planning: climbing a ladder? European Planning Studies, 9, 707-719.

Manuela Rozalia, G. (2009). Typological analysis as analysis method of marketing data. Management \& Marketing, 4, I25-I32.

Maussang, N., Zwolinski, P., Brissaud, D. (2006). A representation of a product-service system during its design phase - an example study of a helium liquefier. In: I3th CIRP International Conference on Life Cycle Engineering. Leuven, Belgium, pp. 555-56I.

Mauthoor, S. (20I7). Uncovering industrial symbiosis potentials in a small island developing state: The case study of Mauritius. Journal of Cleaner Production I47, 506-5I3.

May, T. (200I). Social science research. Lund: Studentlitteratur.

Mazza, L. (20I3). If Strategic "Planning Is Everything, Maybe It's Nothing. The Planning Review, 49, 40-42.

Meier, H., Roy, R., and Seliger, G. (20I0) Industrial Product-Service Systems-IPS2. CIRP Annals - Manufacturing Technology. 59, 607-627.

Merriam, S. B. (1994). Fallstudien som forskningsmetod. Lund: Studentlitteratur.

Merriam, S. B. (1998). Qualitative research and case study applications in education. Revised and expanded. San Francisco: Jossey-Bass Publishers.

Miles, M. B., Huberman, A. M. (1994). Qualitative data analysis: An expanded sourcebook. Sage.

Ministry of Enterprise, Energy and Communications (2012). Promemoria - Förslag på åtgärder för utvecklade fjärrvärmemarknader till nytta för kunder och restvärmeleverantörer. N2012/1676/E. Stockholm: Ministry of Enterprise, Energy and Communications.

Mintzberg, H. (1994). The Rise and Fall of Strategic Spatial Planning, New York: Free Press.

Mirata, M and Emtairah, T. (2005). Industrial symbiosis networks and the contribution to environmental innovation: The case of the Landskrona industrial symbiosis programme. Journal of Cleaner Production, 13, 993-I002.

Mont, O., Dalhammar, C., Jacobsson, N., A. (2006). New business model for baby prams based on leasing and product remanufacturing. Journal of Cleaner Production, I4, I509I5I8.

Mont, O. (2008). Innovative approaches to optimising design and use of durable consumer goods. International journal of product development: IJPD. 6(3/4), 227-250. 
Mäntysalo, R. (2000). Land-use Planning as Inter-organisational Learning. Faculty of Technology, Department of Architecture, University of Oulu, Oulu.

Mäntysalo, R. (2013). Coping with the Paradox of Strategic Spatial Planning. The Planning Review 49, 5I-52.

National Board of Housing, Building and Planning. (2015). Förslag till svensk tillämpning av nära-nollenergibyggnader Defenition av energiprestanda och kvantitativ riktlinje. [Proposal for Swedish application of near-zero energy buildings Definition of energy, and quantitative guideline]. Report: 20I5:26 REGERINGSUPPDRAG

National Board of Housing, Building and Planning. (20I6). Kommunens verktyg. [Municipal utilities]. Date of publication: 2016-06-I3.

Nelson, Michael A. (1992). Municipal amalgamation and the growth of the local public sector in Sweden. Journal of Regional Science 32 (I): 39-54.

Ness, D. (2008). Sustainable urban infrastructure in China: towards a factor Io improvement in resource productivity through integrated infrastructure system. International Journal of Sustainable Development \& World Ecology. 15, 288-30I.

Nicolas, M., Cerceau, J., Shi, L., Park, H.S., Junqua, G., Lopez-Perber, M. (2015). Socioecological transition towards low-carbon port cities: trends, changes and adaptation processes in Asia and Europe. Journal of Cleaner Production, II4, 362-375.

Nilsson, K.L., (2007). Managing Complex Spatial Planning Processes. Planning Theory \& Practice 8, 43I-447.

Nyström, Jan (2003). Planeringens grunder: En översikt. 2 ed. Lund: Studentlitteratur.

Oliva, R., Kallenberg, R. (2003). Managing the transition from products to services. International Journal of Service Managemen, I4, I60-I72.

Osterwalder, A. (2004). The business model ontology - A proposition in a design science approach. Dissertation I73, University of Lausanne, Switzerland.

Osterwalder, A. and Pigneur, Y., Business Model Generation: A Handbook for Visionaires, Game Changers and Challengers (John Wiley \& Sons, 20IO).

Pacione, M. (20I4). The power of public participation in local planning in Scotland: the case of conflict over residential development in the metropolitan green belt. GeoJournal, $79,3 \mathrm{I}-57$.

Park, H., Rene E., Choi S., Chiu A.S.F. (2008). Strategies for sustainable development of industrial park in Ulsan, South Korea: from spontaneous evolution to systematic expansion of industrial symbiosis. Journal of Environmental Management 87, I-I3.

Park H.S., Behera S.K. (20I5). Role of eco-production in managing energy and environmental sustainability in cities: a lesson from Ulsan Metropolis, South Korea. In: Dev SM, Yedla S (eds) Cities and Sustainability. Springer Publishers, Delhi 
Patel, R. Davidsson, B. (2003). Forskningsmetodikens grunder, Studentlitteratur Lund.

Patton, Q. (2012). Qualitative research and evaluation methods, (3rd ed.) Sage Publications, Thousand Oaks, USA.

Pearce, D., Turner, R.K. (1990). Economics of Natural Resources and the Environment. Johns Hopkins University Press, Baltimore.

Persson, U. and Werner, S. (20I2). District heating in sequential energy supply. Applied Energy 95, I23-I3I.

Poister, T., Streib, G. (1999). Strategic management in the public sector: concepts, models and process. Public Productivity \& Management Review. 22, 308-325.

Prodromidis, G.N., Coutelieris, F.A (2017). Thermodynamic analysis of biogas fed solid oxide fuel cell power plants. Renewable Energy, I08, I-IO.

Proposition 2009/IO:I70. En enklare plan- och bygglag.

Proposition 20I0/II:63. Komplettering av den nya plan- och bygglagen.

Pädam, S., Larsson, O., Wigren, A, Wårell, L., Krook Riekkola, A. (20I3). Samhällsekonomisk analys av fjärrvärme, Fjärrvärmens samhällsekonomiska nytta i energisystems idag och i framtiden Report: 2013:5

Ranhagen, U. (2008). Fysisk planering för ett hållbart samhälle. Metoder och verktyg för att integrera energifrågor i översiktlig planering. [Spatial planning for a sustainable society. Methods and tools for the integration of energy issues into comprehensive planning]. KTH Arkitektur och Samhällsbyggnad, Stockholm.

Reidhav, C., Werner, S. (2005). Profitability of sparse district heating. Applied Energy 85 (2008) 867-877.

Richards, D. (1996). Elite Interviewing: Approaches and Pitfalls. Politics I6 (3): I99-204.

Richardson, J. (2008). The business model: an integrative framework for strategy execution. Strategic Change, I7, I33-I44.

Ritchie, J., Spencer, L. (2002). Qualitative data analysis for applied policy research. The Qualitative Researcher's Companion, 573, 305-329.

Rockström, J., Steffen, W., Noone, K., Persson, A., Chaplin III, F. S., Lambin, E., Lenton, T. M., Sheffer, M., Folke, C., Schellnhuber, H. (2009). Planetary Boundaries: Exploring the Safe Operating Space for Humanity. Ecology and society I4(2), 32.

Rowley, J. (20I2). Conducting research interviews. Management Research Review 35:26027 I.

Rydén, B. (2006). Effektiv energiplanering för ett hållbart samhälle: en handbok, in: Johansson, B., Olofsdotter, B., Rolén, C., Sellber, B. (Eds.), Energy and the built 
environment in Sweden. Formas, Västerås.

Sachs, W. (2009). Fair Wealth: Pathways to Post-Development. Development in a Carbon-Constrained World Development Cooperation and Climate Change, 196

Sahlin, T. (20I3). Historien om fjärrvärmen - en historia om affärsmodellutveckling. [The history of district heating - a story of the business development] Fjärrsyn, Swedish District Heating Association, Stockholm, Sweden.

Salet, W. (2014). The Authenticity of Spatial Planning Knowledge. European Planning Studies, 22, 293-305.

SCB. (20I7). SCB:s allmänna företagsregister.

Şenlier, N., Albayrak, A.N. (20II). Opportunities for Sustainable Industrial Development in Turkey: Eco-Industrial Parks. Gazi University Journal of Science, 24, 637-646.

SFS 1977: 439. Municipal Energy Planning Act, in: Swedish Parliament (Ed.).

SFS 1987:IO. Plan and Building Act, in: Swedish Parliament (Ed.).

SFS 1998:808. Environmental Code, in: Swedish Parliament (Ed.).

SFS 2008:263. Fjärrvärmelag, in: Swedish Parliament (Ed.).

SFS 20I0:900. Plan and Building Act, in: Swedish Parliament (Ed.).

SFS 20I4:900. Förordning om ändring i plan- och bygglagen (2010:900), in: Swedish Parliament (Ed.).

SFS 2015:517. Förordning om stör till lokala klimatinvesteringar, in: Swedish Parliament (Ed.).

SFS 20I7:815. Förordning om ändring i förordningen (2015:517) om stöd till lokala klimatinvesteringar, in: Swedish Parliament (Ed.).

Short, S. E., Bocken, N. M. P., Barlow, C. Y., Chertow, M. R. (20I4). From Refining Sugar to Growing Tomatoes. Industrial Ecology and Business Model Evolution. Journal of Industrial Ecology, I8.

SOU (2005:33). Fjärrvärme och kraftvärme i framtiden: betänkande - SOU 2005:33. Stockholm: Fritze.

SOU (20II:44). Fjärrvärme i konkurrens: betänkande - SOU 20II:44. Stockholm: Fritze.

Srivastava, S.K. (2007). Green Supply-Chain Management: A State-of-the-Art Literature Review. International Journal of Management Reviews 9, 53-80.

Stake, R. E. (2013). Multiple case study analysis. Guilford Press. 
Steffen, W., Richardson, K., Rockström, J., Cornell, S. E., Fetzer, I., Bennett, E. M., Biggs, R., Carpenter, S. R., Vries, W., Wit, C. A., Folke, C., Gerten, D., Heinke, J., Mace, G. M., Persson, L. M., Ramanathan, V., Reyers, B., Sörlin, S. (2015). Planertary Boundaries: Guiding Human Development on a Changing Planet. Science 347 (6223), I259855.

Strömgren, Andreaz (2007). Samordning, hyfs och reda: stabilitet och förändring i svensk planpolitik 1945-2005. Doctoral Dissertation, Uppsala University.

Swedenergy (20I7). Tillförd energi. Swedenergy, stockholm, Sweden. https://www.energiforetagen.se/statistik/fjarrvarmestatistik/tillford-energi/.

Swedish Association of Local Authorities and Regions. (2017). Municipalities, county councils and regions. Available:

https://skl.se/tjanster/englishpages/municipalitiescountycouncilsandregions.Io88.html

Swedish District Heating Association. (2009). Fjärrvärme - A Real Success Story. Swedish District Heating Association, Stockholm, Sweden

Swedish Energy Agency (2007). Uppvärmning i Sverige 2007, Energimarknadsinspektionen, EMIR 2007:03

Swedish Energy Agency (20I0). FOKUS III -Energiintensiv industri (in Swedish), 20I0; p. 46.

Swedish Energy Agency (2016). Skapar el av ljummet vatten. Available: http:/www.energimyndigheten.se/forskning-och-innovation/affarsutveckling-ochkommersialisering/foretag-i-framkant/climeon/

Swedish Environmental Protection Agency (20I0). Effekter av investeringsprogrammen LIP och Klimp, in: Natutvårdsverket (Ed.), Natutvårdsverket.

Swedish Environmental Protection Agency (20I2). Vi utvecklar miljörätt och ekonomiska styrmedel för att nå miljömålen. Swedish Environmental Protection Agency., http://www.naturvardsverket.se/Start/Lagar-och-styrning/Ekonomiska-

styrmedel/Investeringsprogram/Lokala-investeringsprogram-LIP/

Swedish University of Agricultural Sciences. (20I2). Överskottsvärme blir mat och nya livsmiljöer. Avaliable:

http://www.slu.se/ew-nyheter/nyhetsarkiv/20I2/I2/overskottsvarme-blir-mat-och-nya$\underline{\text { livsmiljoer/ }}$

Terryn, E., Boelens, L. and Pisman, A. (2016). European Plnanning Studies, 24, NO. 6, I079-I097.

Tewdwr-Jones, M., Gallent, and Janice Morphet, N. (20I0). An Anatomy of Spatial Planning: Coming to Terms with the Spatial Element in UK Planning.European Planning Studies I8, 239-57.

Tsvetkova, A., Gustafsson. (2012). Business models for industrial ecosystems: a modular approach. Journal of Cleaner Production, 29, 246-254. 
Tuckett, A. G. (2005). Applying thematic analysis theory to practice: A researcher's experience. Contemporary Nurse, 19, 75-87.

Tukker, A. (2004). Eight types of producteservice system: eight ways to sustain- ability? Experiences from SusProNet. Business Strategy and Environment I3 (4), 246-26o.

Tukker, A., Tischner, U. (2006). New Business for Old Europe. Greenleaf Publishing, Sheffield.

UNIDO (20II). UNIDO Green industry: Policies for Supporting Green Industry. Vienna, Austria: UNIDO.

Uzzi, B. (1996). The source and consequence of embeddedness for the economic performance of organizations: the network effect. American Sociological Review 6I, 674698.

Uzzi, B. (1997). Social structure and competition in interfirm networks: the paradox of embeddedness. Administrative Science Quarterly 42(I), 35-67.

Van den Broeck, J. (2013). Balancing Strategic and Institutional Planning: The Search for a Pro-active Planning Instrument. The Planning Review, 49, 43-47.

Vedung, E. (2006). Konsten Att Utvärdera Nätverk. Stakes: Helsinki.

Von Malmborg, F. (2004). Networking for knowledge transfer: towards an understanding of local authority roles in regional industrial ecosystem management. Business Strategy and the Environment, 13, 334-346.

Walls, J. L., Paquin, R. L. (20I5). Organisational Perspectives of Industrial Symbiosis: A Review and Synthesis. Organisation \& Environment. 28, 32 -53.

Werner, S. (2007). Low Carbon District Heat in Sweden. Euroheat \& Power 4: 20-25.

Werner, S. (2004). District heating and cooling. Encyclopedia of Energy. I, 84I-848.

Werner, S. (20I6). European District Heating Price Series. Report: 20I6:3I6, ISBN: 978-9I7673-316-5, Energiforsk, Stockholm, Sweden.

Wibeck, V. (20I0). Fokusgrupper - Om fokuserade gruppintervjuer som undersökningsmetod, andra upplagan. Studentlitteratur AB, Lund.

Woodard, C. (200I). Growing greener industries. The Chronicle of Higher Education, 47 (22).

Yedla, S., Park, H. S. (20I7). Eco-industrial networking for sustainable development: review of issues and development strategies. Clean Technologies and Environmental Policy, 19, 39I-402.

Yin, R.K. (2009). Example Study Research: Design and Methods. SAGE Publications.

Zander, S., Trang, S., Kolbe, L.M. (20I6). Drivers of network governance: a multitheoretic 
perspective with insights from case studies in the German wood industry. Journal of Cleaner Production, IIO, IO9-I2O.

Ziafati Bafarasat, A. (2015). Reflections on the Three Schools of Thought on Strategic Spatial Planning. Journal of Planning Literature,30, I32-I48.

Zott, C., Amit, R. (2008). The fit between product market strategy and business model: implications for firm performance. Strategy Management Journal, 29.

Zott, C., Amit, R., Massa, L. (20II). The business model: recent developments and future research. Journal of Management, 37, IOI9-IO42. 


\section{Papers}

The papers associated with this thesis have been removed for copyright reasons. For more details about these see:

http:// urn.kb.se/ resolve?urn=urn:nbn:se:liu:diva-143193 